\title{
Design, synthesis, and activity study of cinnamic acid derivatives as potent anti-neuroinflammatory agents
}

Shun Huanga, Wenfeng Liu ${ }^{\mathrm{b}, c^{*}}$, Yonglian Lid, Kun Zhang ${ }^{\mathrm{b}}$, Xi Zheng ${ }^{\mathrm{b}, \mathrm{e}}$, Hubing Wu ${ }^{\mathrm{a}}$, Ganghua Tang

${ }^{a}$ Nanfang PET Center, Nanfang Hospital, Southern Medical University, Guangzhou, Guangdong, China

${ }^{b}$ School of Biotechnology and Health Sciences, Wuyi University, Jiangmen, China

${ }^{c}$ International Healthycare Innovation Institute (Jiangmen), China

${ }^{d}$ School of Eco-environment Technology, Guangdong Industry Polytechnic, Guangzhou, China

eSusan Lehman Cullman Laboratory for Cancer Research, Department of Chemical Biology, Ernest Mario School of Pharmacy, Rutgers,

The State University of New Jersey, Piscataway, NJ, USA

*Corresponding author. E-mail: wyuchemlwf@126.com

\section{Supporting Information}

\section{List of Contents}

1. ${ }^{1} \mathrm{H}$ and ${ }^{13} \mathrm{C}$ NMR spectra of target compounds

2. HRMS spectra of target compounds. 


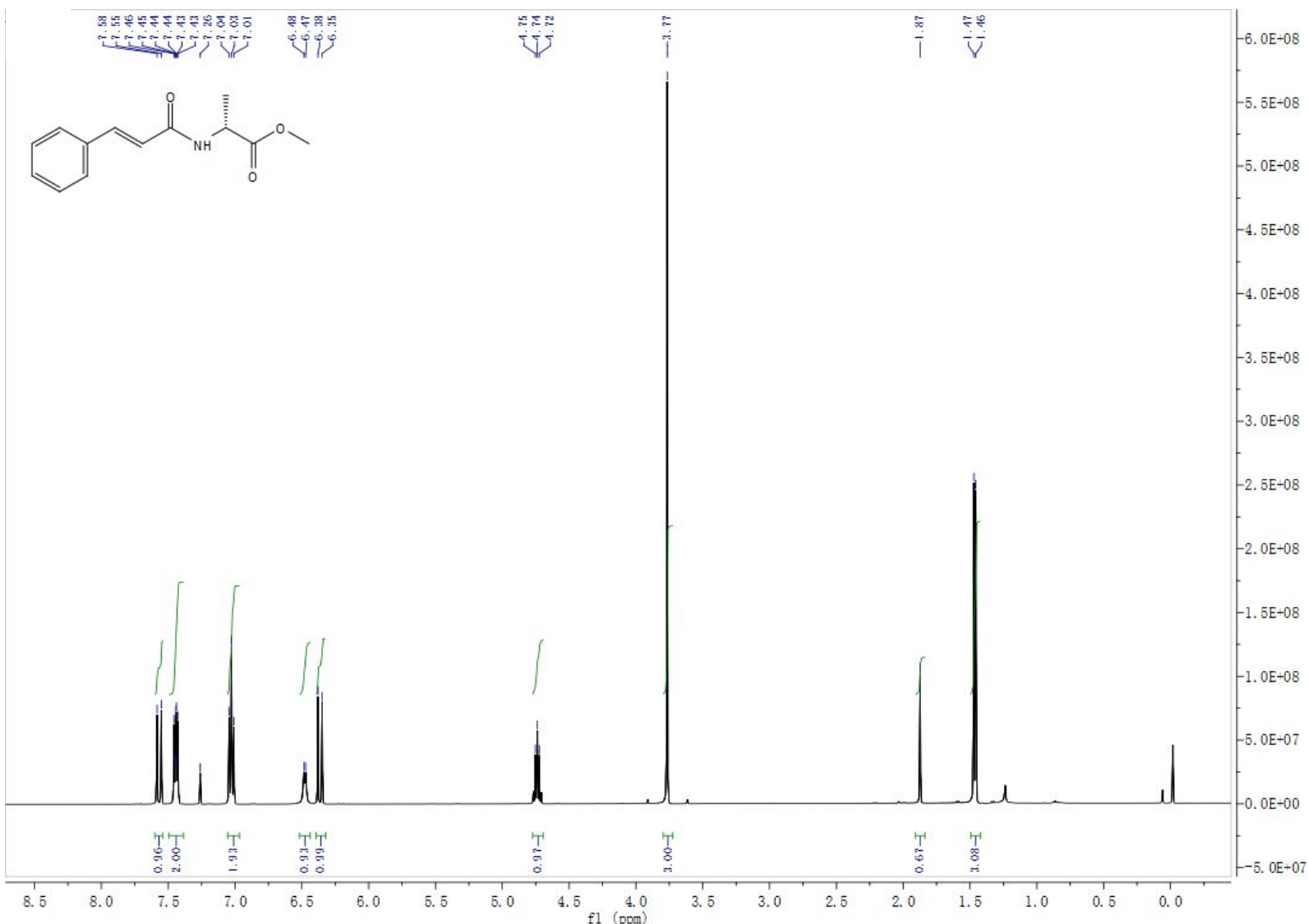

Figure $\mathrm{S} 1{ }^{1} \mathrm{H}$ NMR spectra of compound 2a

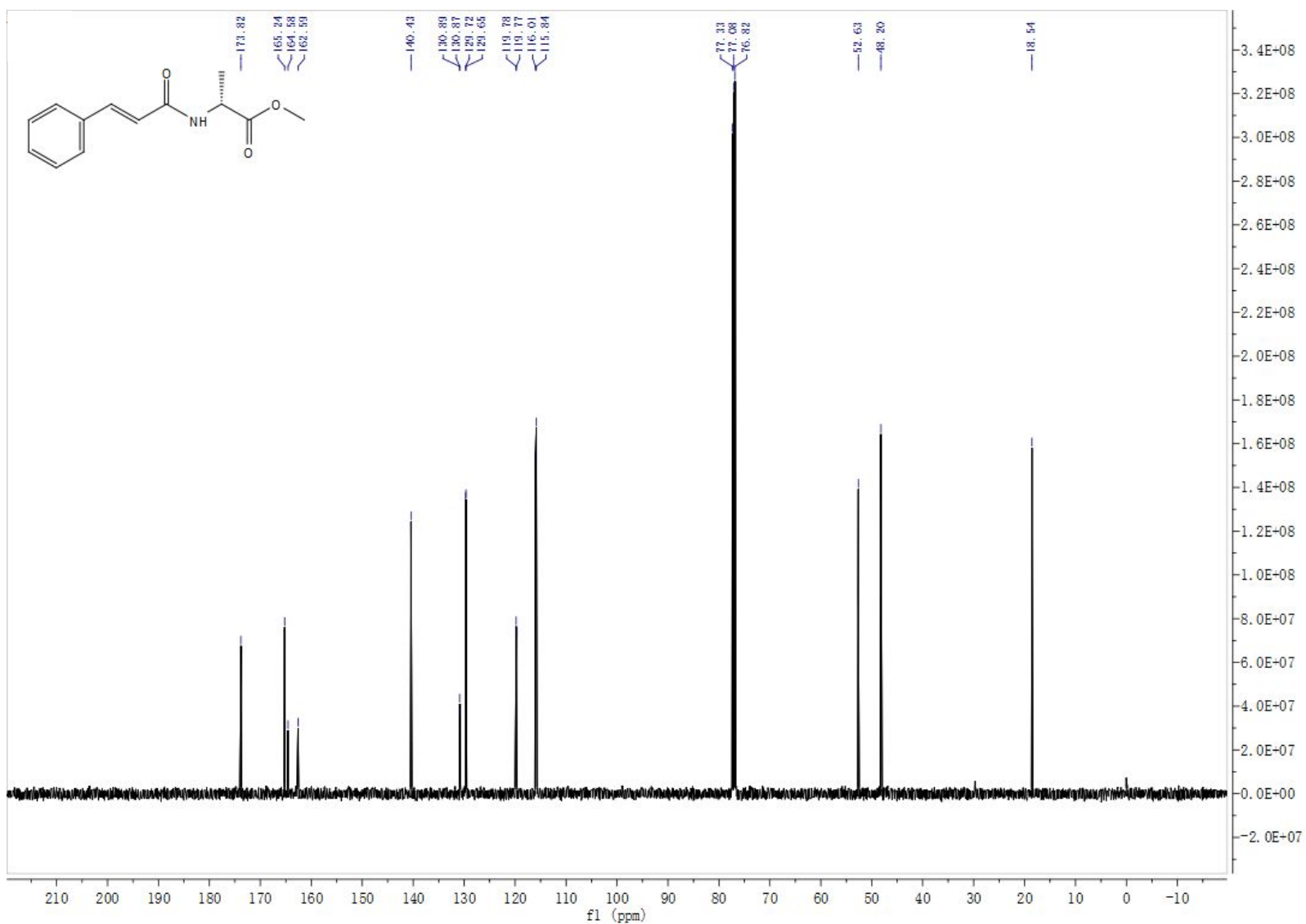

Figure S2 ${ }^{13} \mathrm{C}$ NMR spectra of compound $\mathbf{2 a}$ 


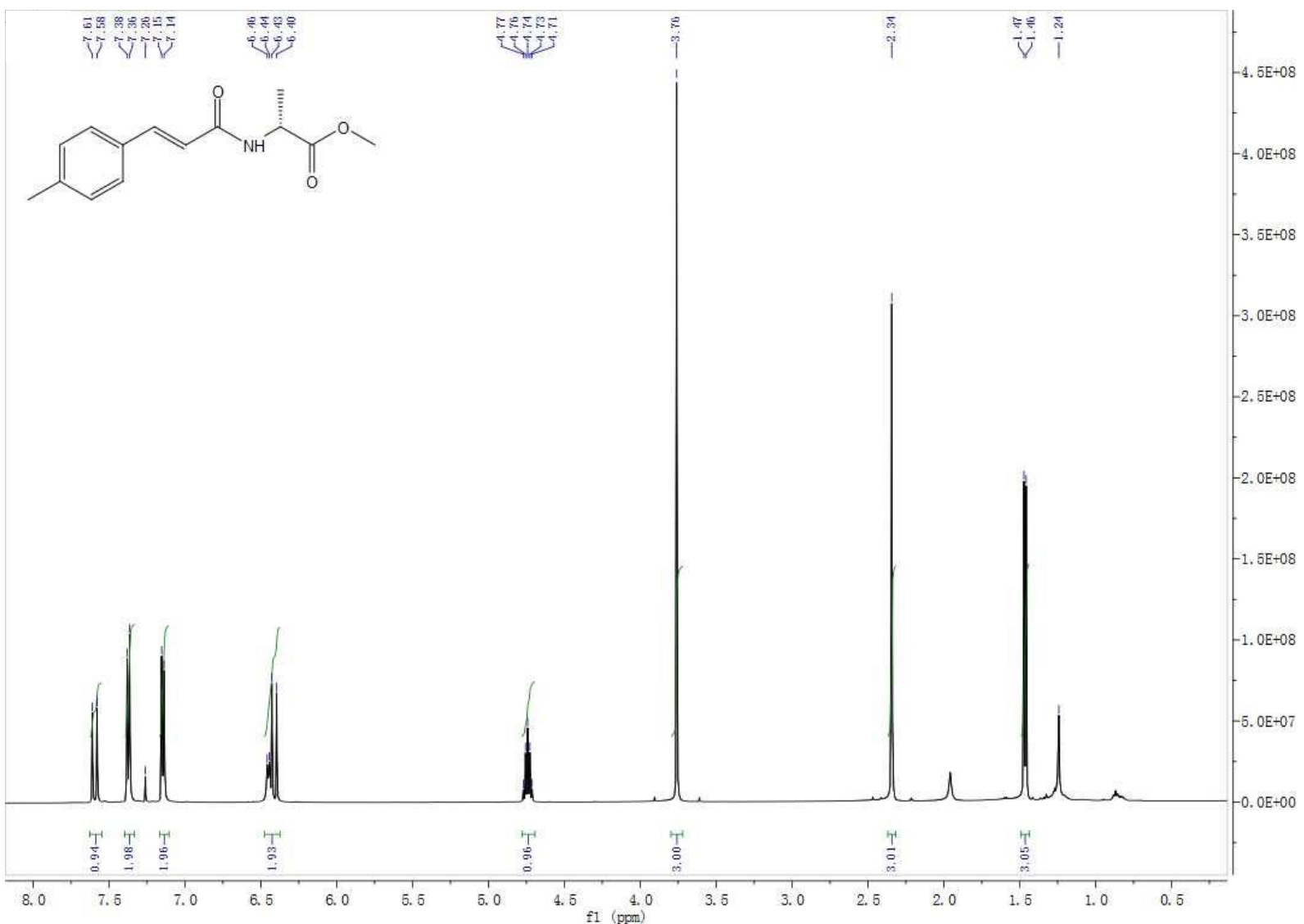

Figure S3 ${ }^{1} \mathrm{H}$ NMR spectra of compound $\mathbf{2 b}$

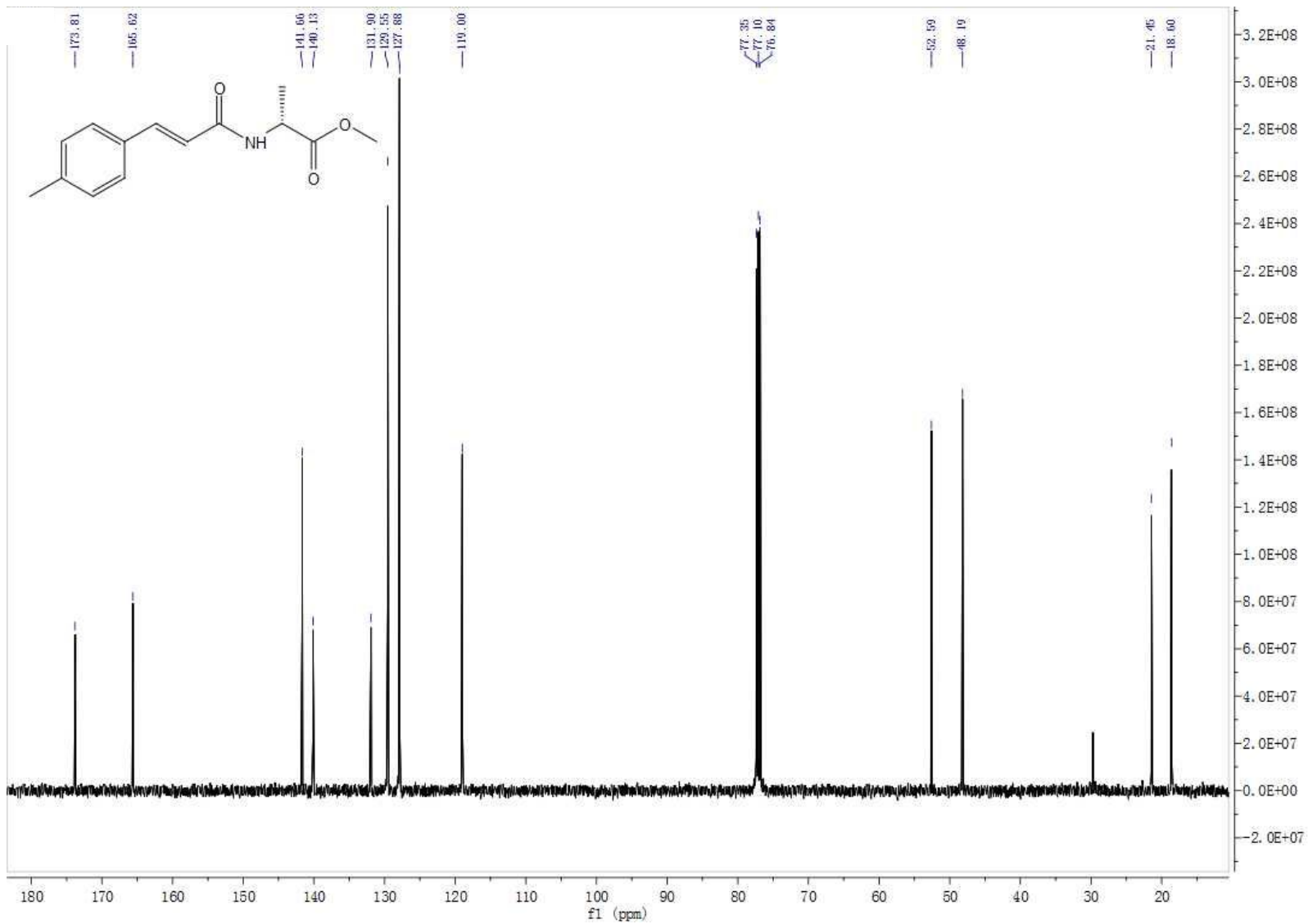

Figure S4 ${ }^{13} \mathrm{C}$ NMR spectra of compound $\mathbf{2 b}$ 


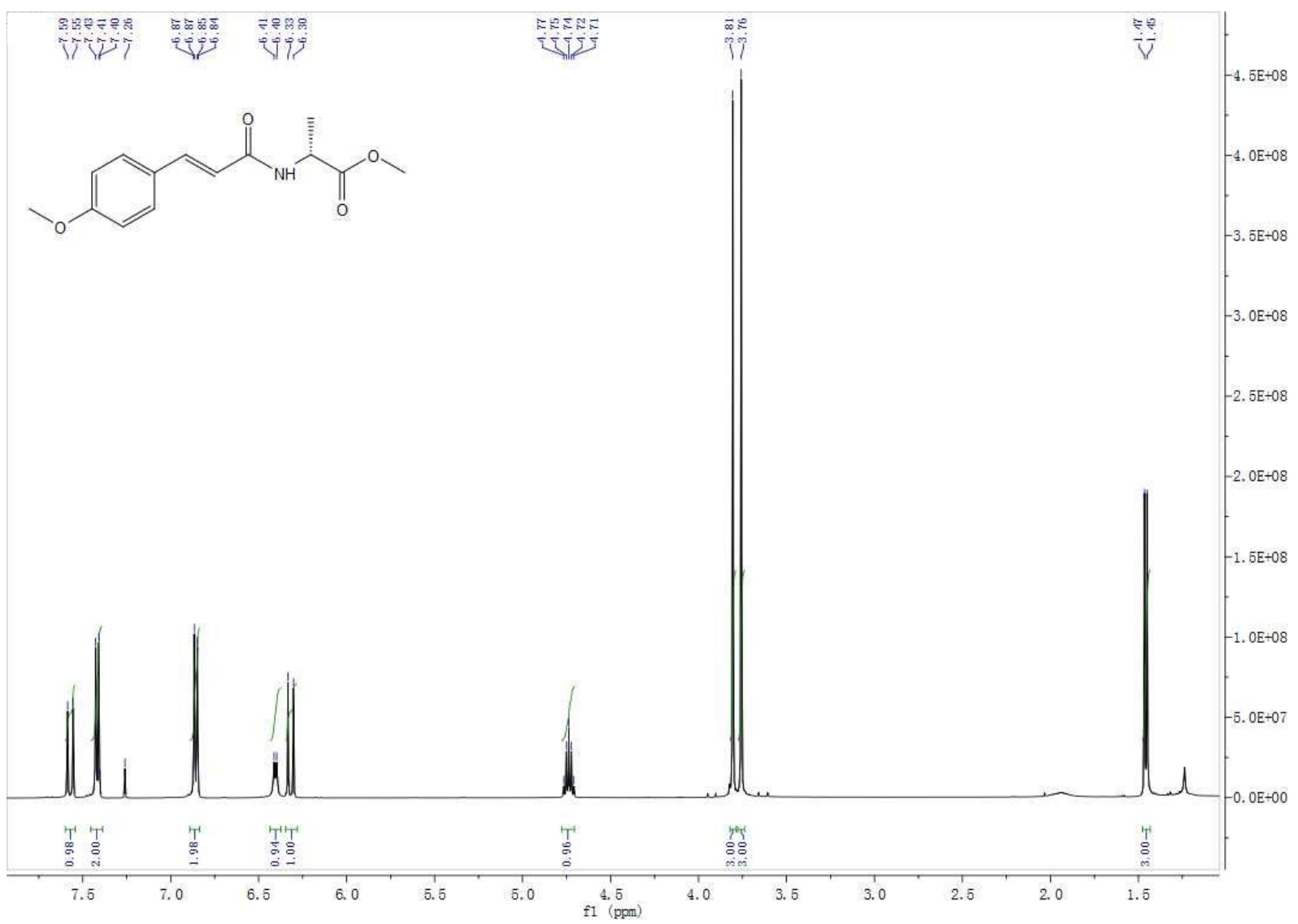

Figure S5 ${ }^{1} \mathrm{H}$ NMR spectra of compound 2c

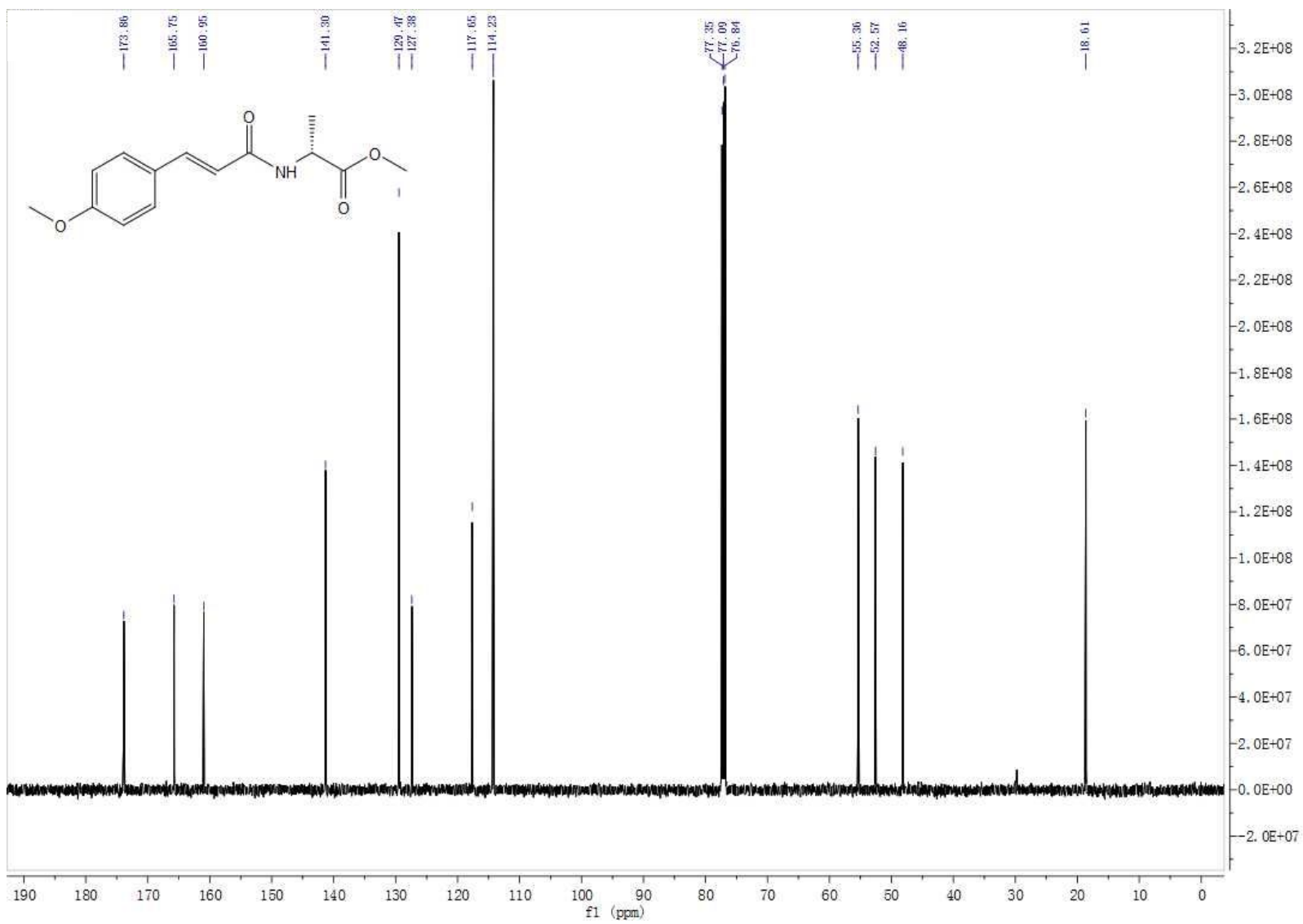

Figure S6 ${ }^{13} \mathrm{C}$ NMR spectra of compound 2c 


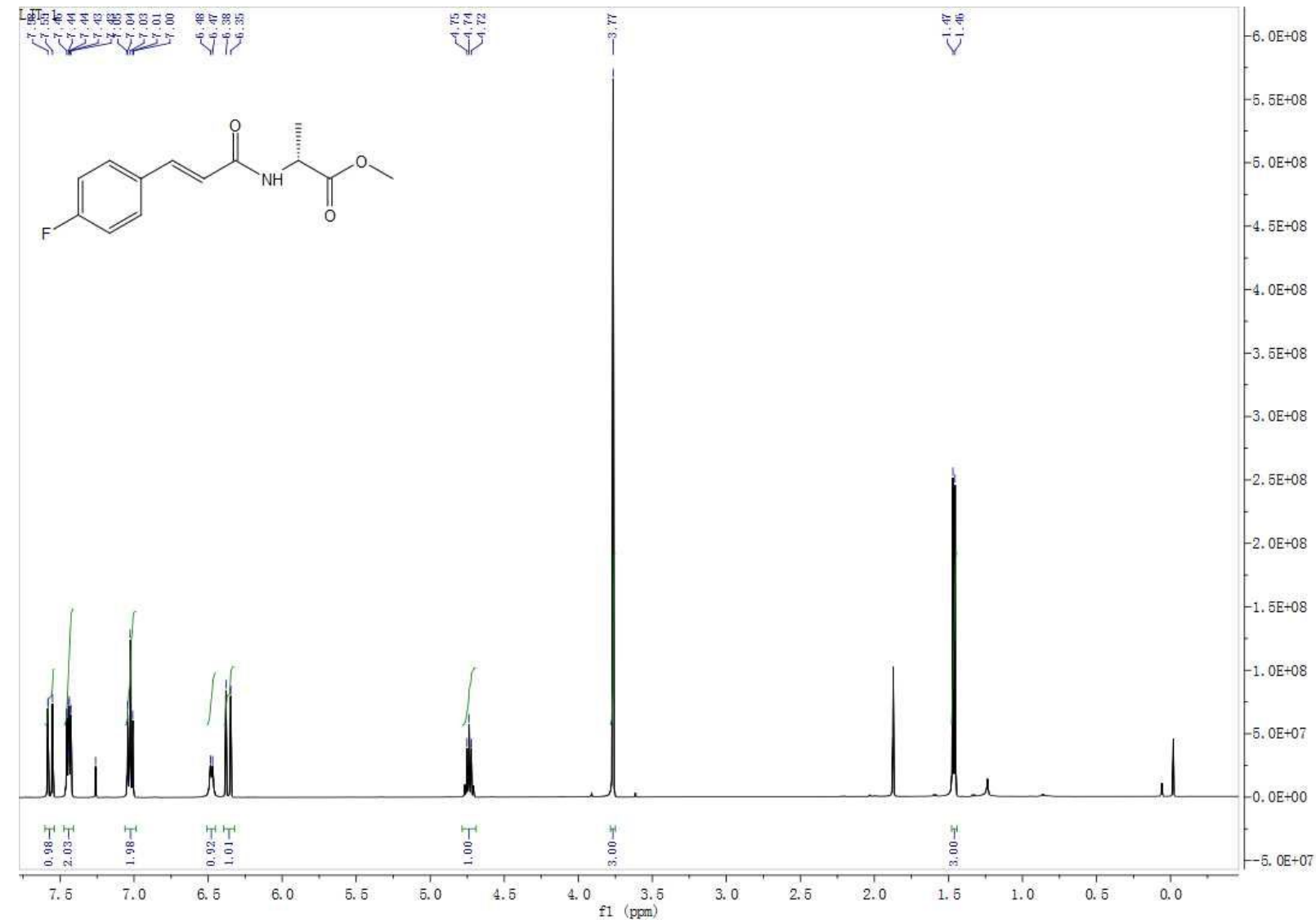

Figure $\mathrm{S} 7{ }^{1} \mathrm{H}$ NMR spectra of compound $\mathbf{2 d}$

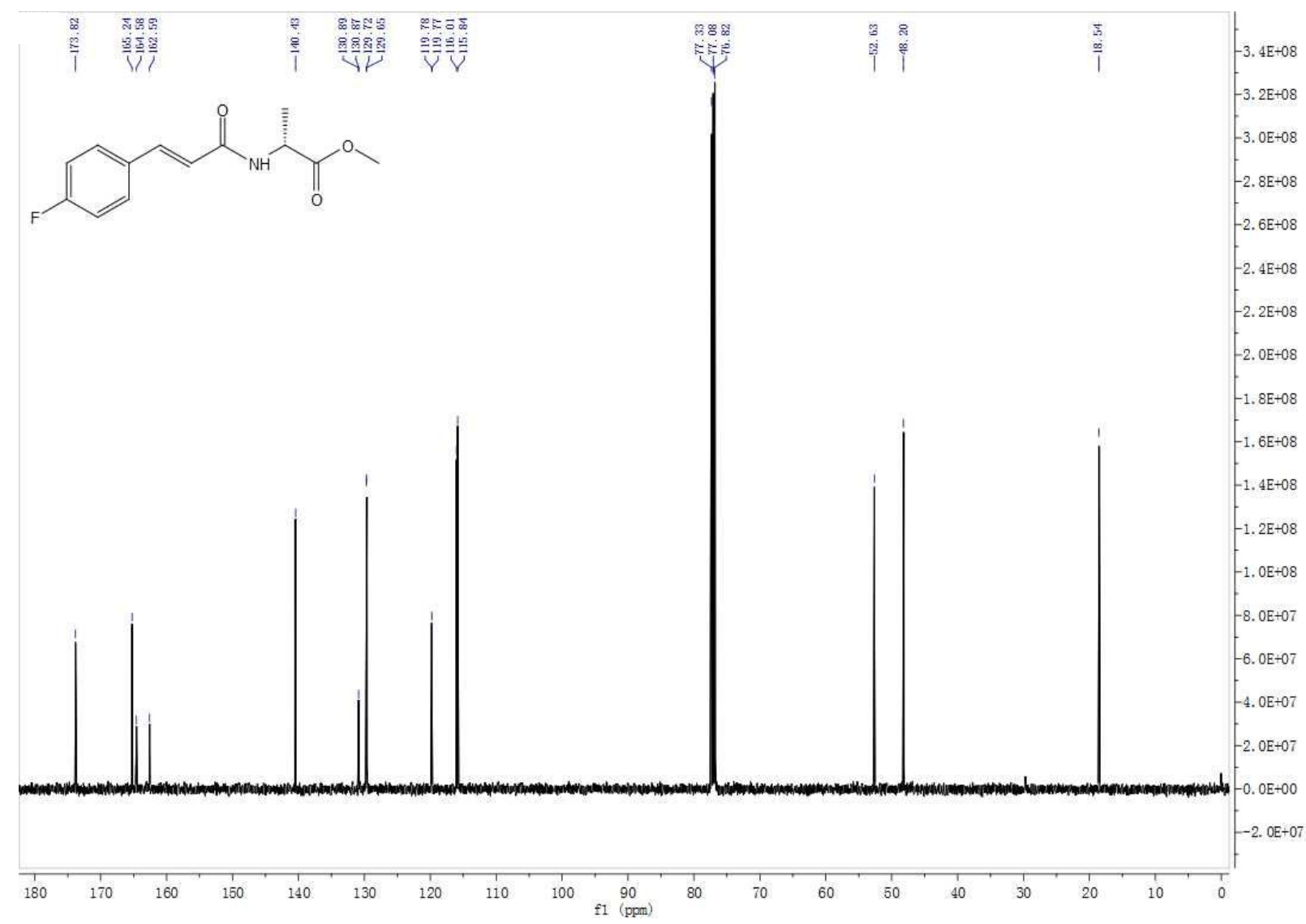

Figure S8 ${ }^{13} \mathrm{C}$ NMR spectra of compound 2d 


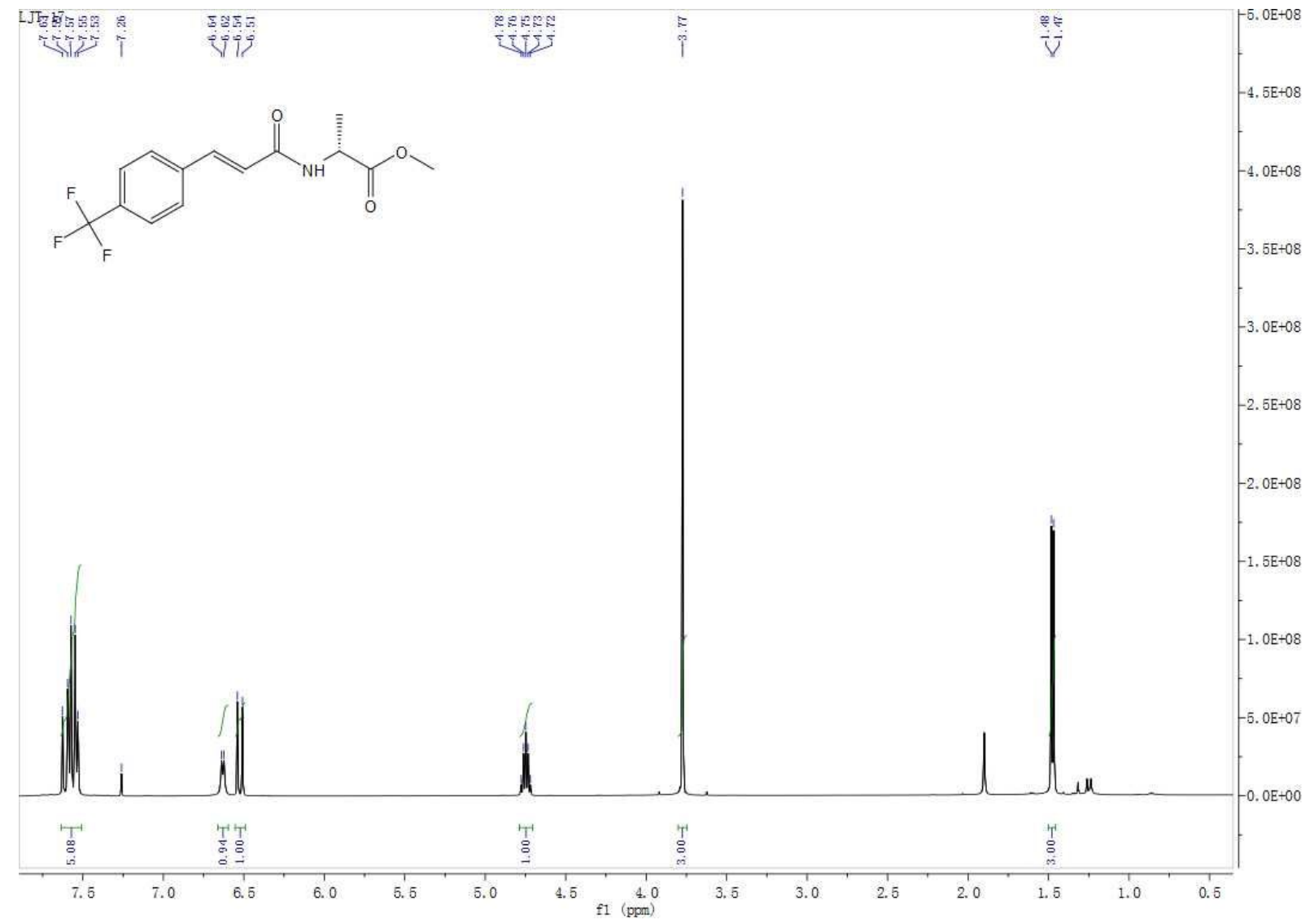

Figure S9 ${ }^{1} \mathrm{H}$ NMR spectra of compound $2 \mathbf{e}$

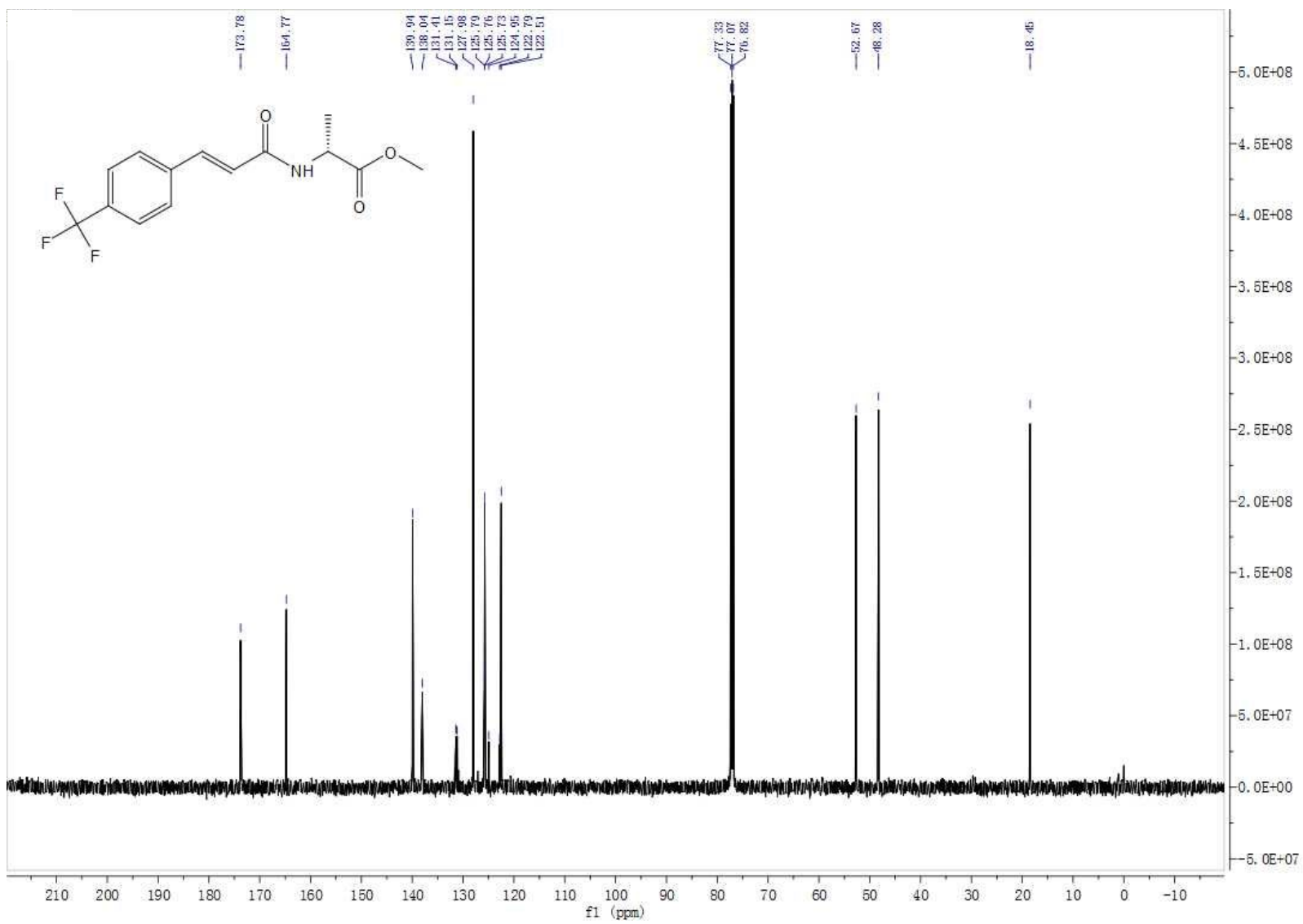

Figure S10 ${ }^{13} \mathrm{C}$ NMR spectra of compound 2e 


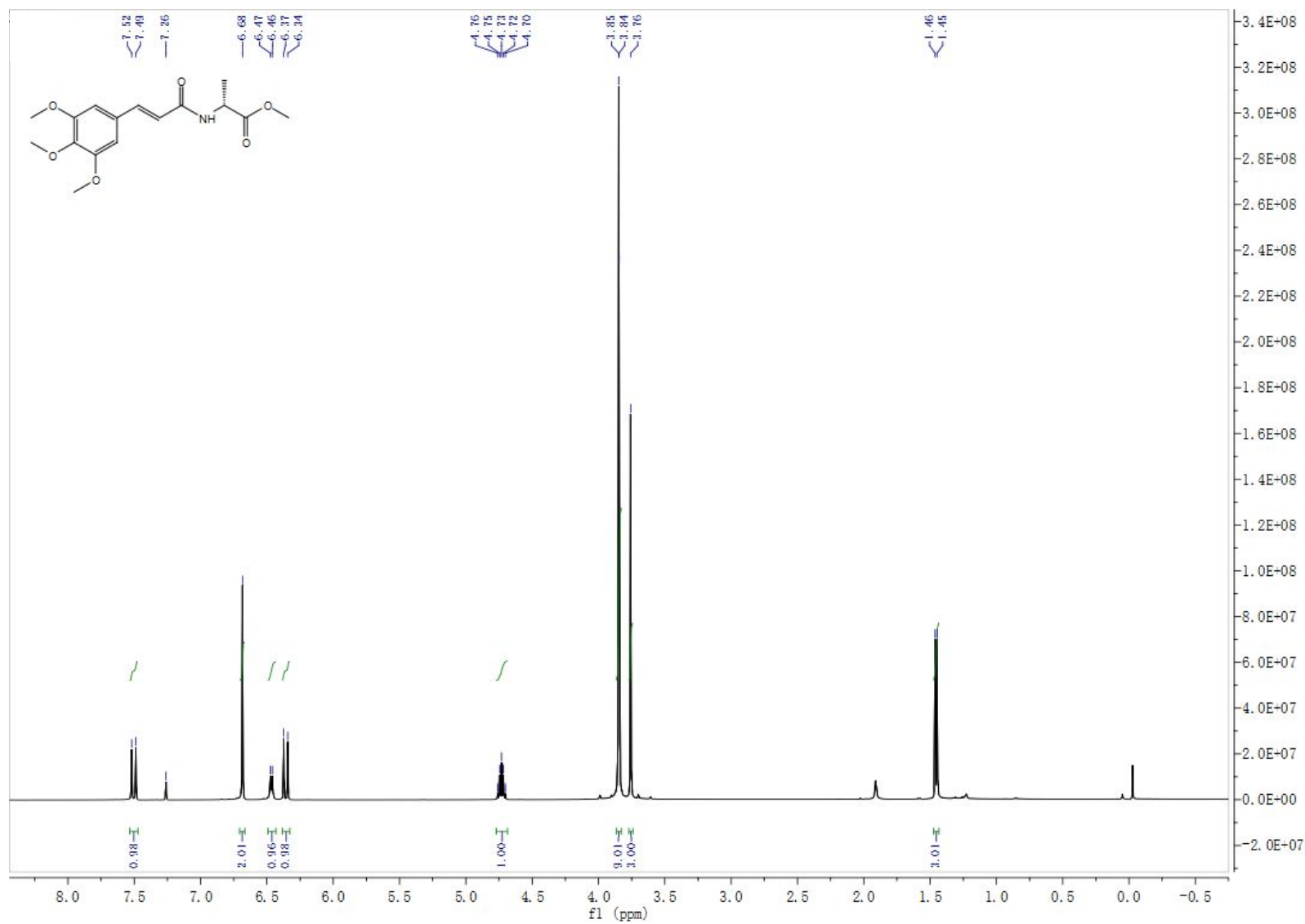

Figure S1 $1{ }^{1} \mathrm{H}$ NMR spectra of compound $\mathbf{2 f}$

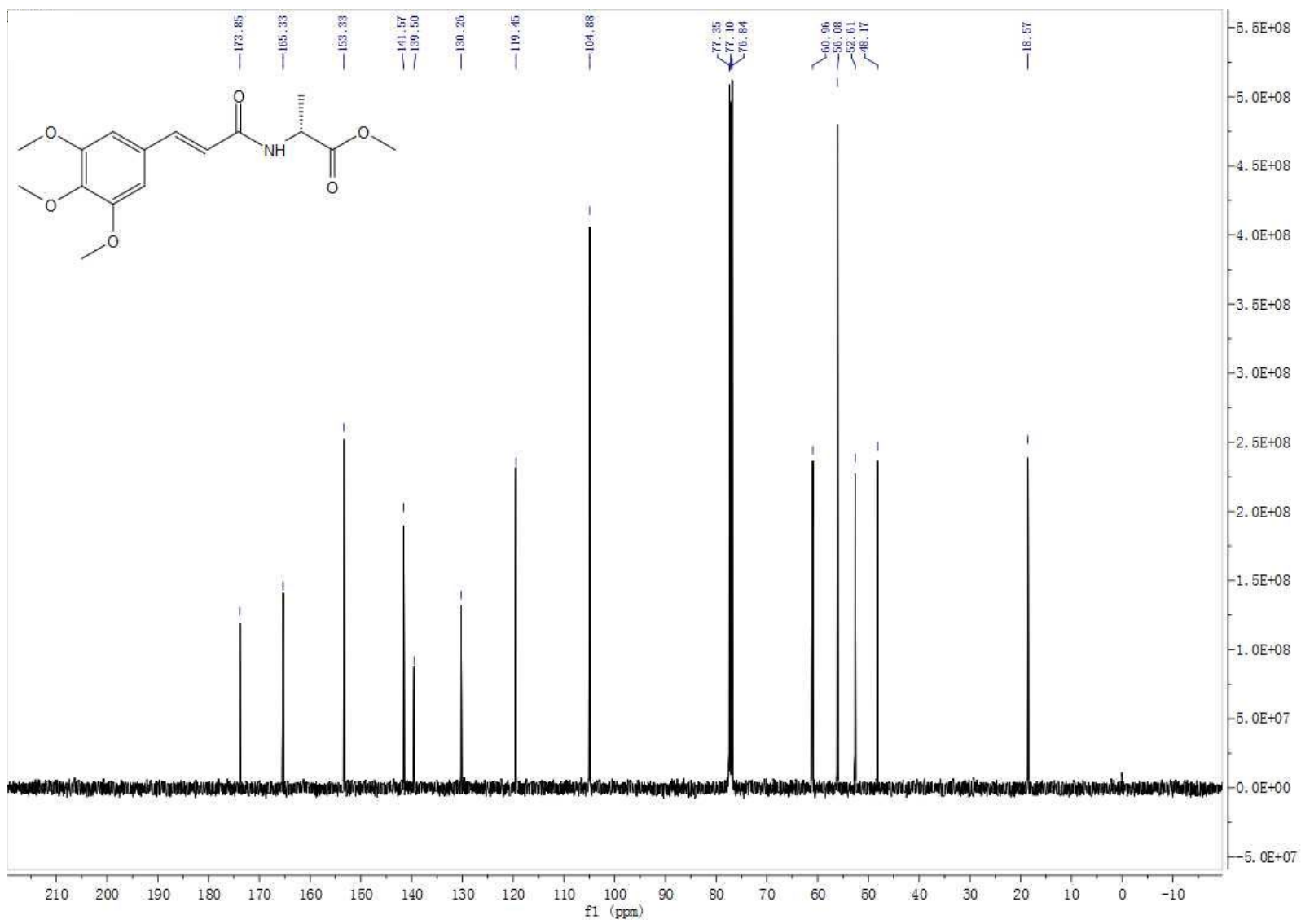


Figure S12 ${ }^{13} \mathrm{C}$ NMR spectra of compound $\mathbf{2 f}$

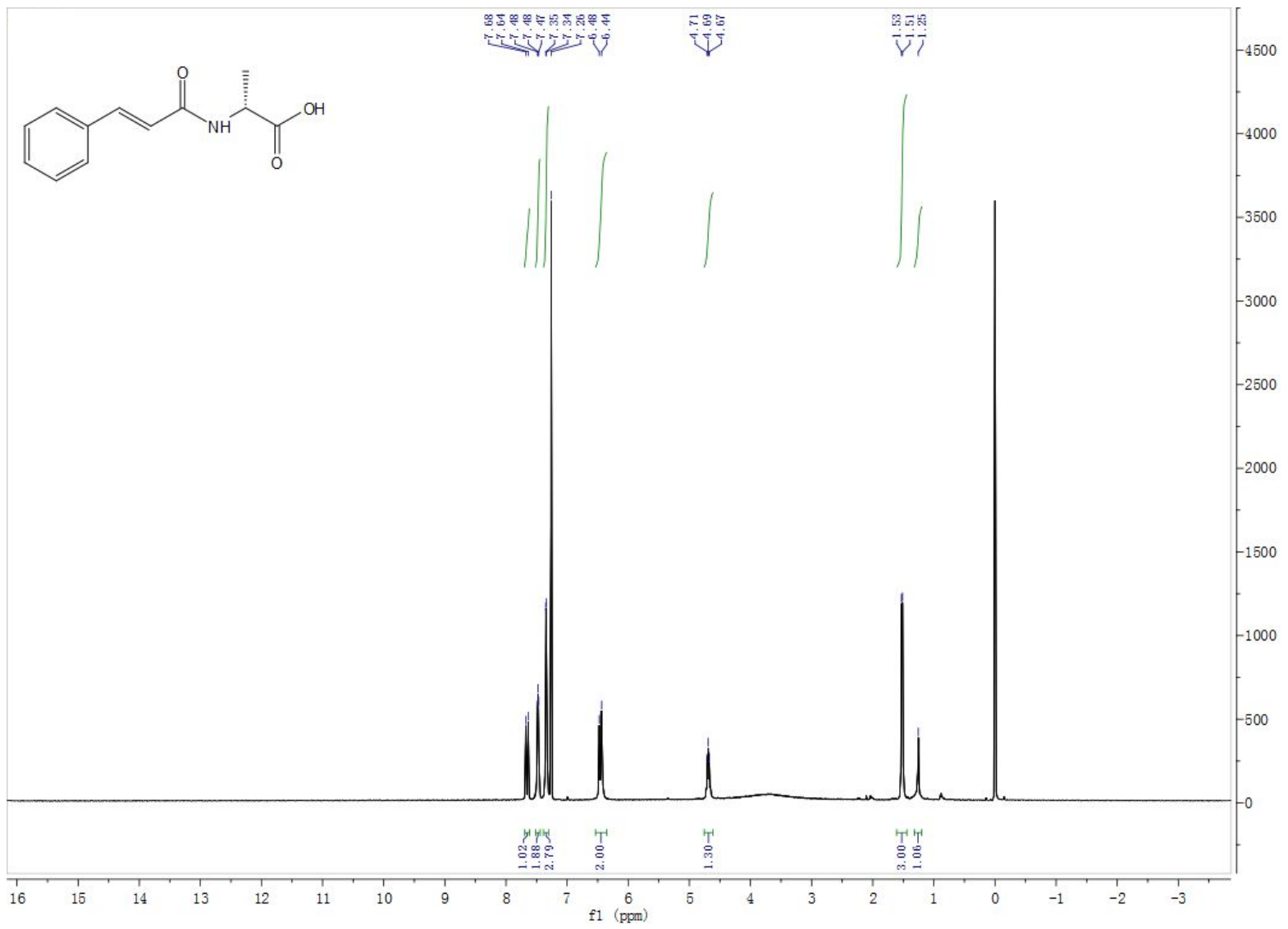

Figure S13 ${ }^{1} \mathrm{H}$ NMR spectra of compound 3a

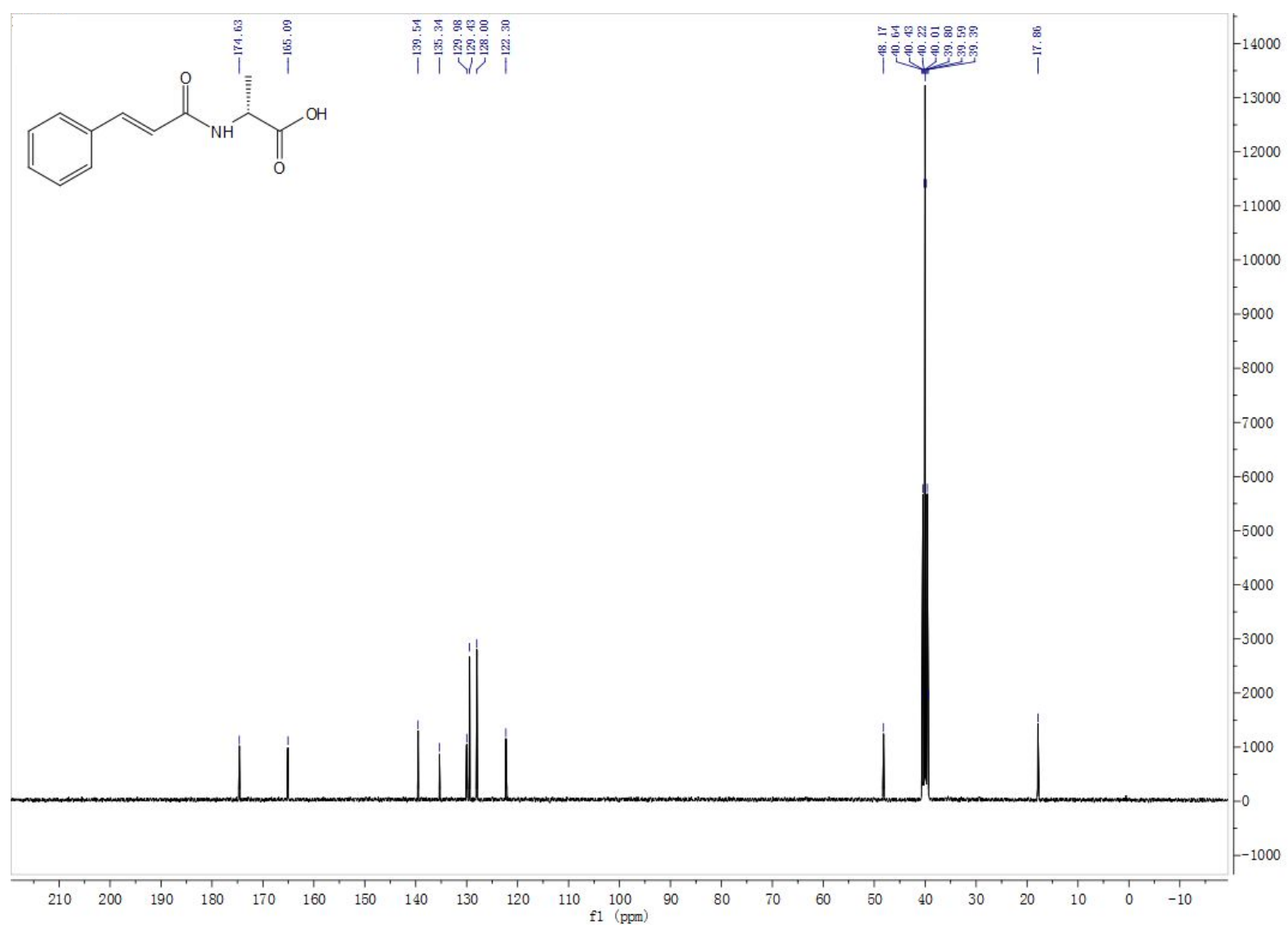


Figure S14 ${ }^{13} \mathrm{C}$ NMR spectra of compound 3a

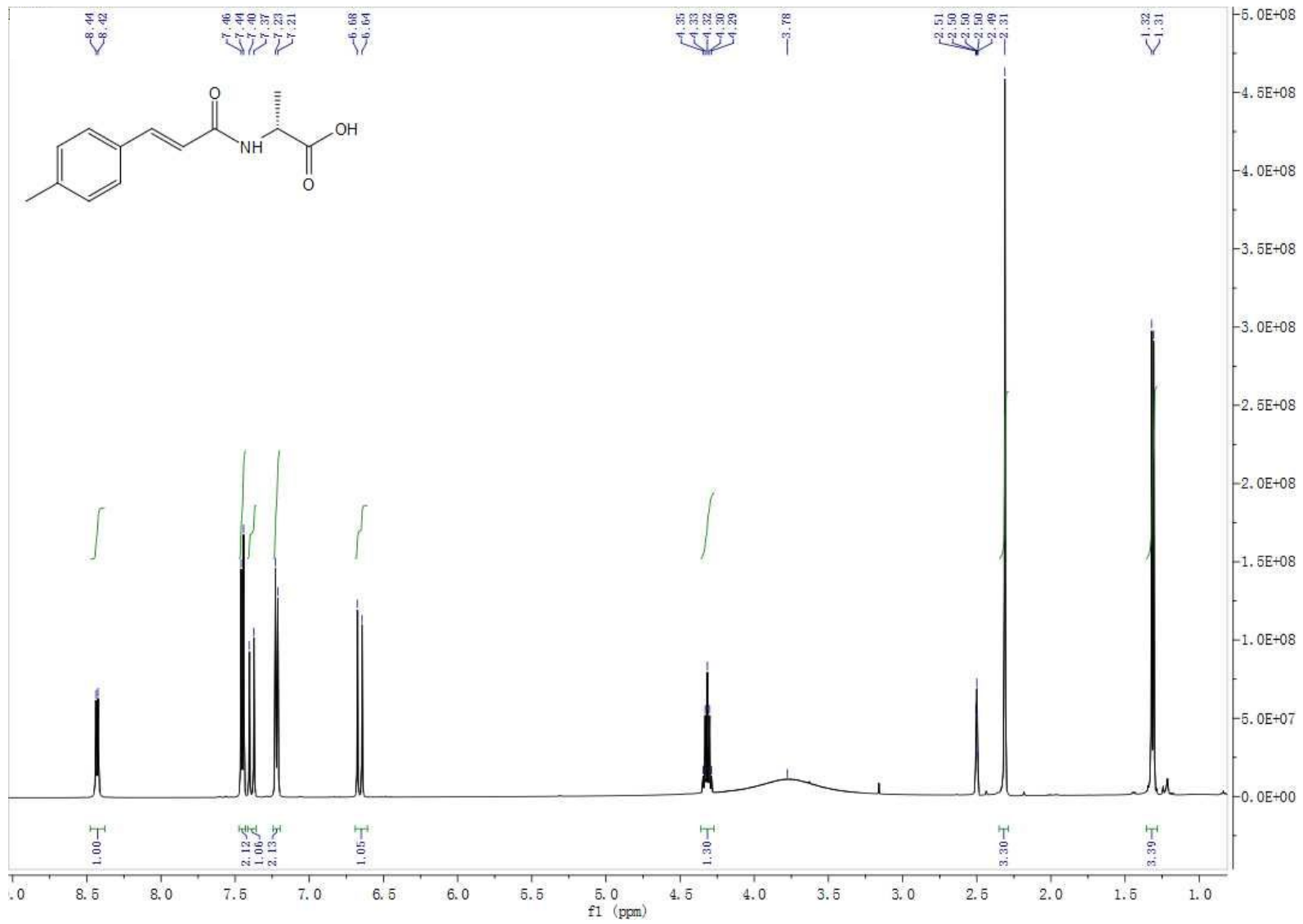

Figure S15 ${ }^{1} \mathrm{H}$ NMR spectra of compound $\mathbf{3 b}$

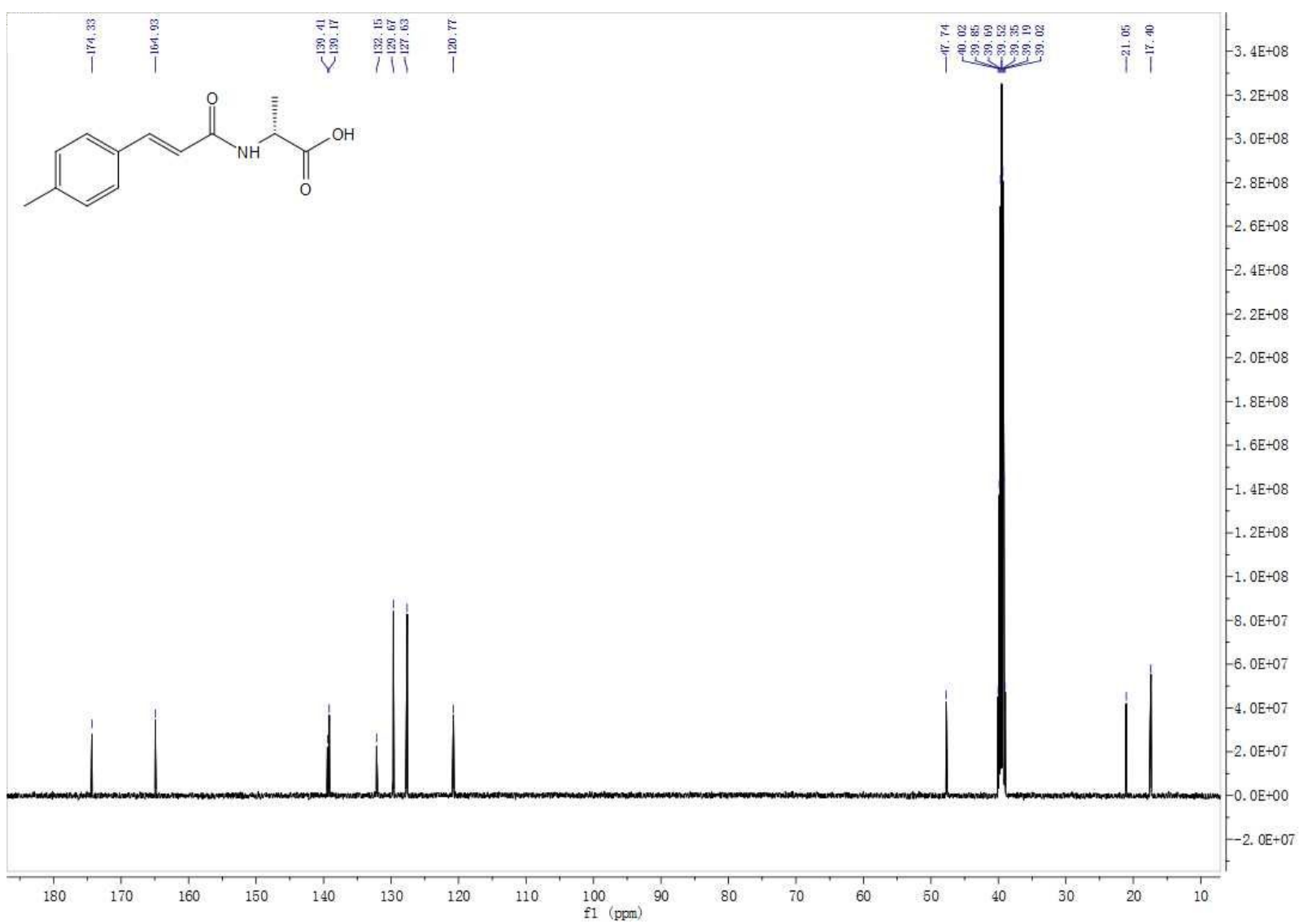


Figure $\mathrm{S} 16{ }^{13} \mathrm{C}$ NMR spectra of compound $\mathbf{3 b}$

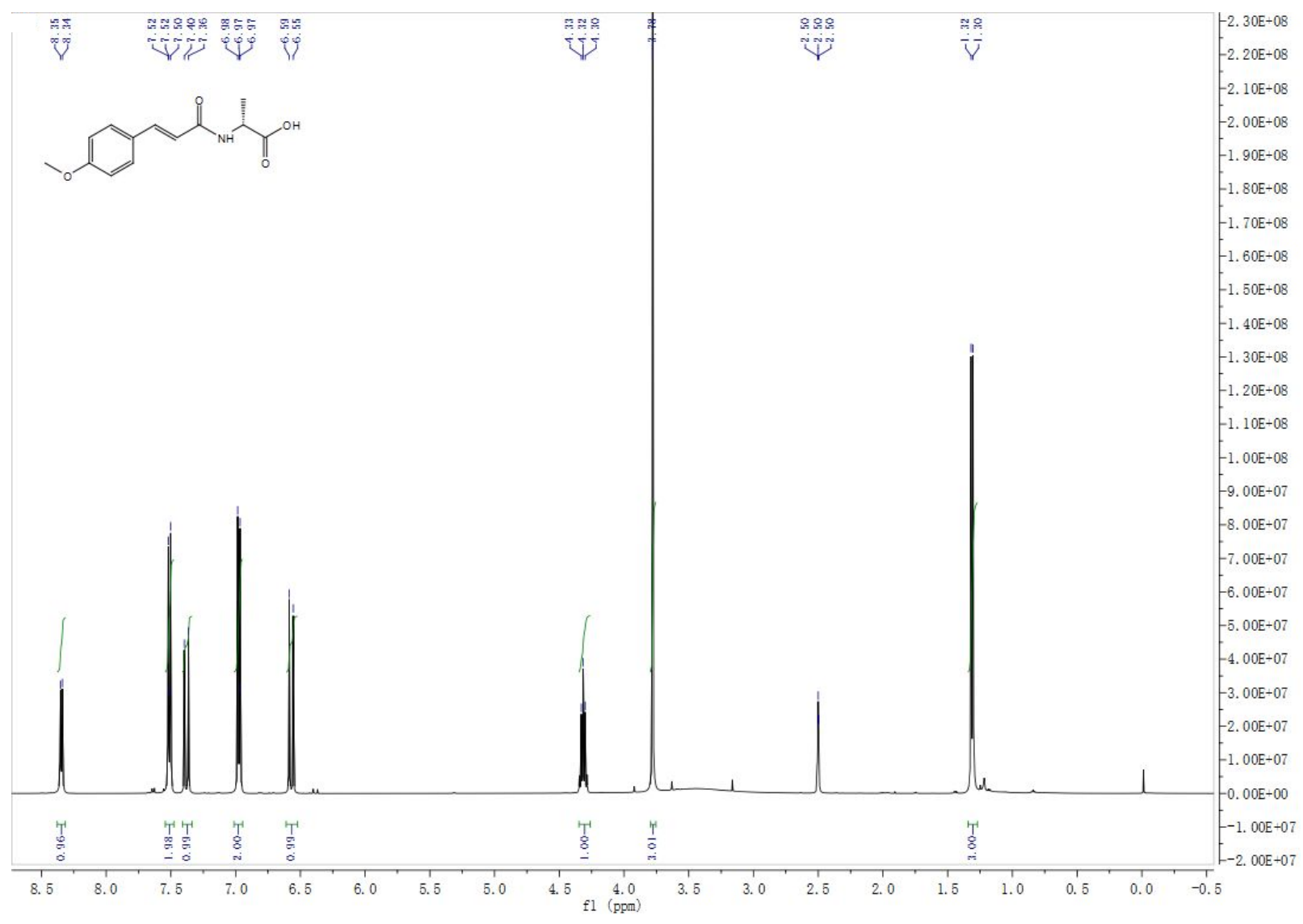

Figure $\mathrm{S} 17{ }^{1} \mathrm{H}$ NMR spectra of compound $\mathbf{3 c}$ 


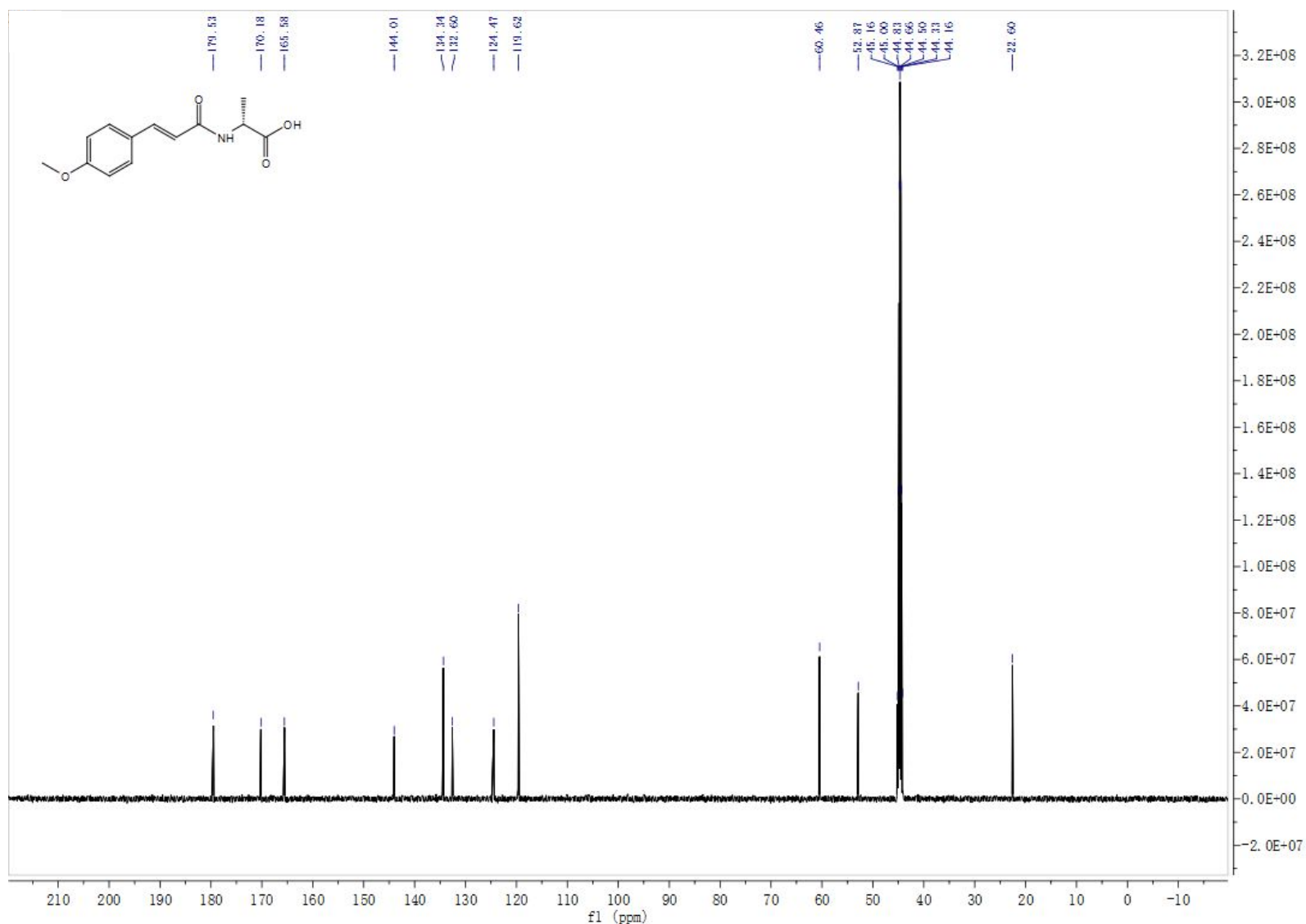

Figure S18 ${ }^{13} \mathrm{C}$ NMR spectra of compound $\mathbf{3 c}$

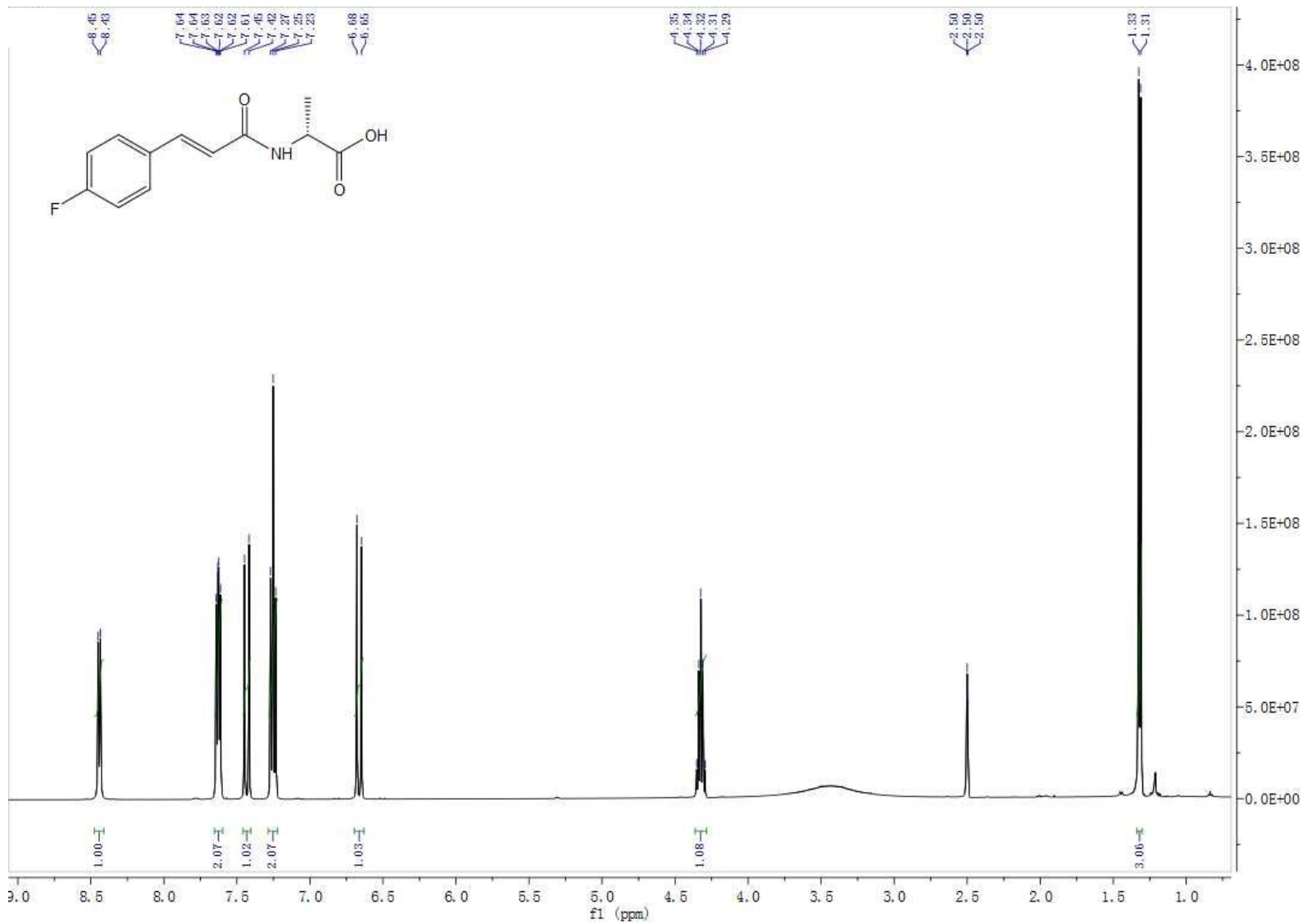

Figure S19 ${ }^{1} \mathrm{H}$ NMR spectra of compound 3d 


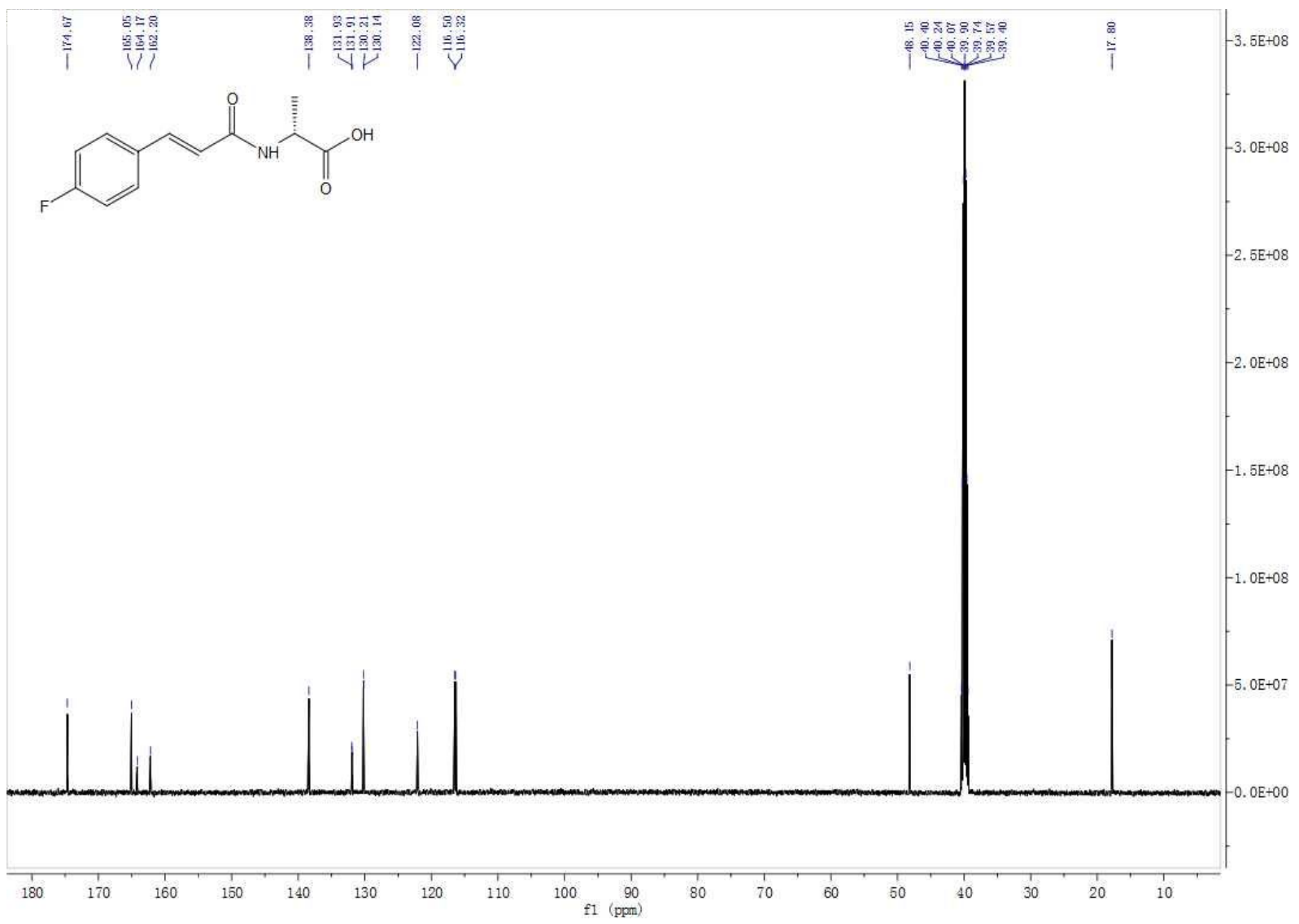

Figure S20 ${ }^{13} \mathrm{C}$ NMR spectra of compound 3d

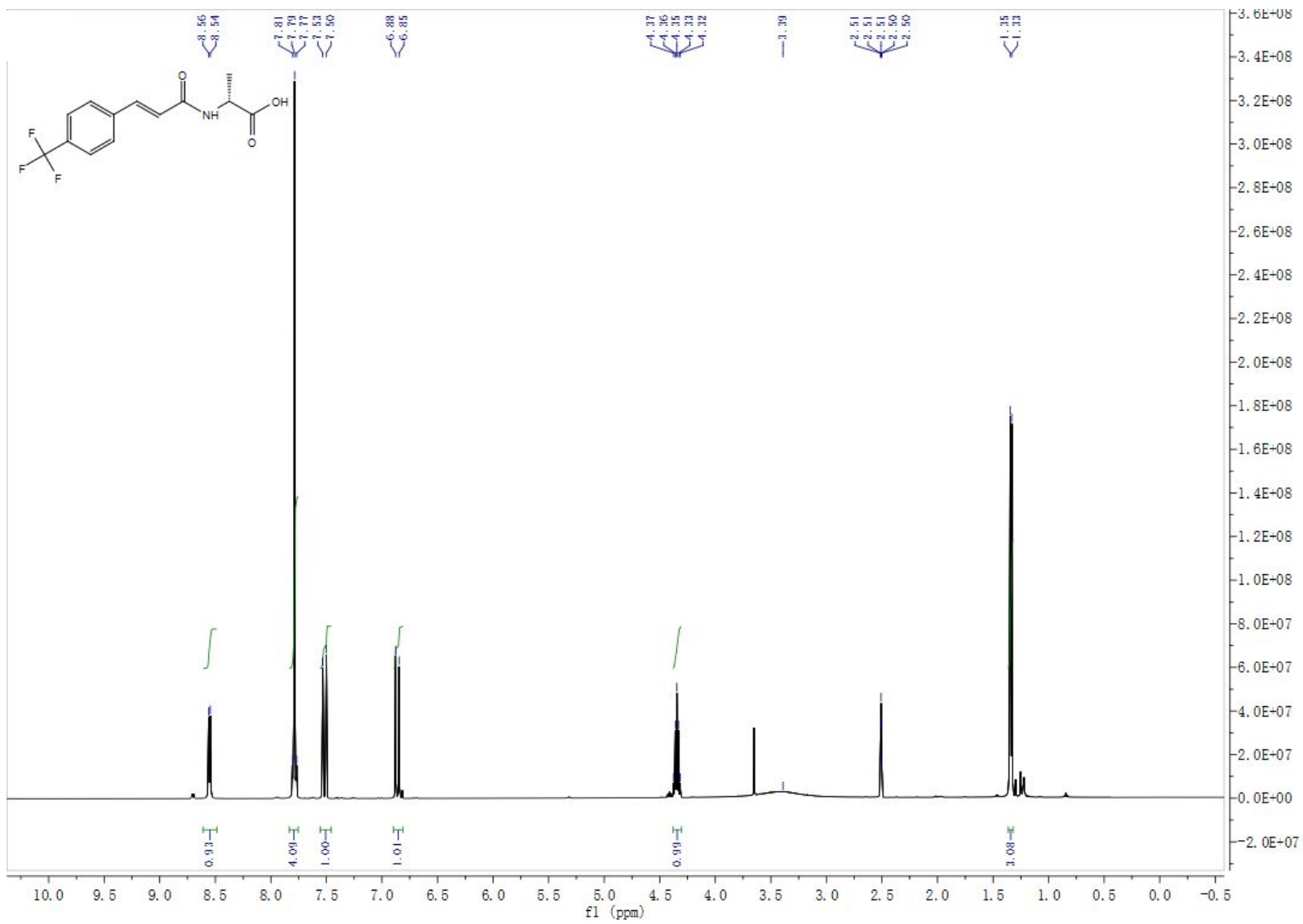

Figure S2 $1{ }^{1} \mathrm{H}$ NMR spectra of compound $3 \mathbf{e}$ 


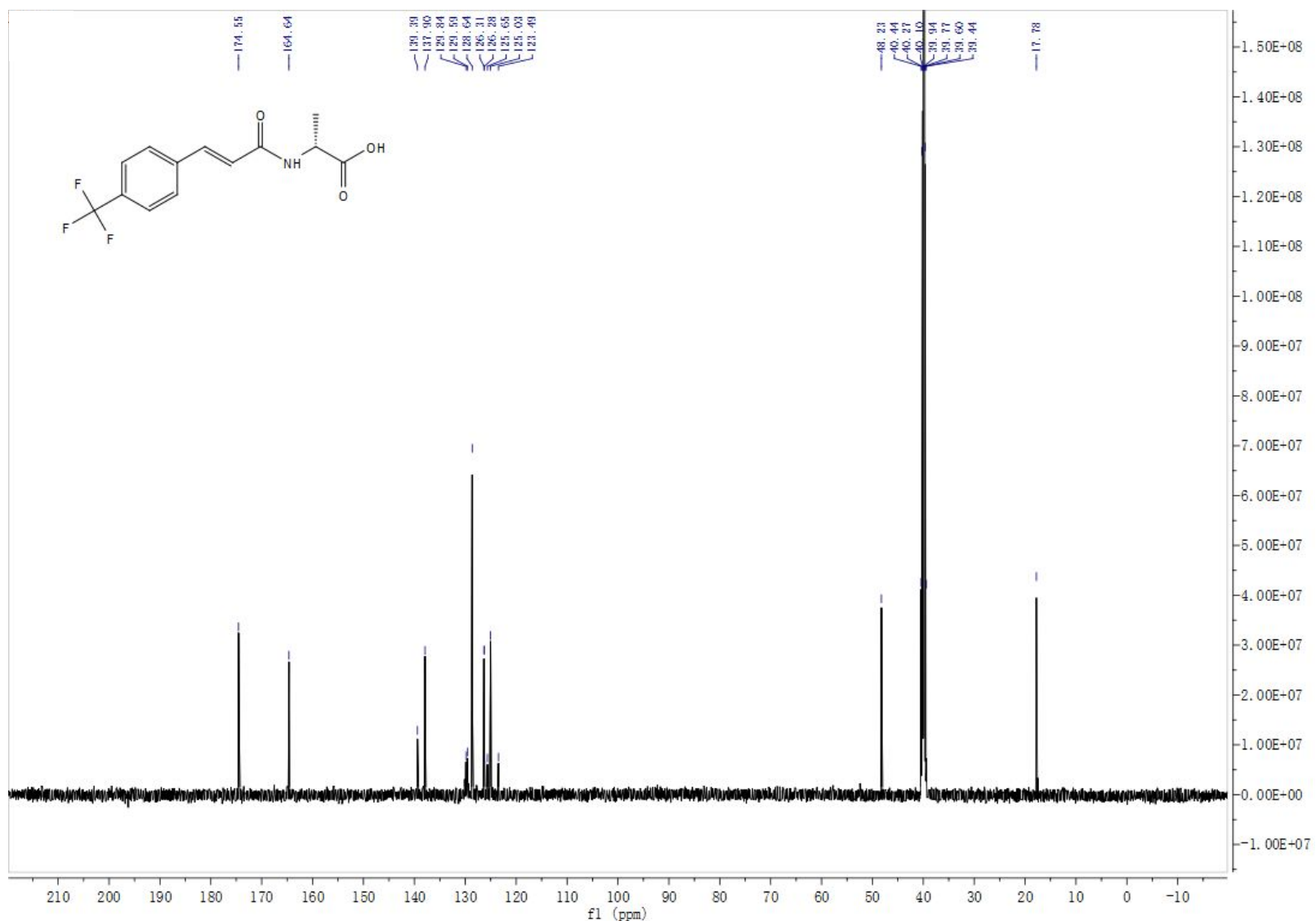

Figure S22 ${ }^{13} \mathrm{C}$ NMR spectra of compound $\mathbf{3 e}$

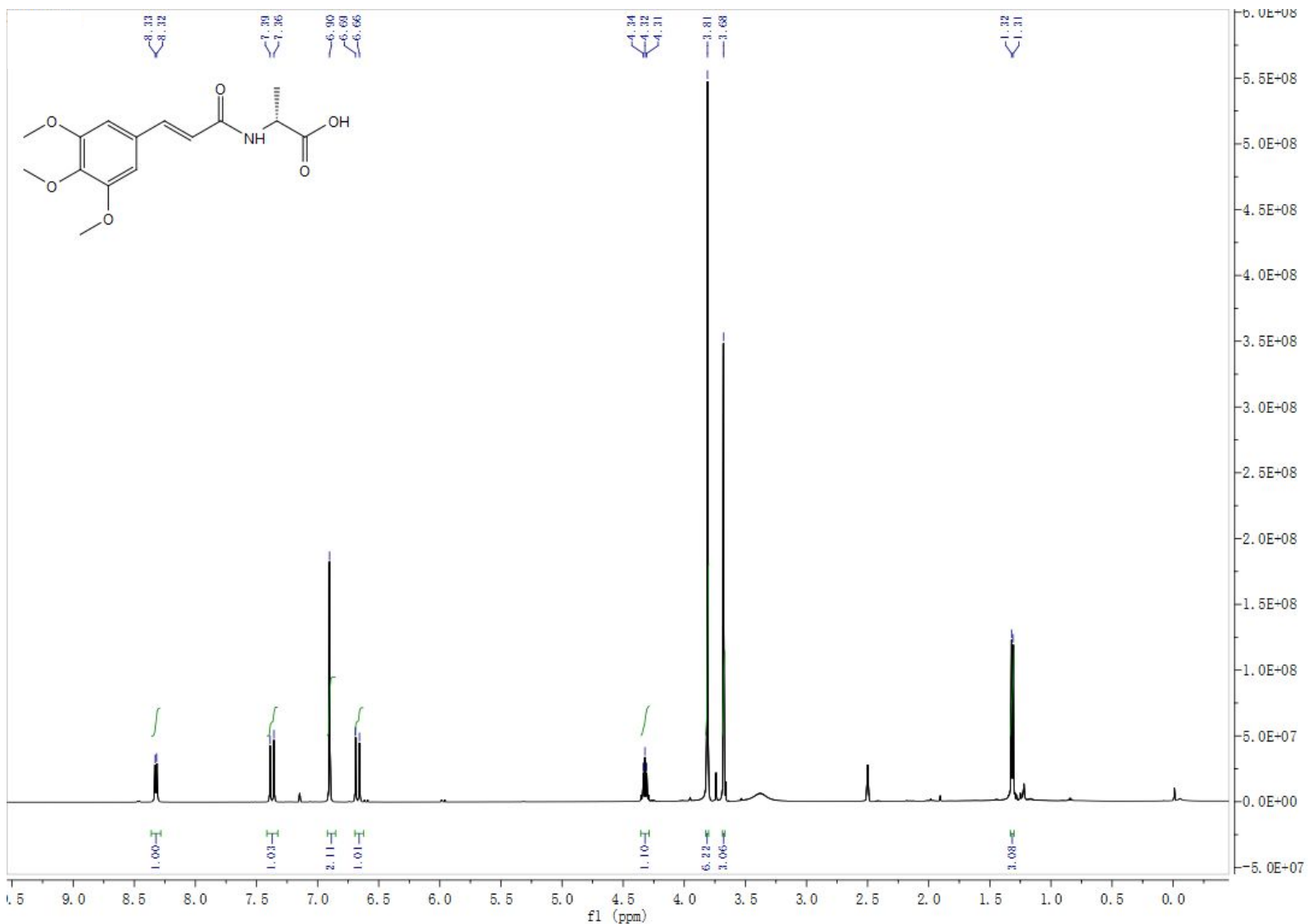

Figure S23 ${ }^{1} \mathrm{H}$ NMR spectra of compound $\mathbf{3 f}$ 


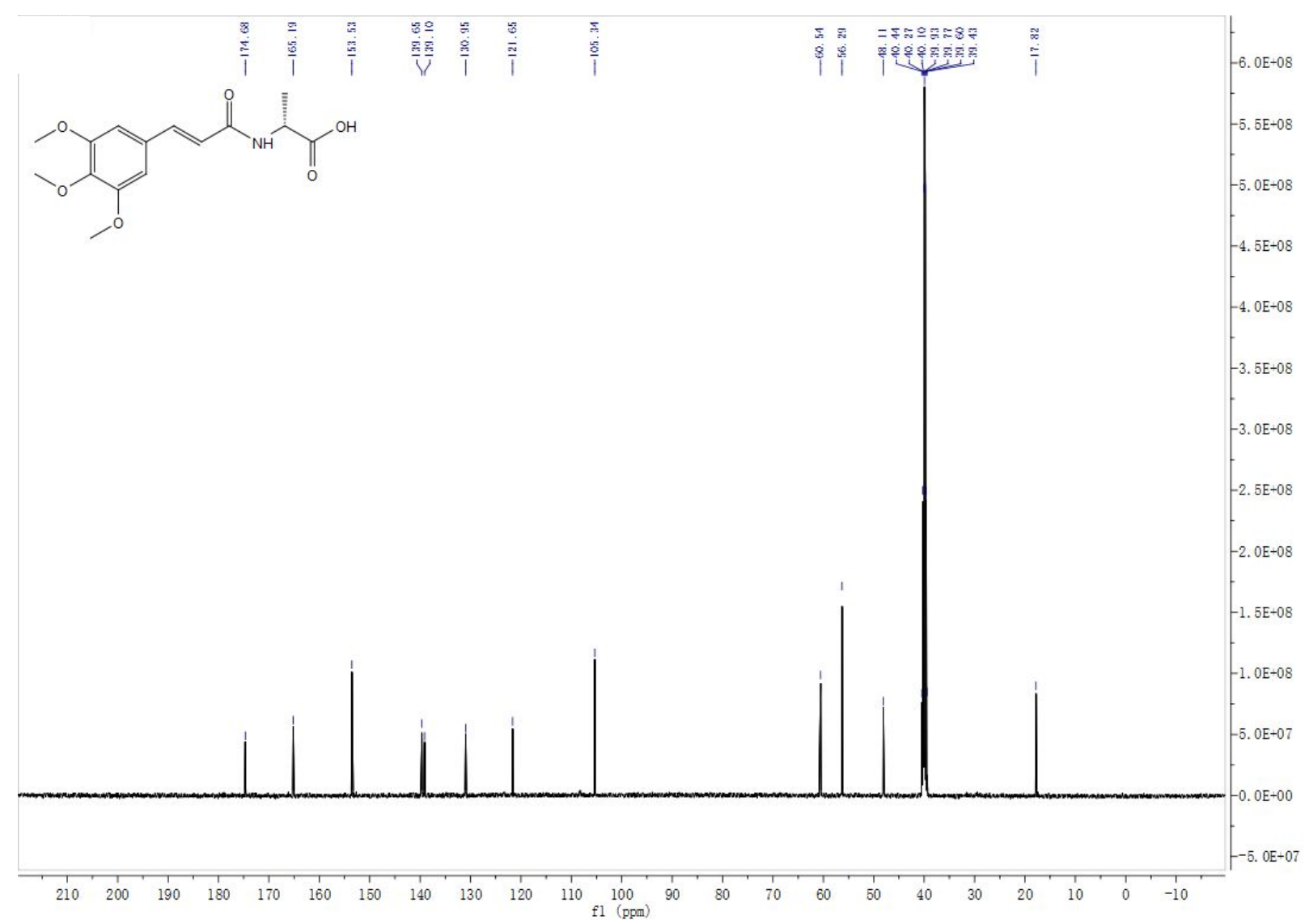

Figure S24 ${ }^{13} \mathrm{C}$ NMR spectra of compound $\mathbf{3 f}$

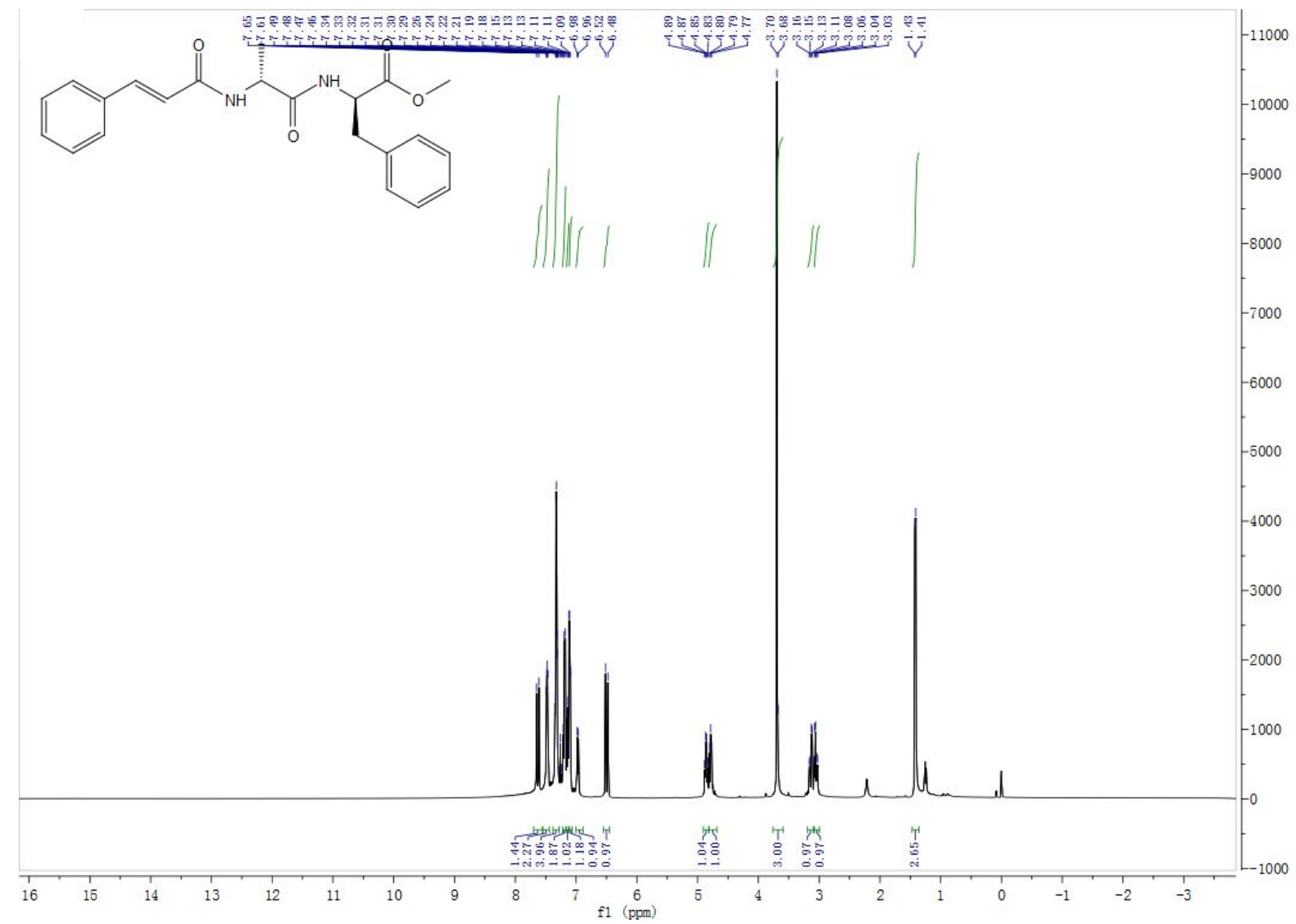

Figure S25 ${ }^{1} \mathrm{H}$ NMR spectra of compound $4 \mathbf{a}$ 


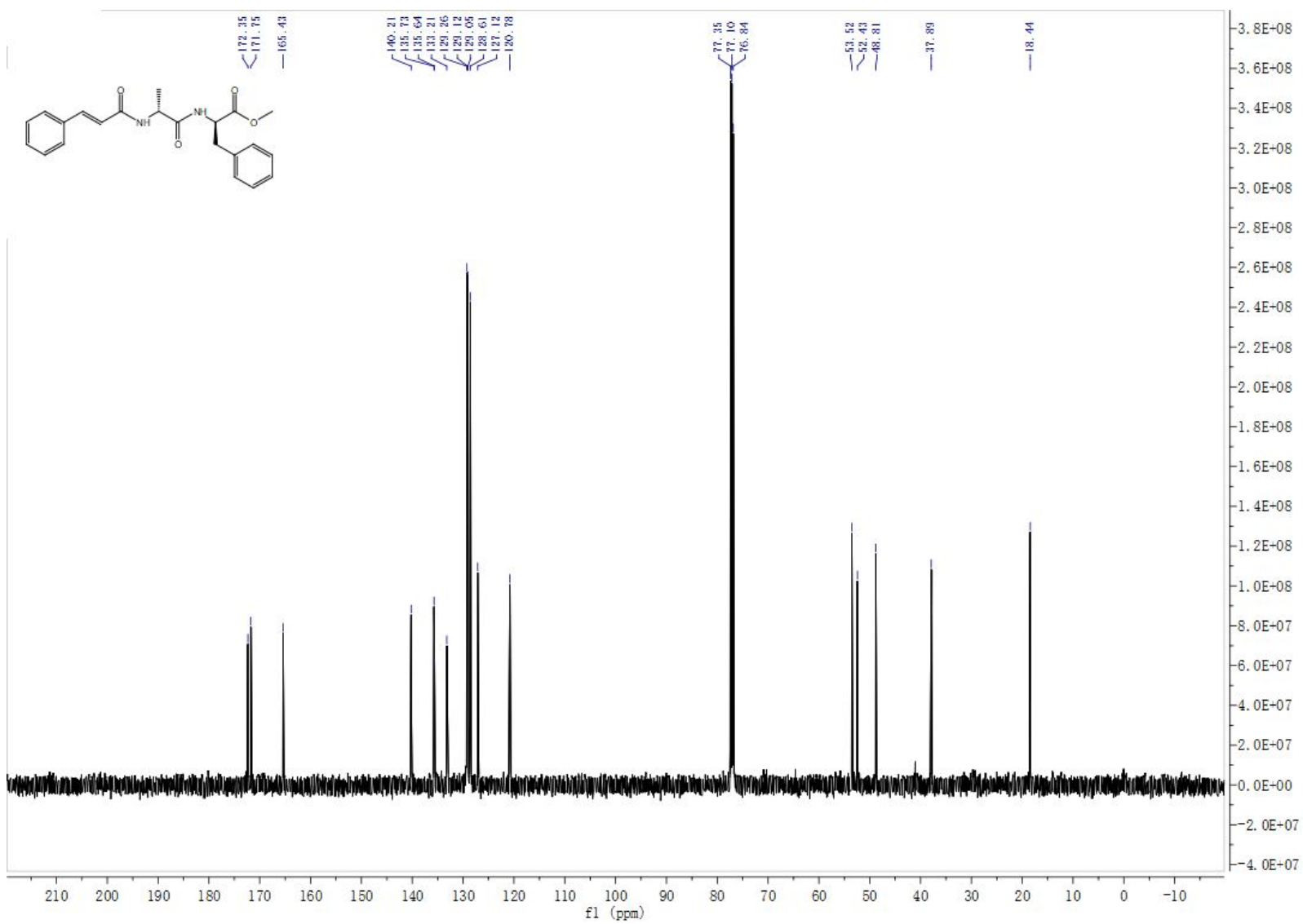

Figure S26 ${ }^{13} \mathrm{C}$ NMR spectra of compound 4a

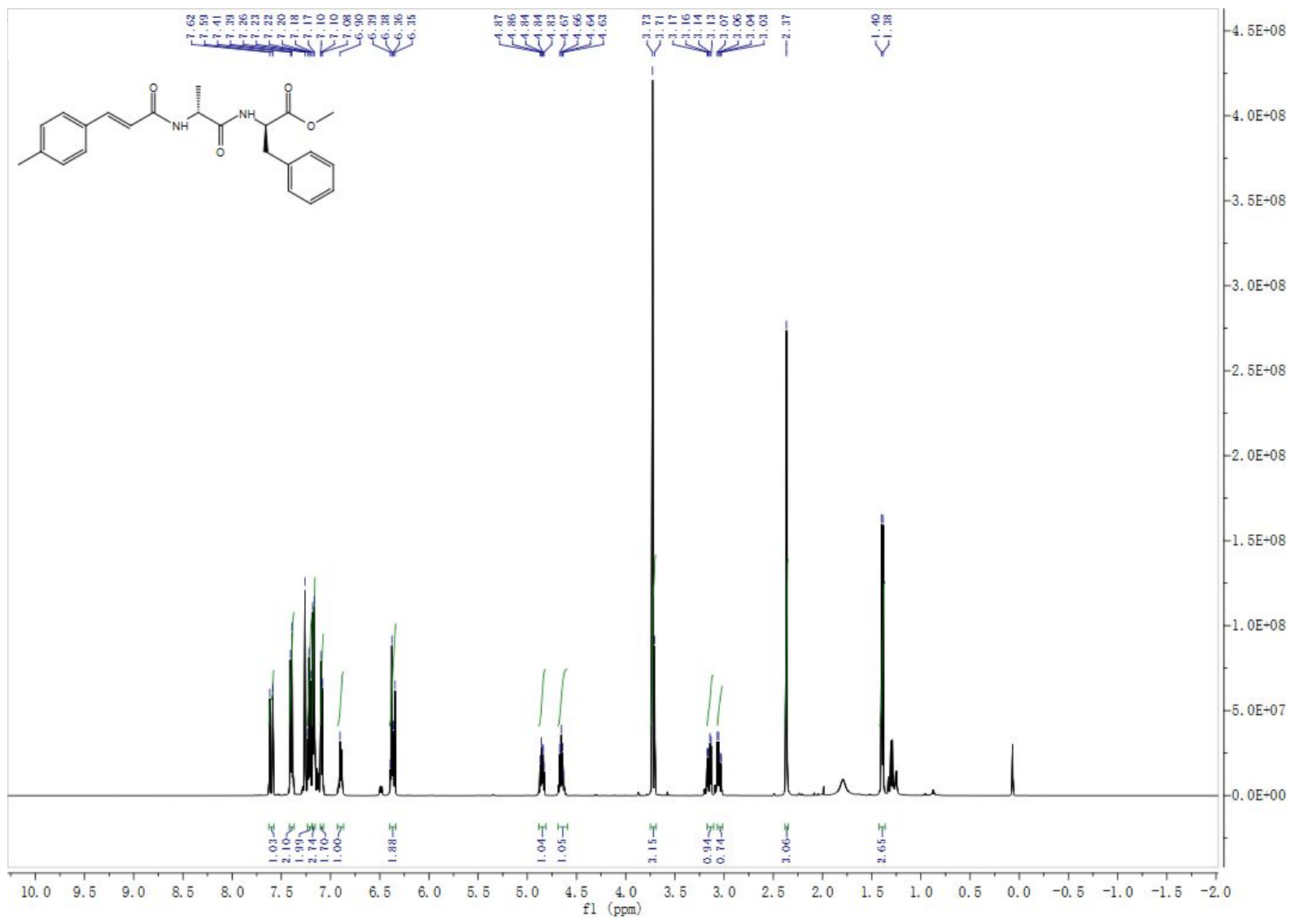

Figure S27 ${ }^{1} \mathrm{H}$ NMR spectra of compound $\mathbf{4 b}$ 


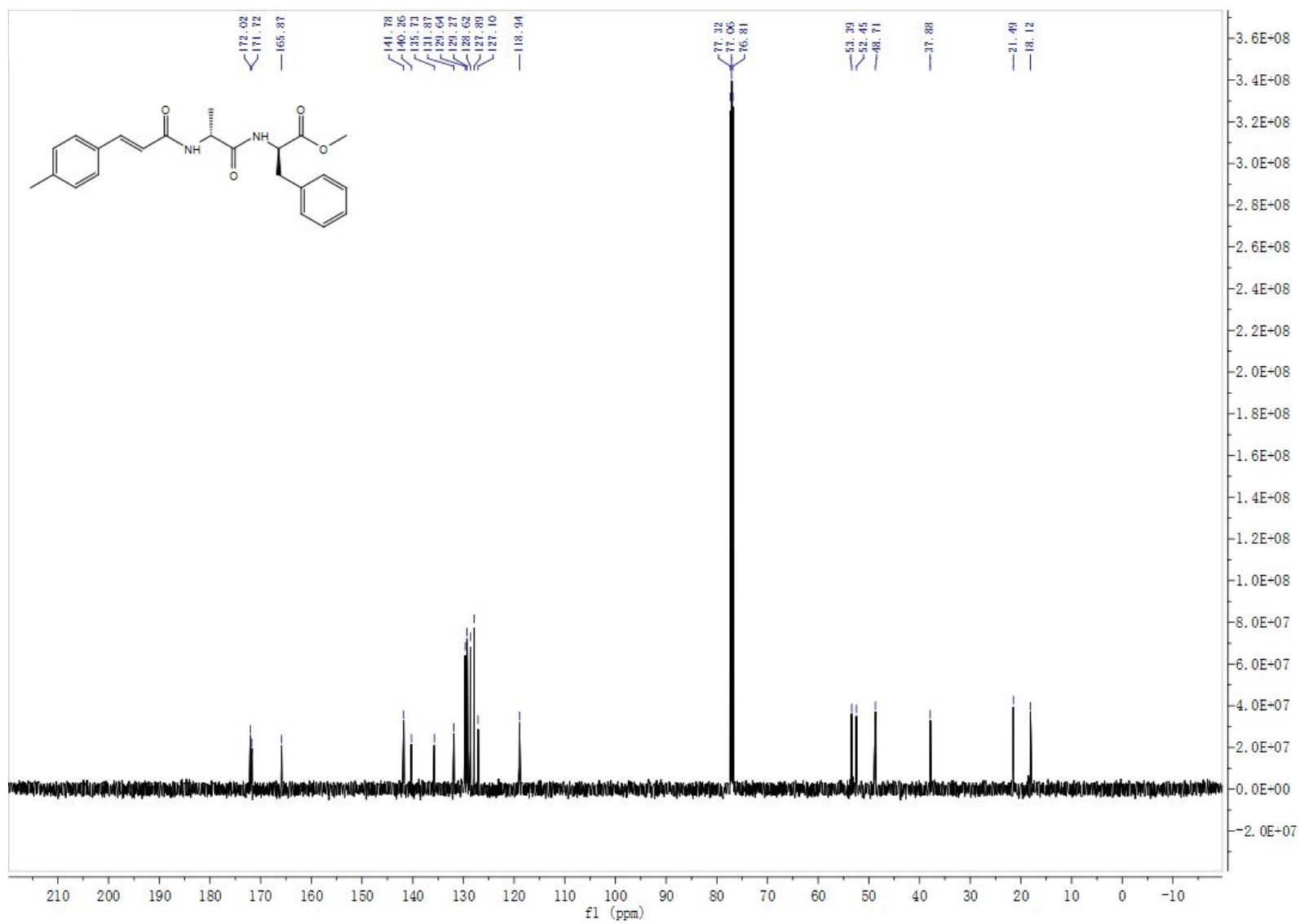

Figure S28 ${ }^{13} \mathrm{C}$ NMR spectra of compound $\mathbf{4 b}$

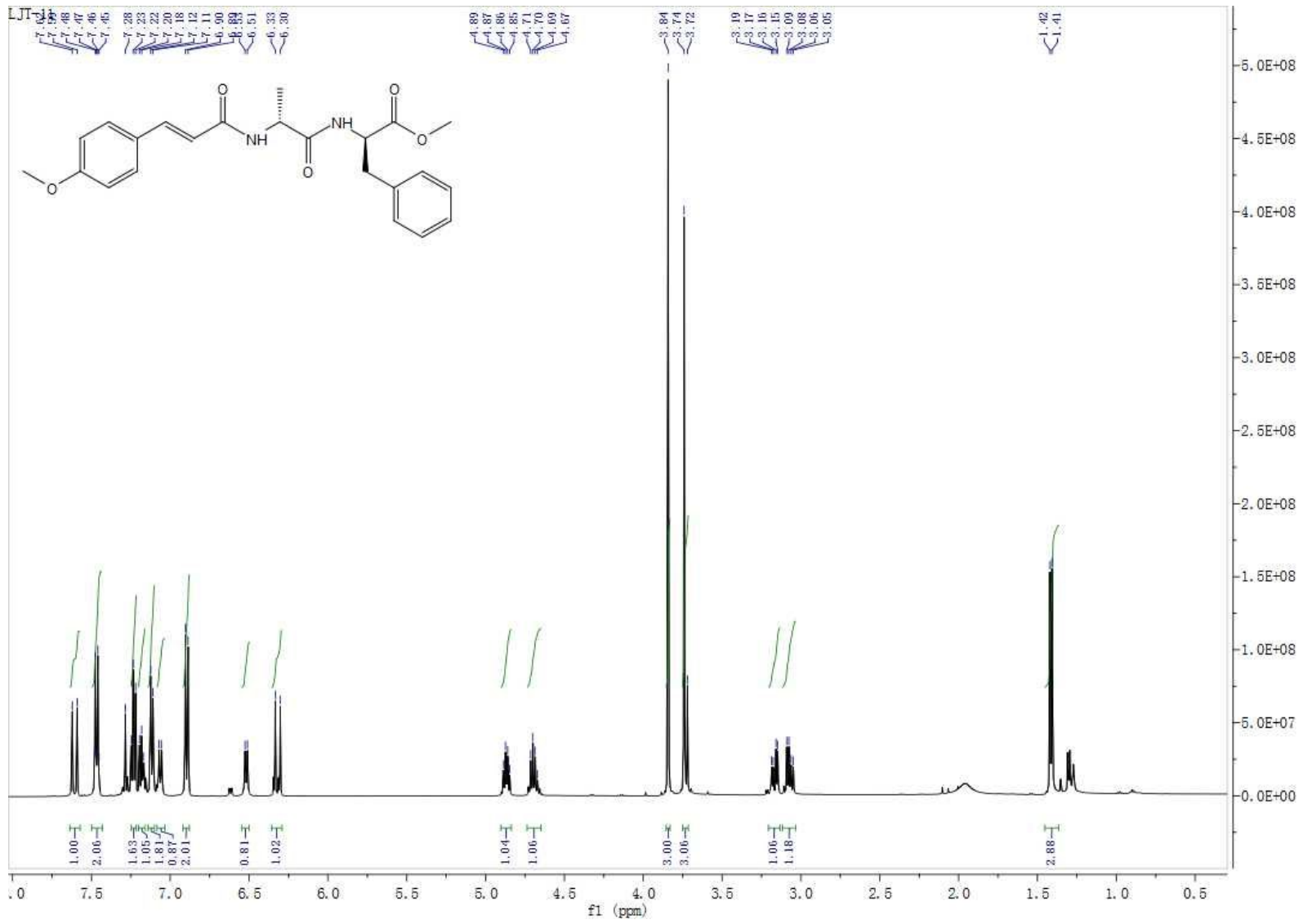

Figure S29 ${ }^{1} \mathrm{H}$ NMR spectra of compound $4 \mathrm{c}$ 


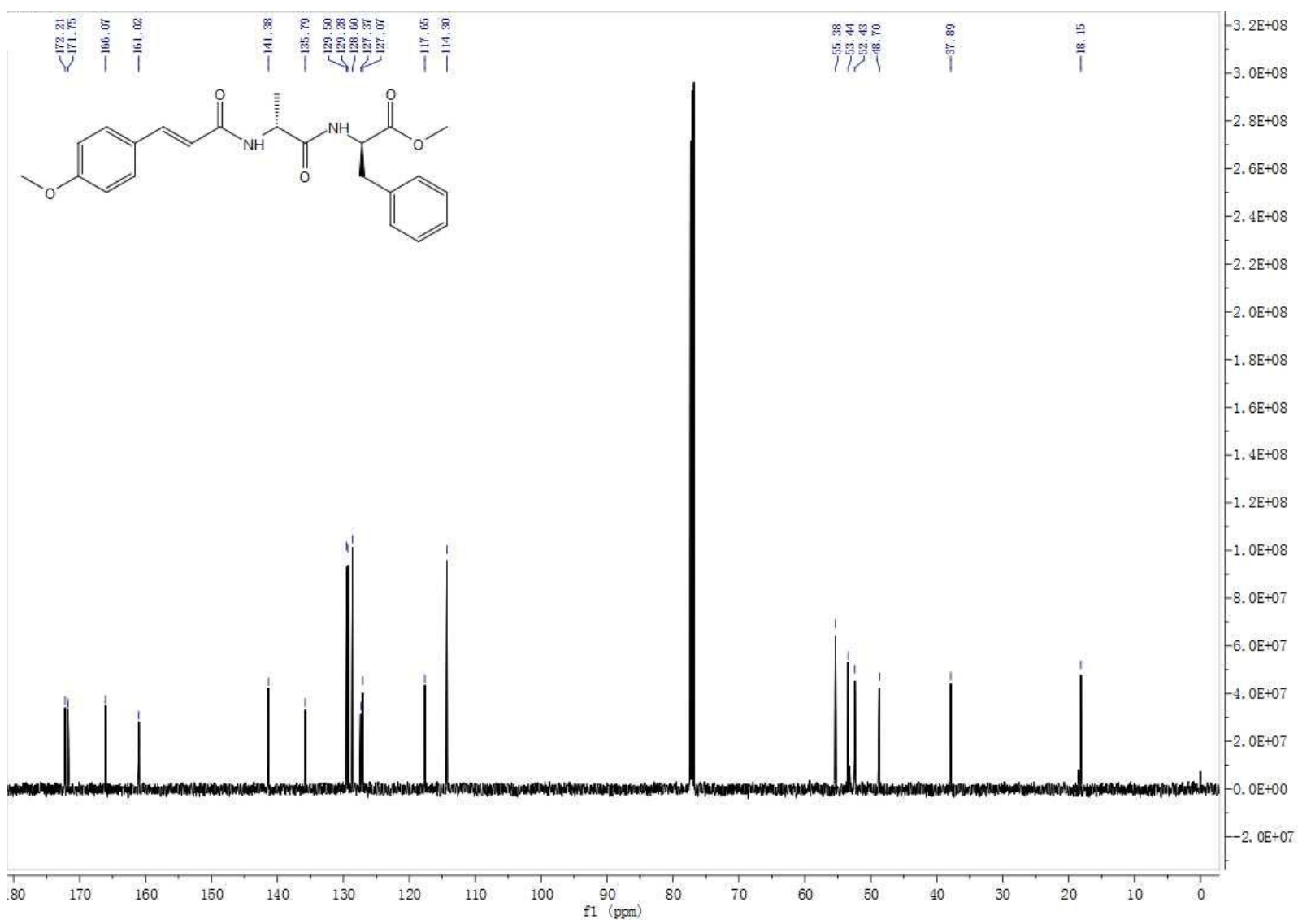

Figure S30 ${ }^{13} \mathrm{C}$ NMR spectra of compound $4 \mathbf{c}$

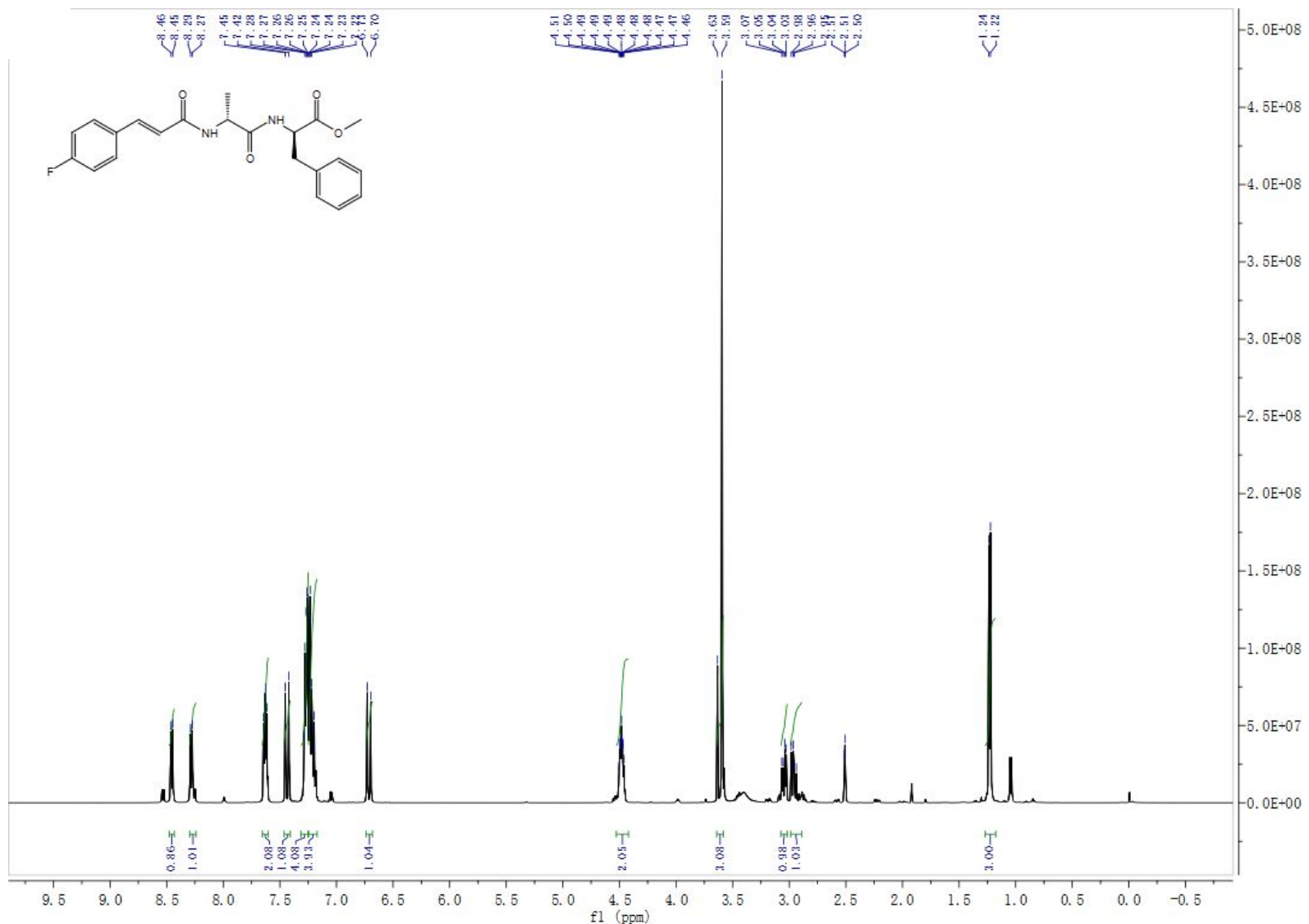

Figure S31 ${ }^{1} \mathrm{H}$ NMR spectra of compound $\mathbf{4 d}$ 


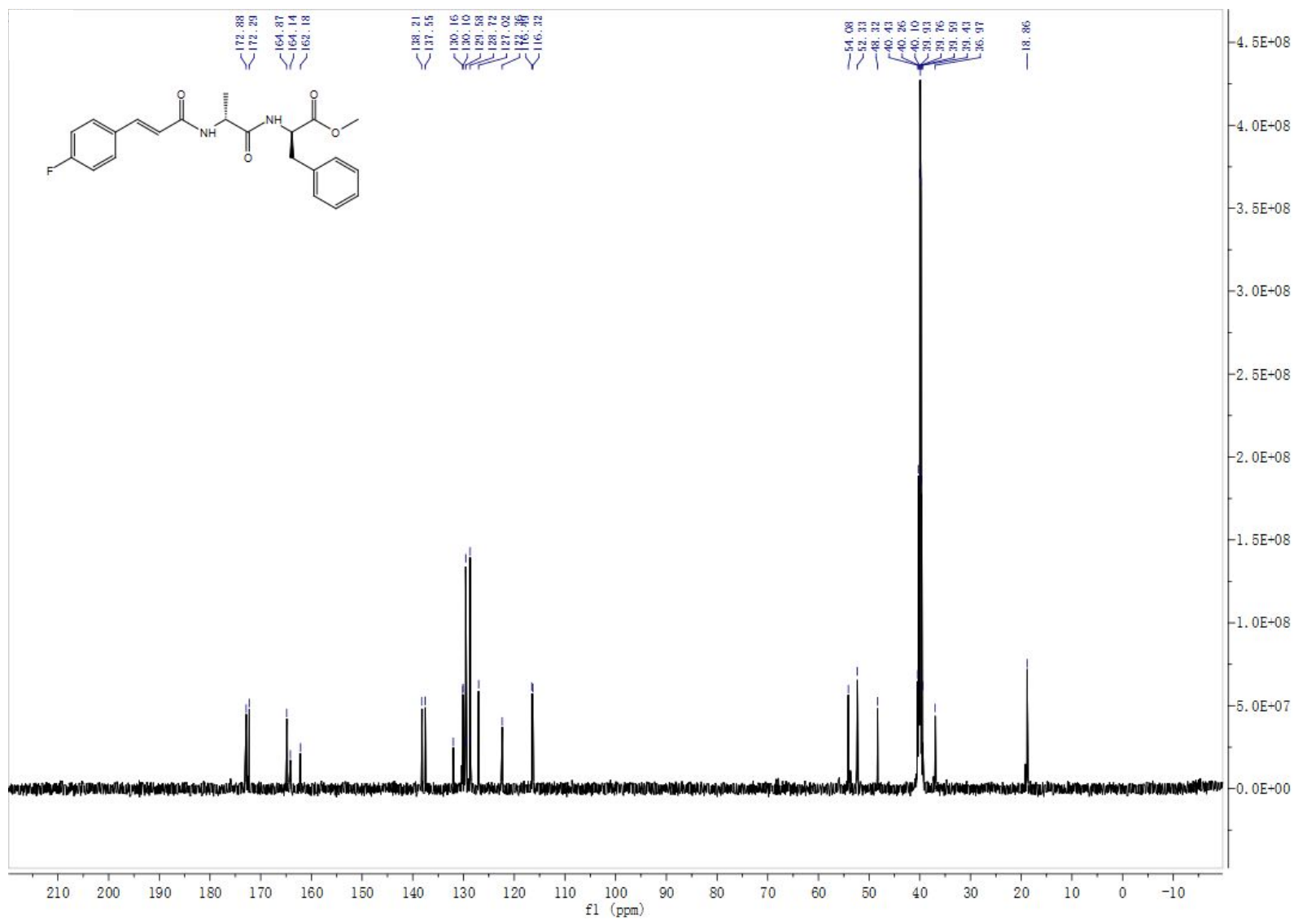

Figure S32 ${ }^{13} \mathrm{C}$ NMR spectra of compound $4 \mathbf{d}$

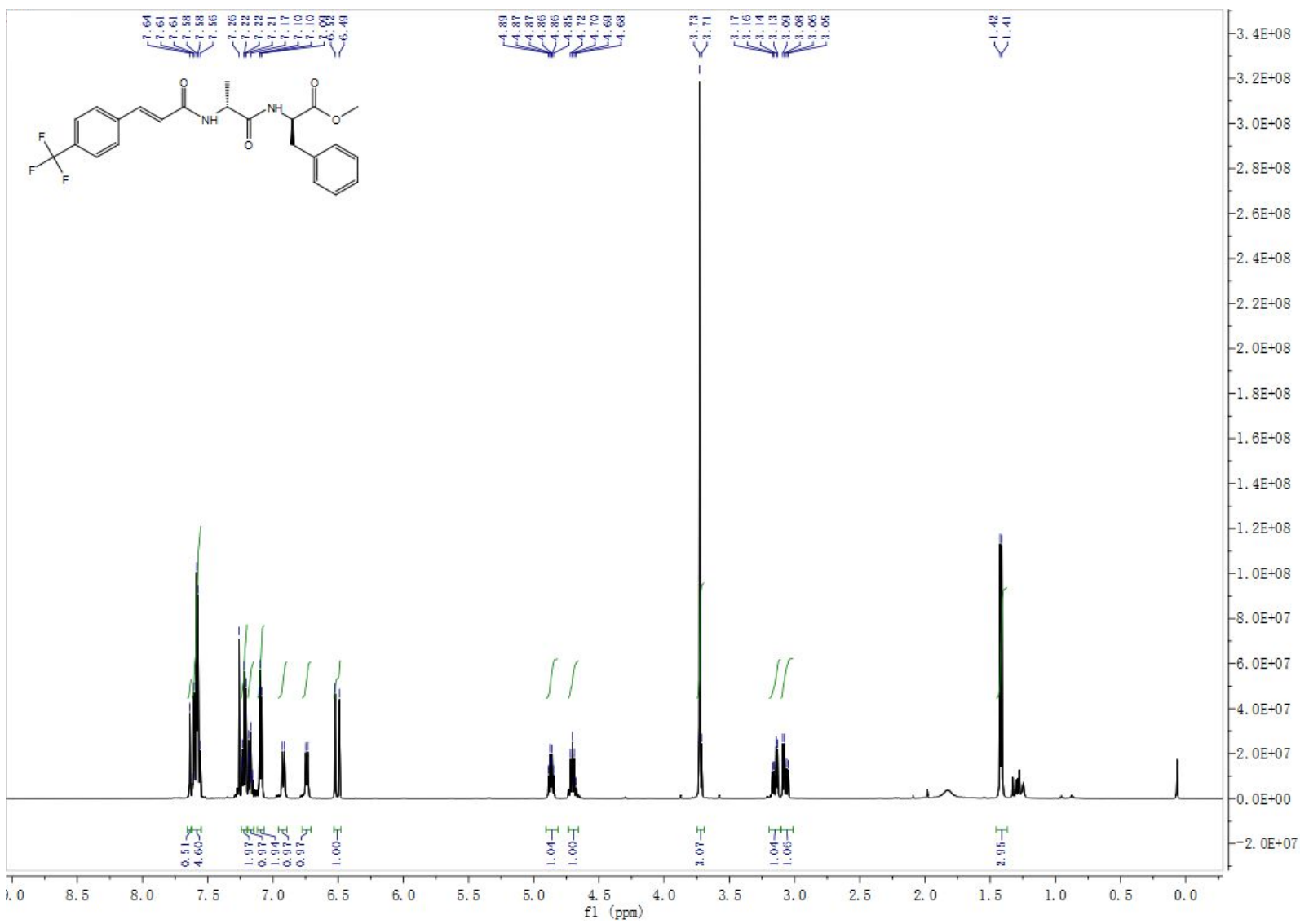

Figure S33 ${ }^{1} \mathrm{H}$ NMR spectra of compound $\mathbf{4 e}$ 


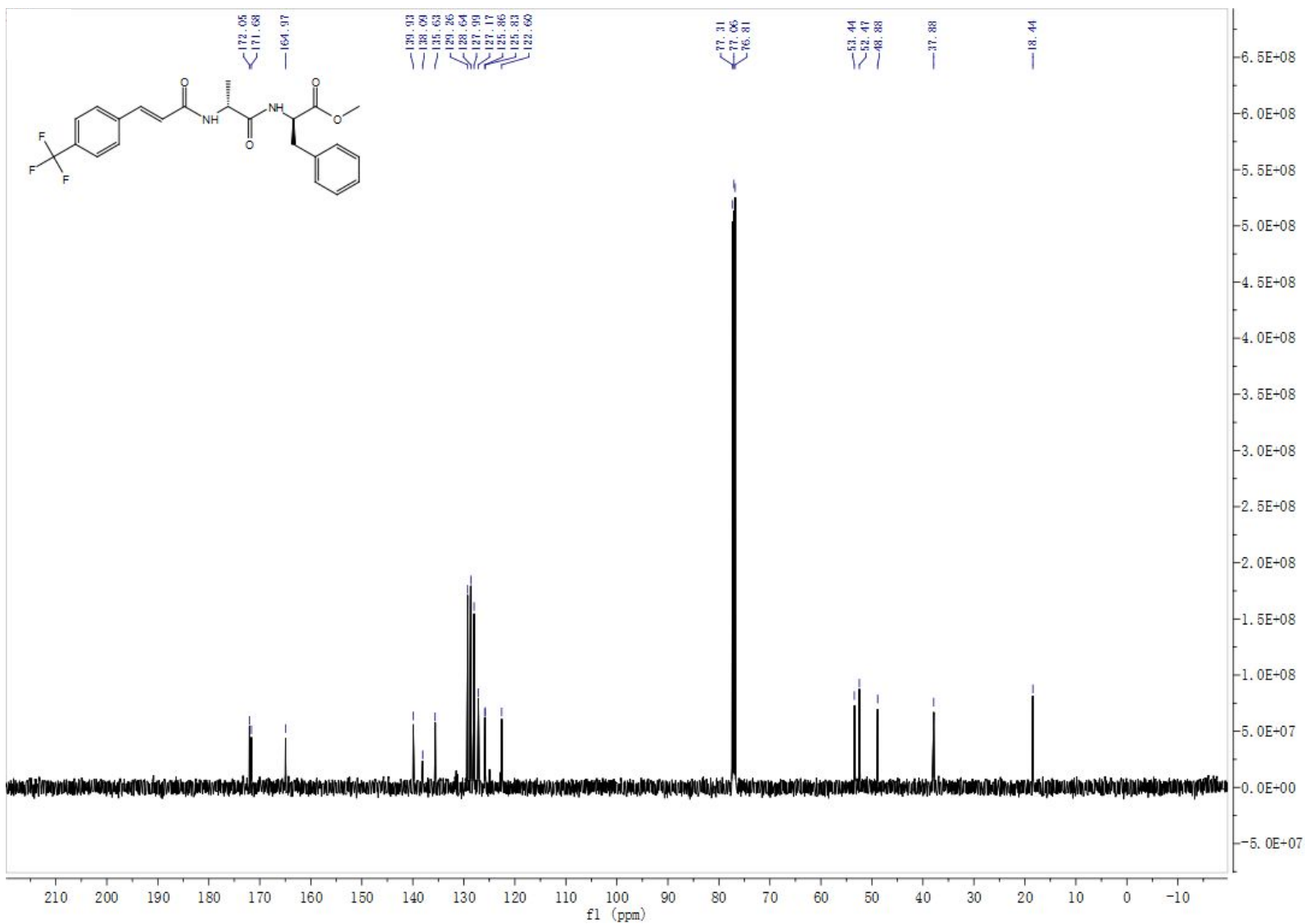

Figure S34 ${ }^{13} \mathrm{C}$ NMR spectra of compound $4 \mathbf{e}$

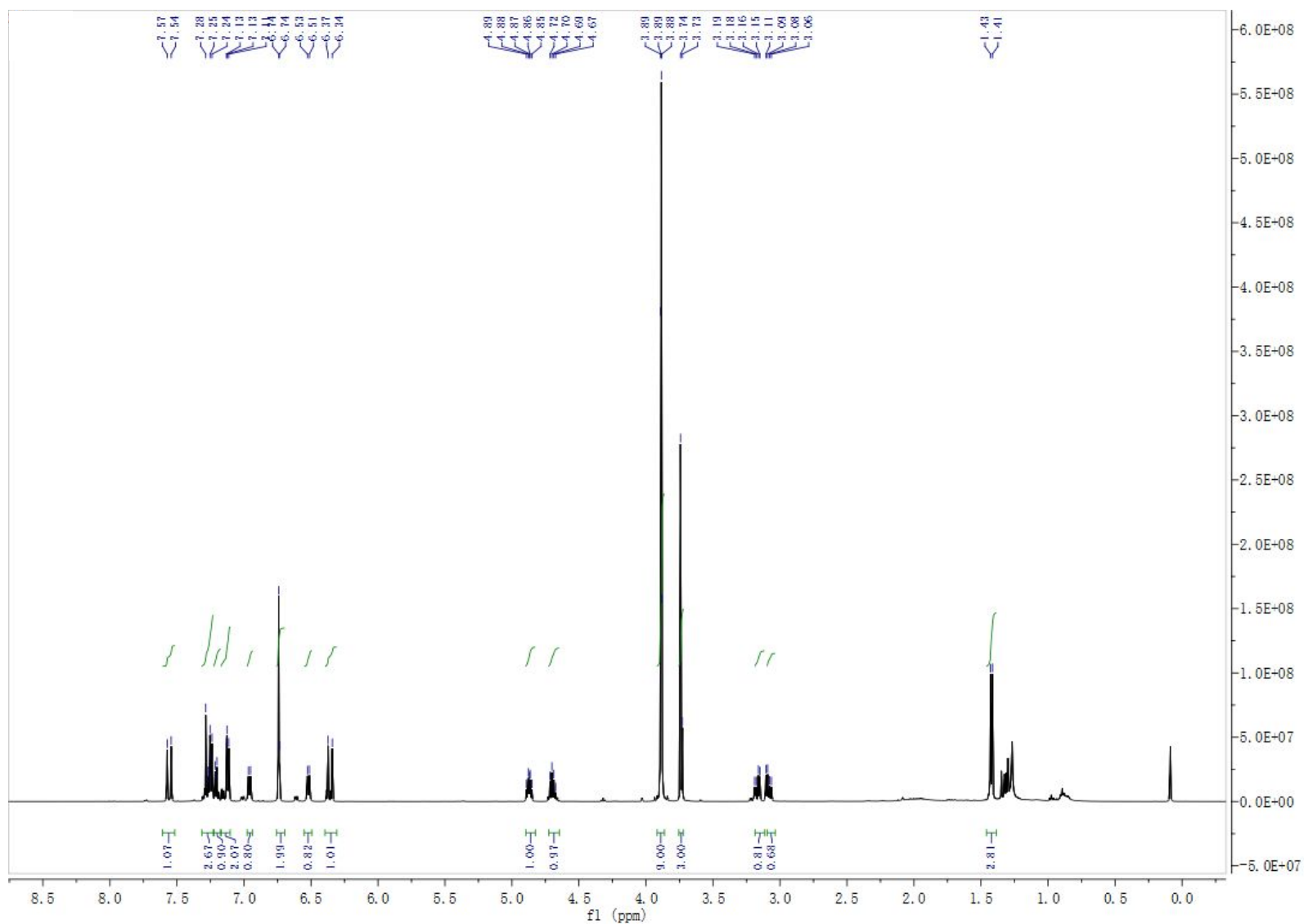

Figure S35 ${ }^{1} \mathrm{H}$ NMR spectra of compound $\mathbf{4 f}$ 


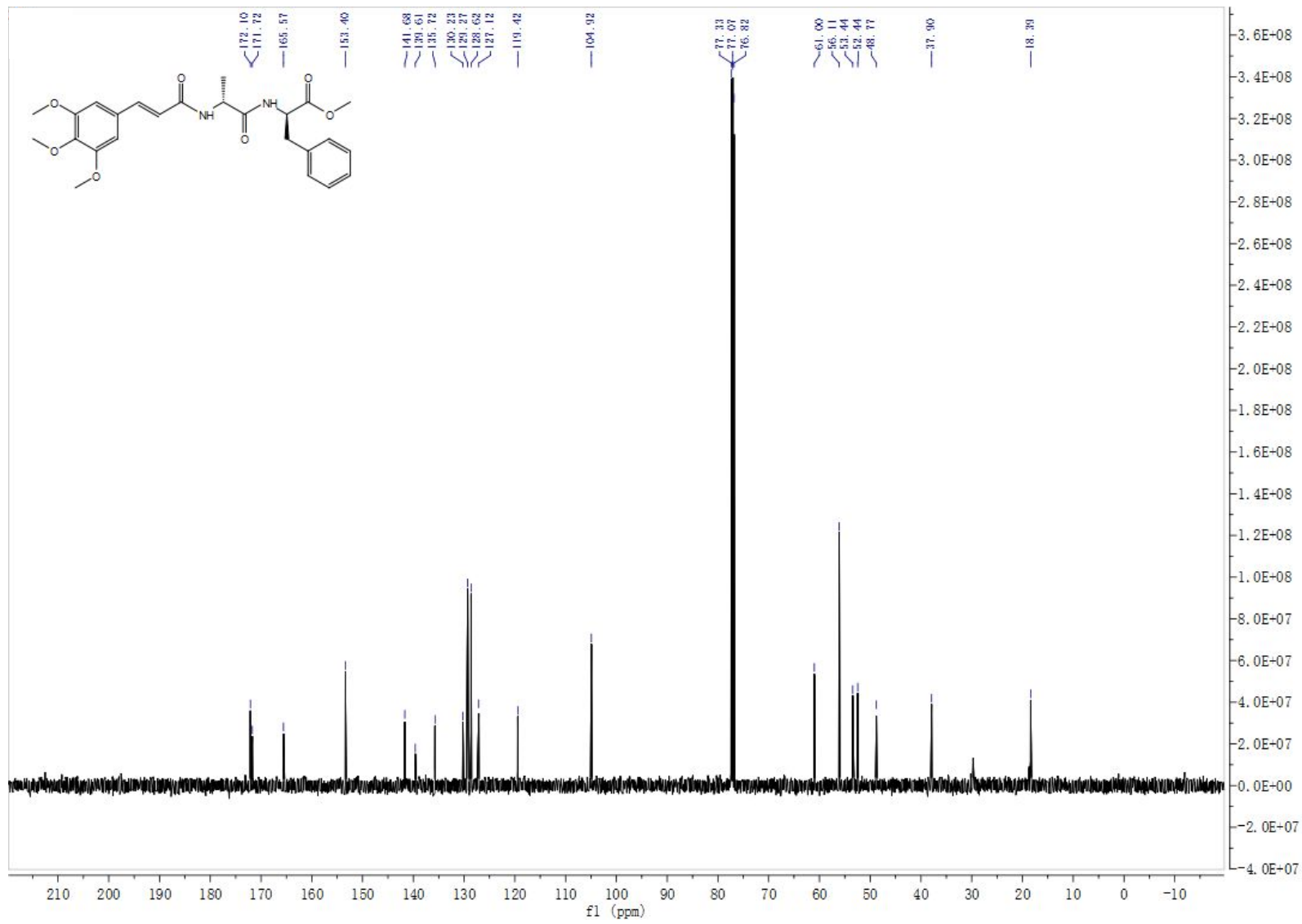

Figure S36 ${ }^{13} \mathrm{C}$ NMR spectra of compound $\mathbf{4 f}$

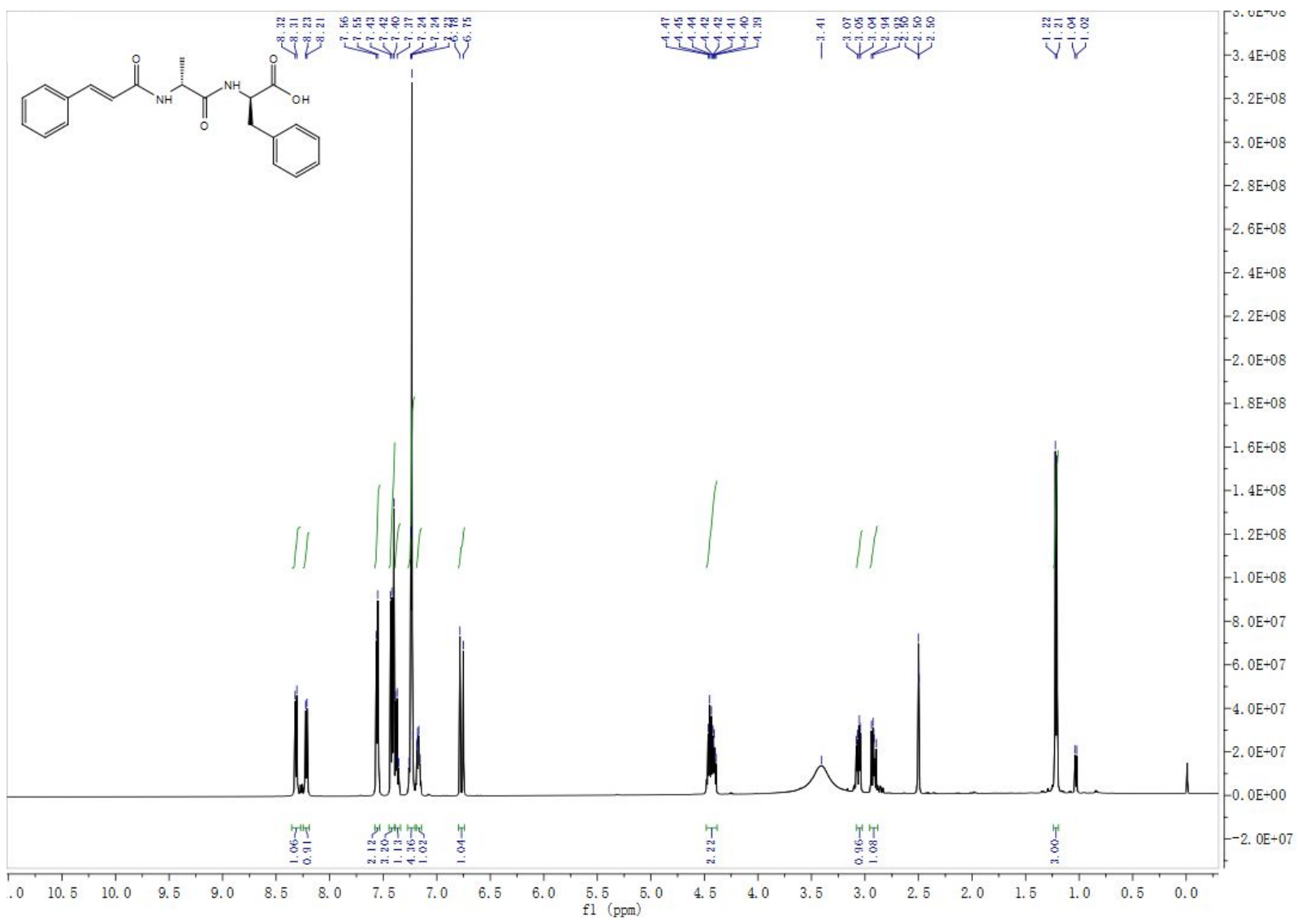


Figure S37 ${ }^{1} \mathrm{H}$ NMR spectra of compound 5a

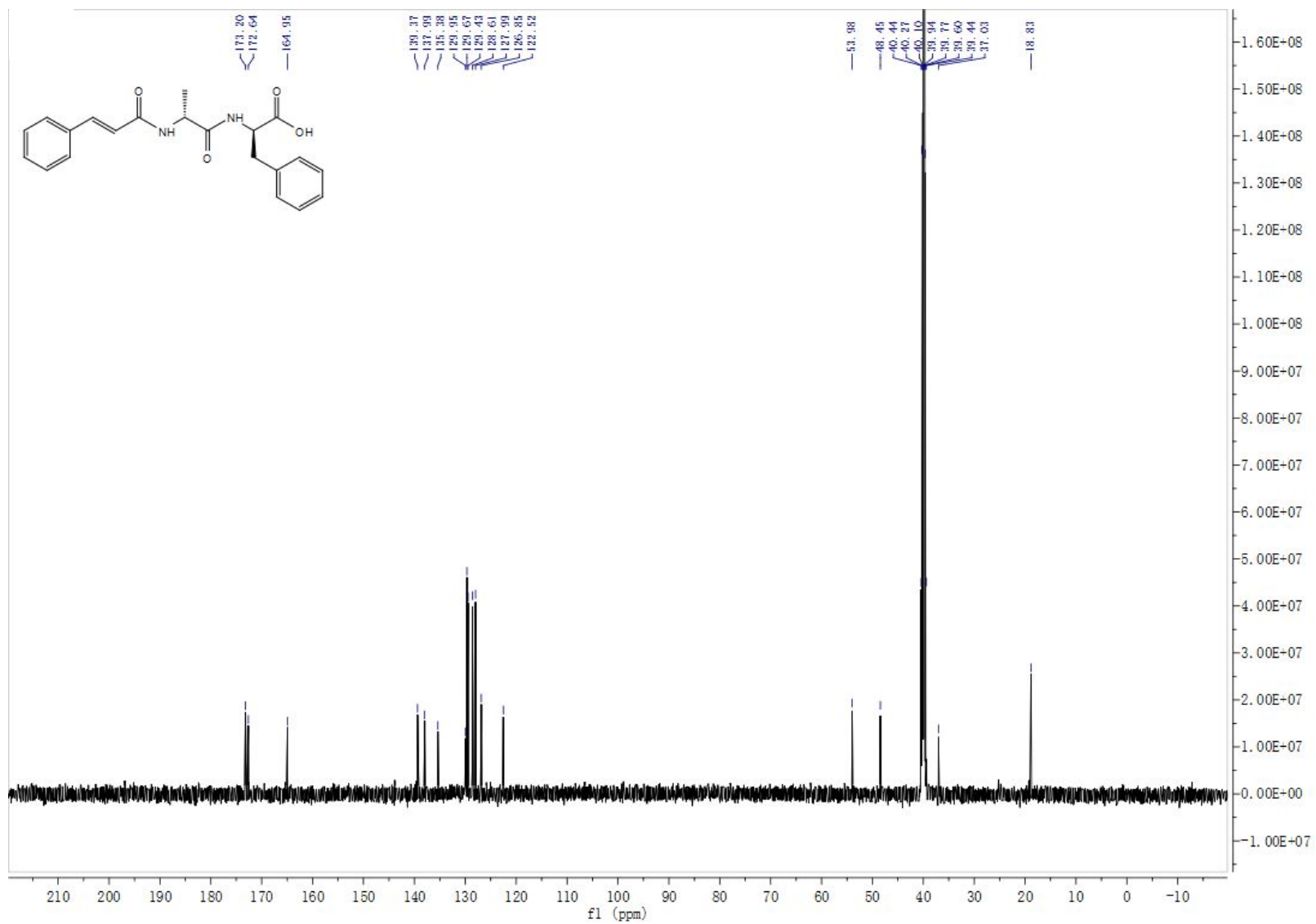

Figure S38 ${ }^{13} \mathrm{C}$ NMR spectra of compound 5a

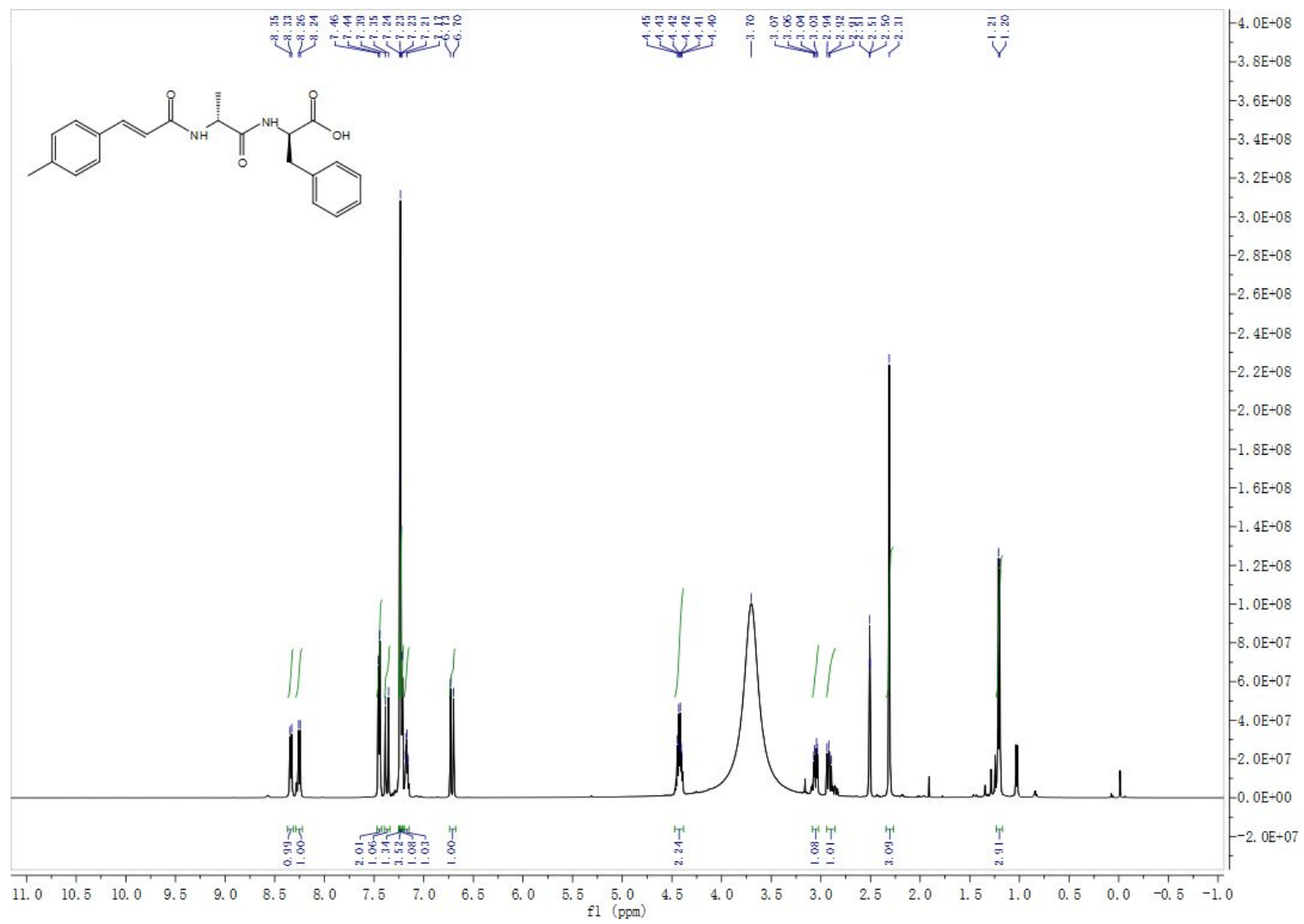


Figure S39 ${ }^{1} \mathrm{H}$ NMR spectra of compound $\mathbf{5 b}$

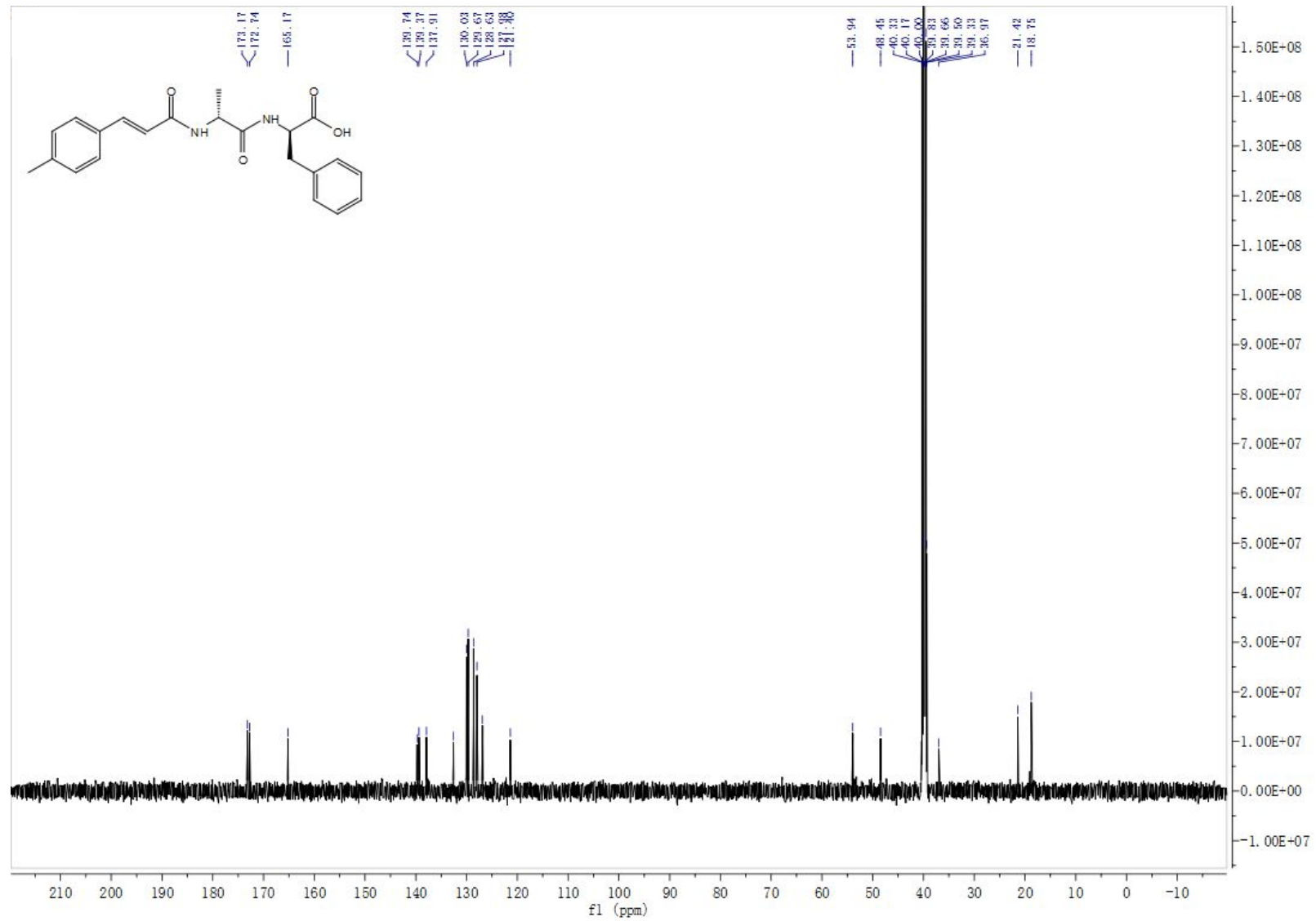

Figure S40 ${ }^{13} \mathrm{C}$ NMR spectra of compound $\mathbf{5 b}$

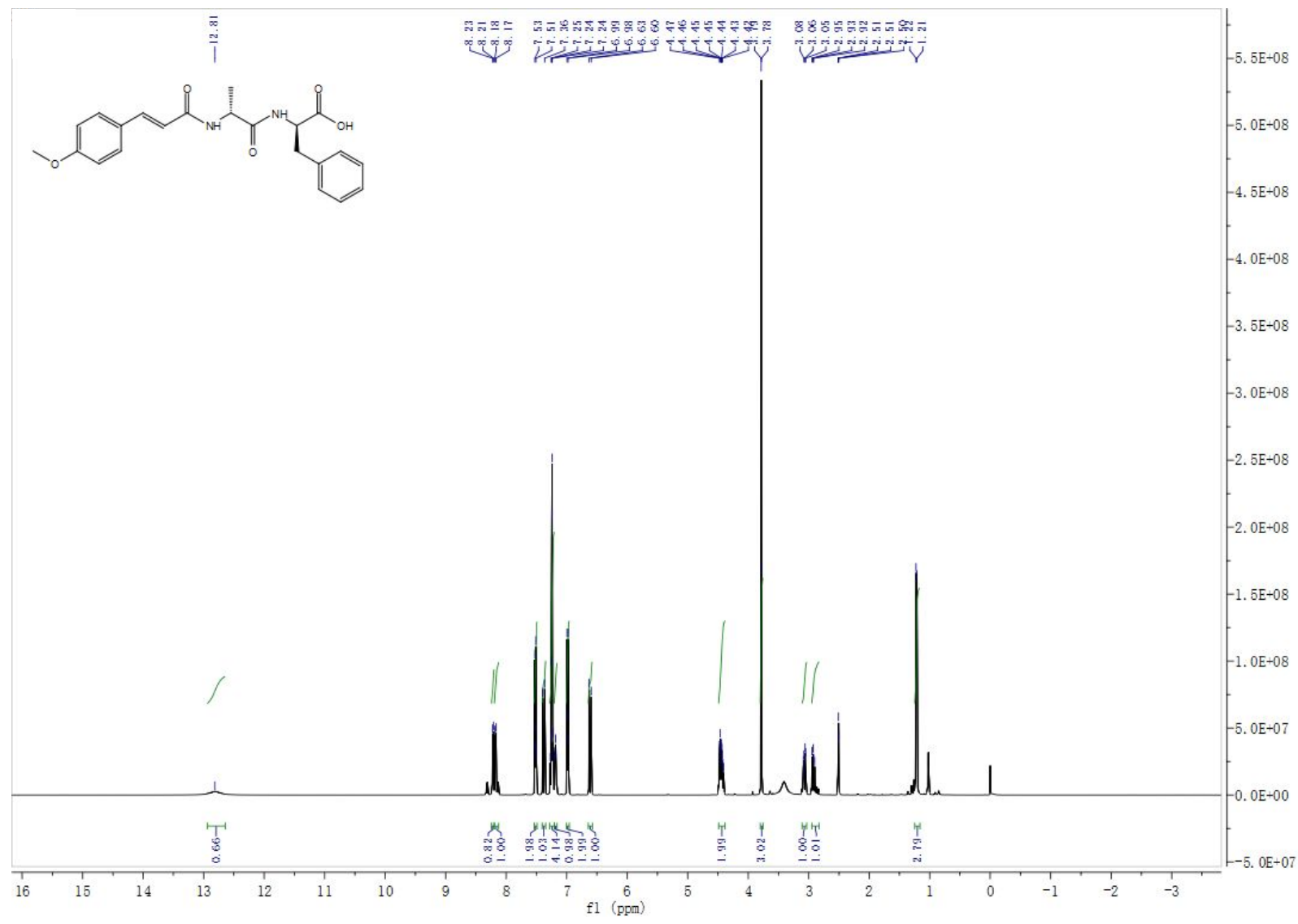


Figure S41 ${ }^{1} \mathrm{H}$ NMR spectra of compound $\mathbf{5 c}$

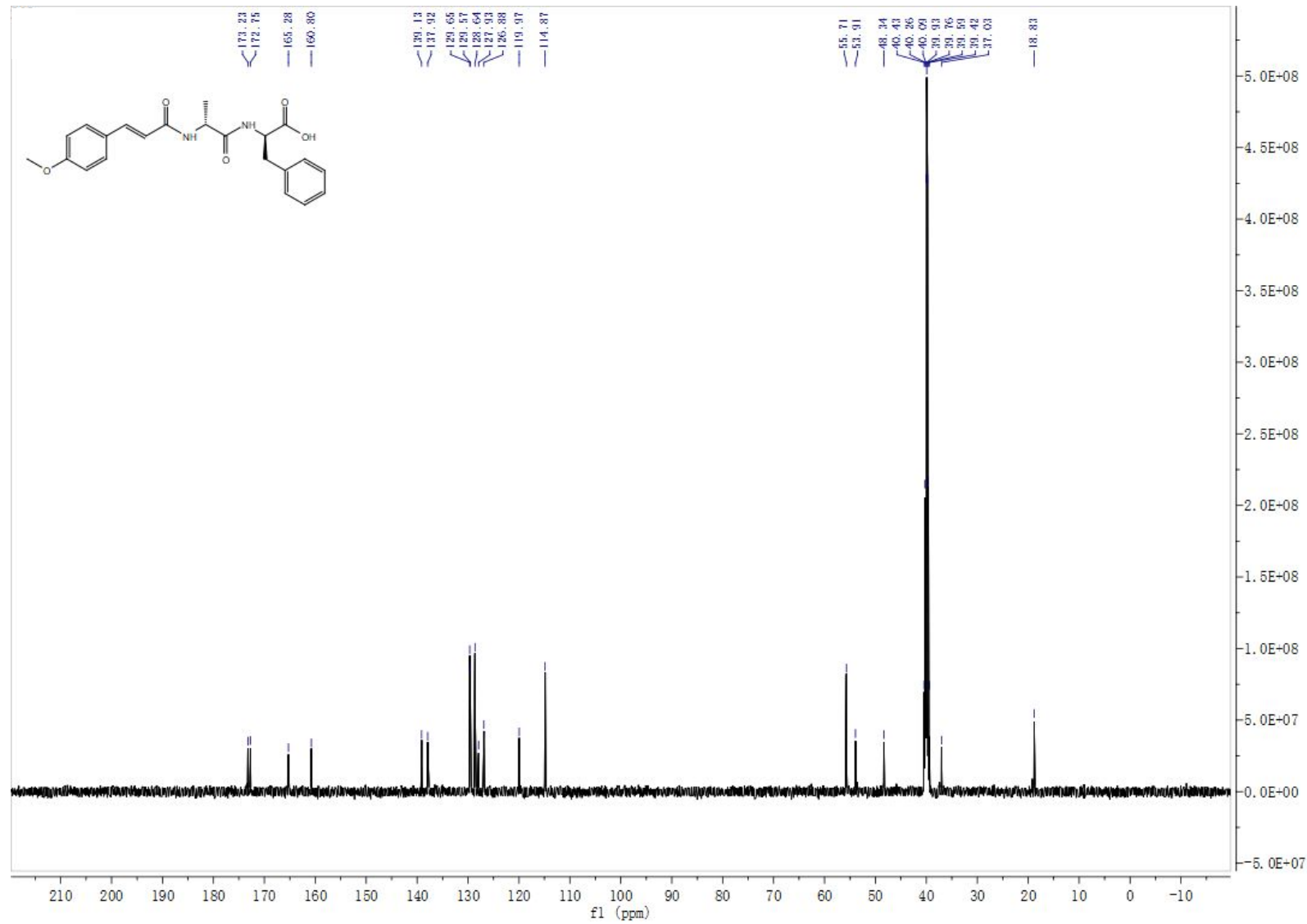

Figure S42 ${ }^{13} \mathrm{C}$ NMR spectra of compound 5c

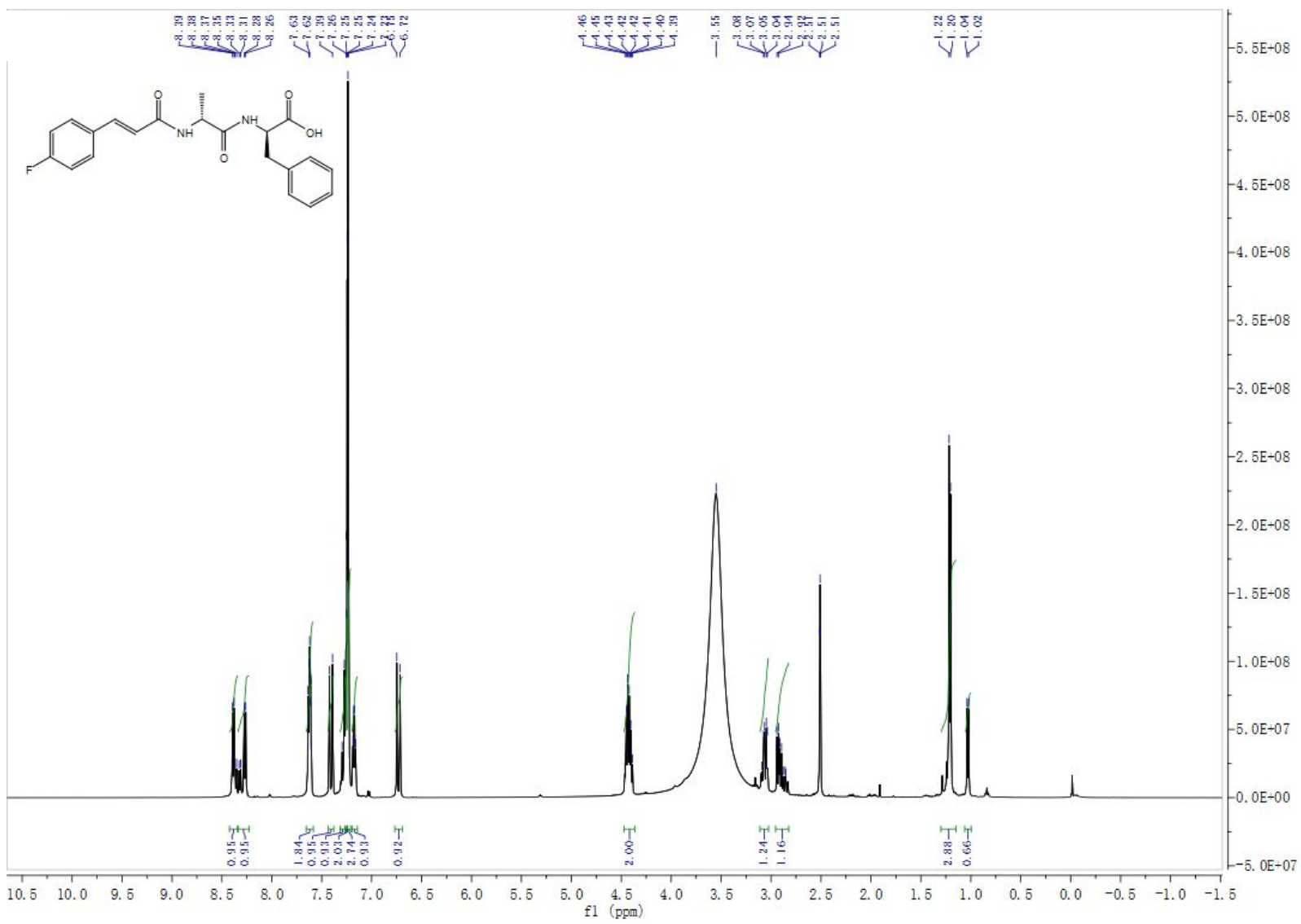


Figure S43 ${ }^{1} \mathrm{H}$ NMR spectra of compound 5d

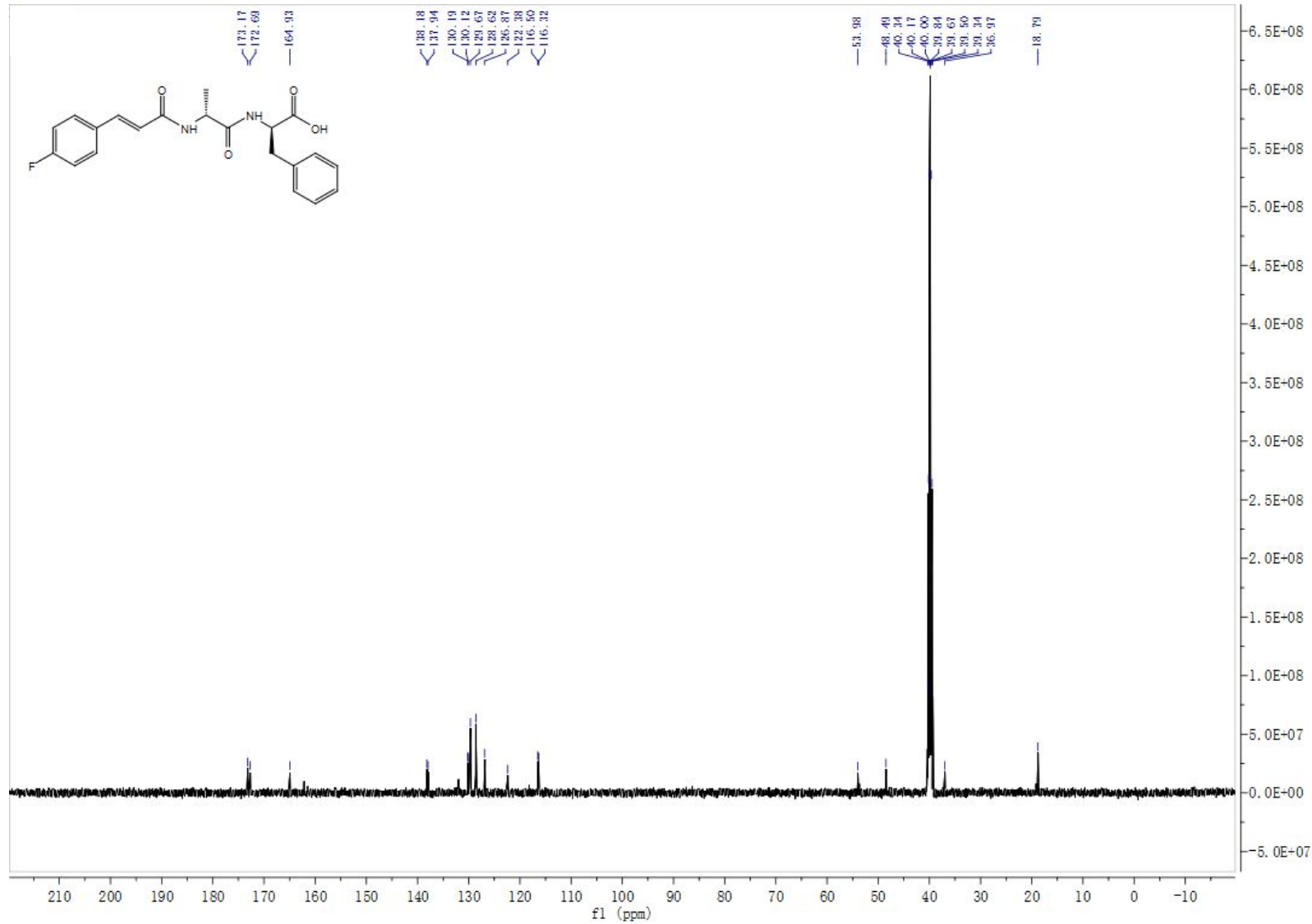

Figure S44 ${ }^{13} \mathrm{C}$ NMR spectra of compound 5d

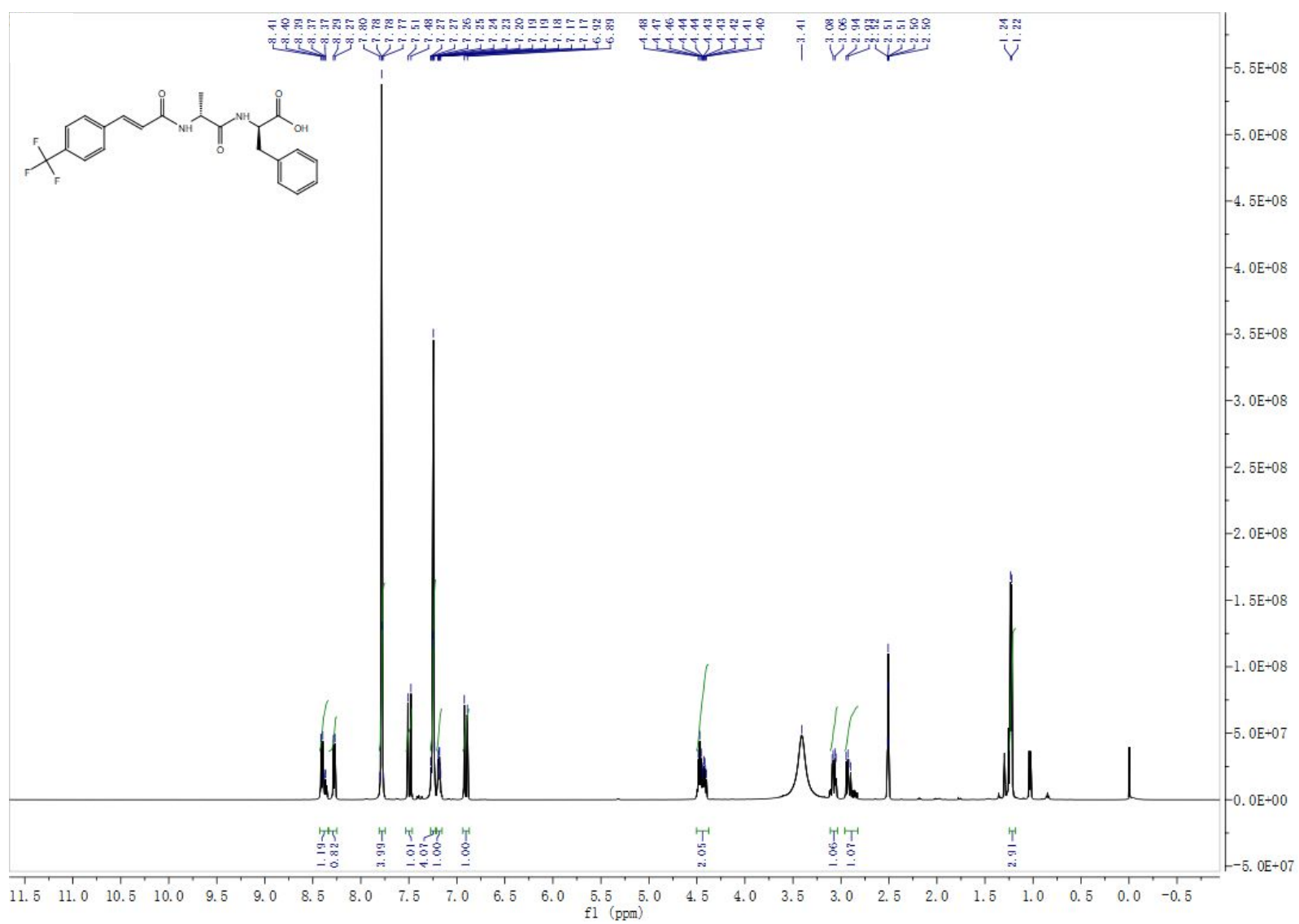


Figure S45 ${ }^{1} \mathrm{H}$ NMR spectra of compound 5e

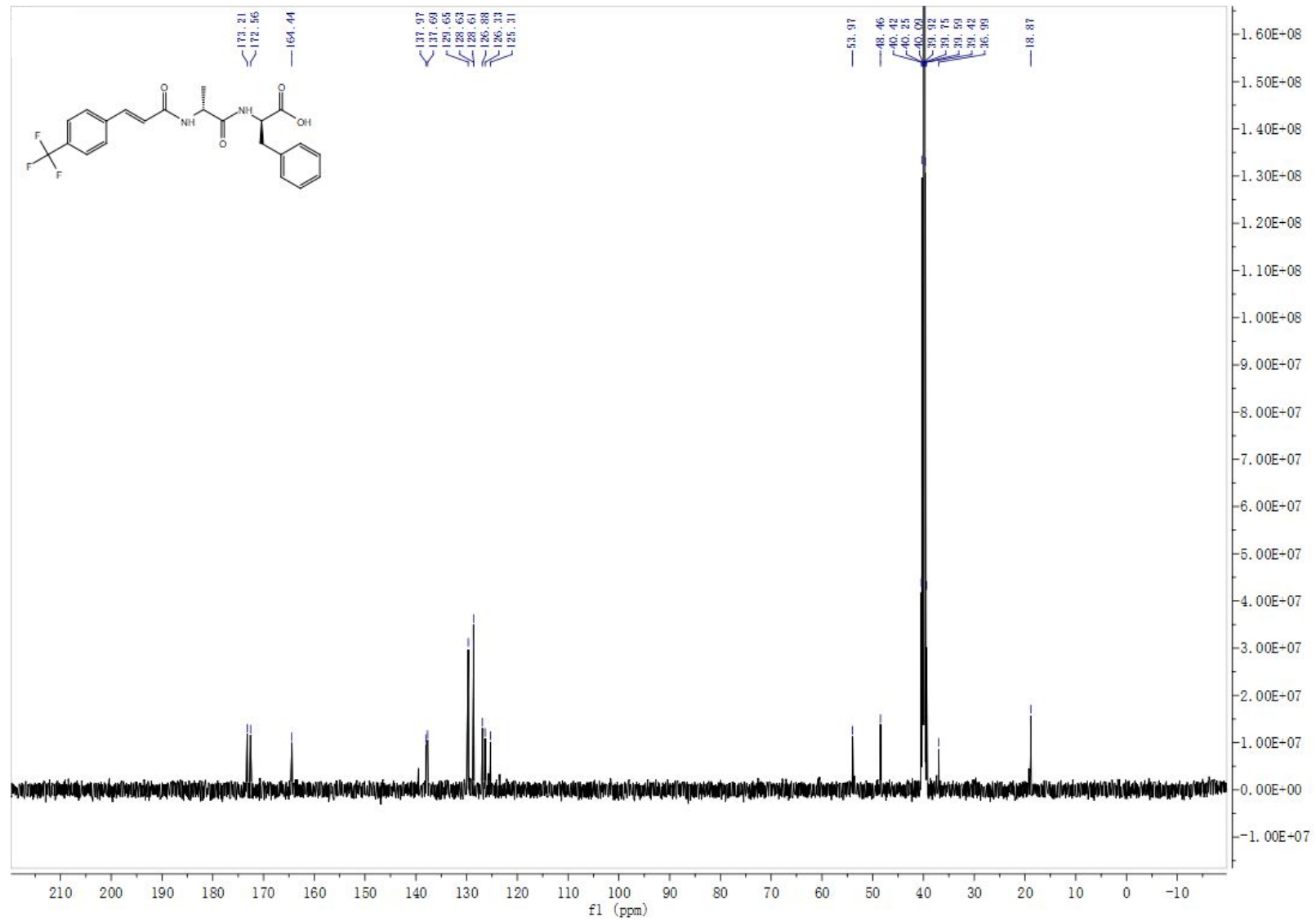

Figure S46 ${ }^{13} \mathrm{C}$ NMR spectra of compound 5e

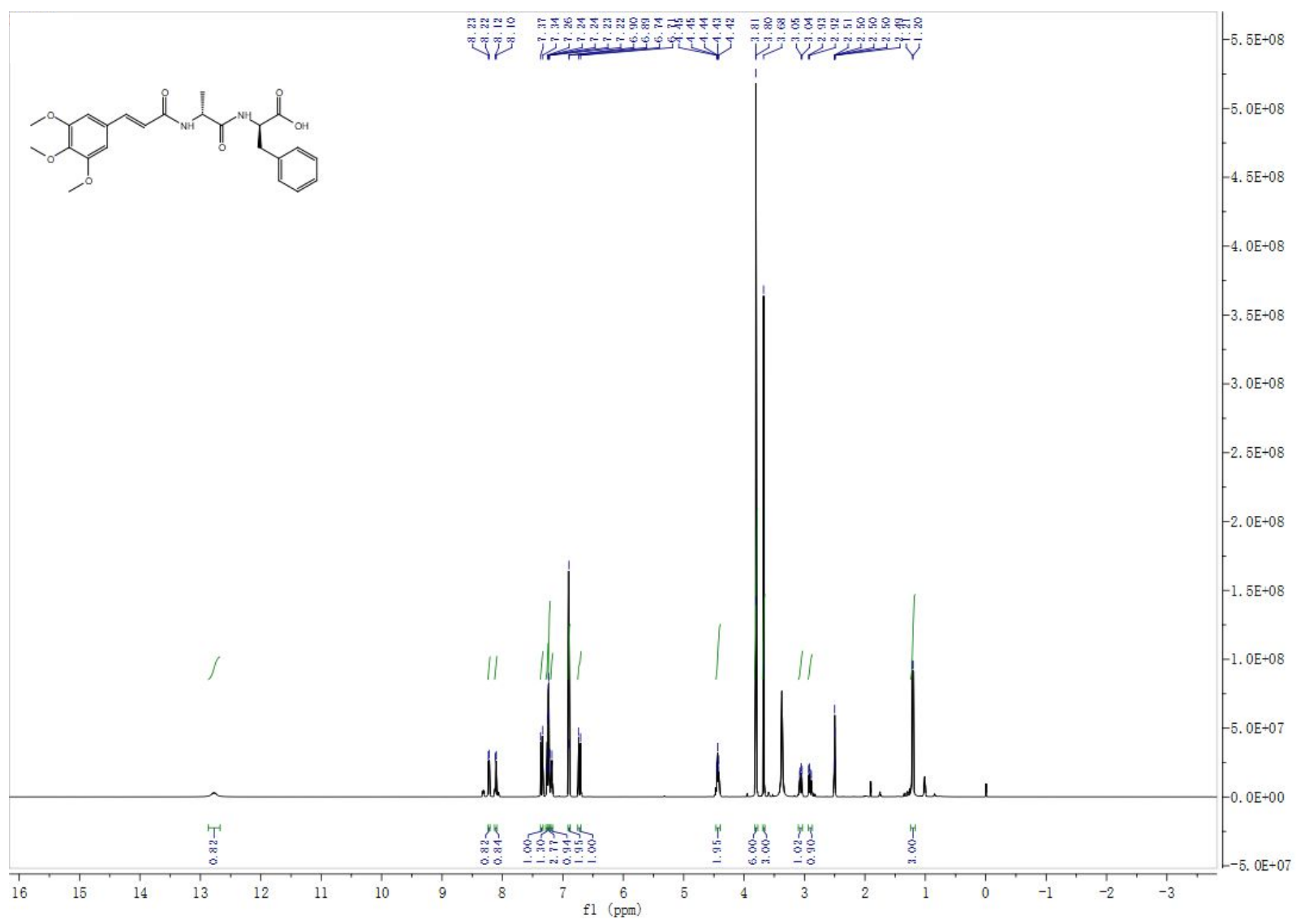


Figure S47 ${ }^{1} \mathrm{H}$ NMR spectra of compound $\mathbf{5 f}$

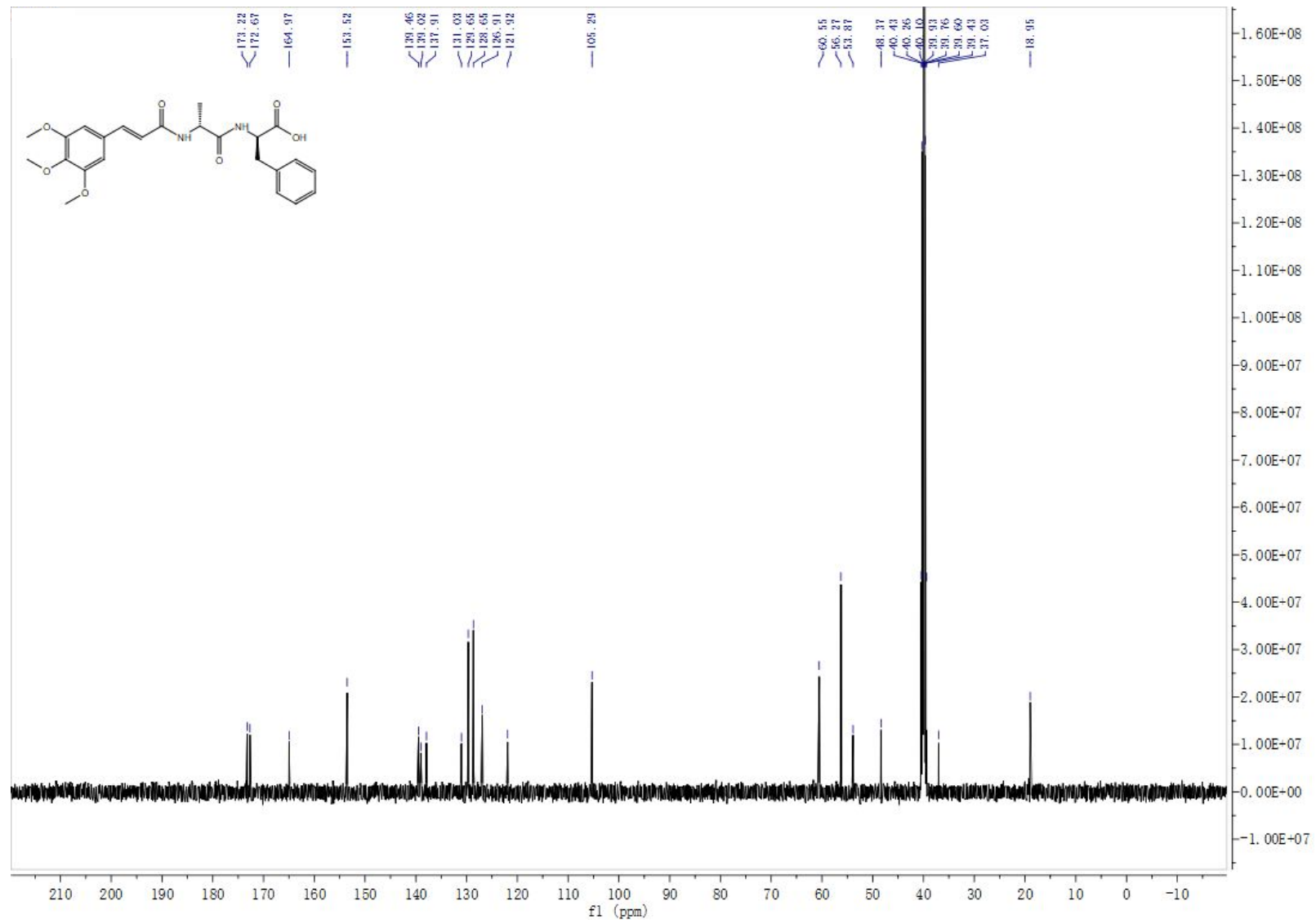

Figure $\mathrm{S} 48{ }^{13} \mathrm{C}$ NMR spectra of compound $\mathbf{5 f}$

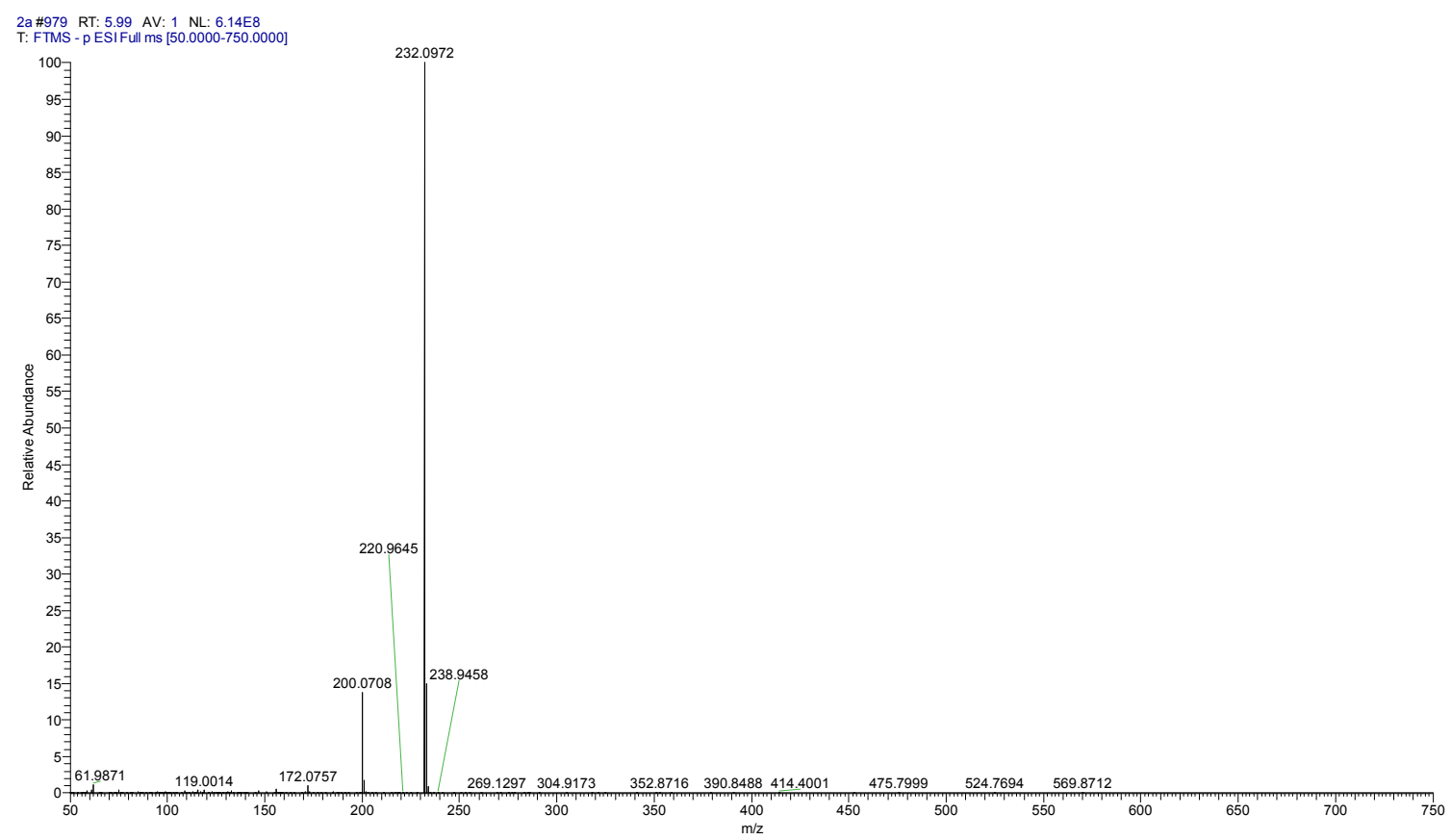

Figure S49 HRMS spectra of compound 2a 


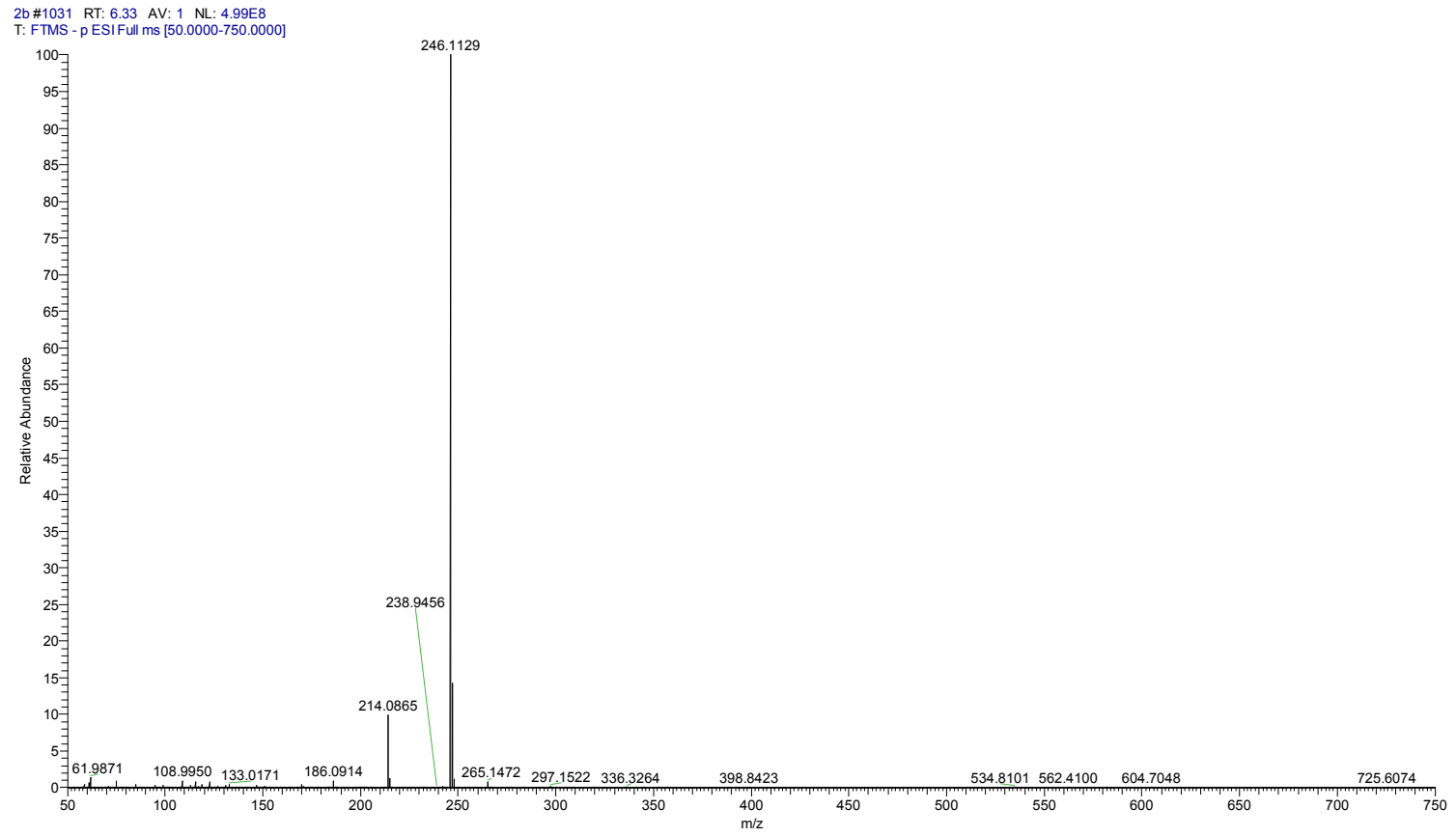

Figure S50 HRMS spectra of compound $\mathbf{2 b}$

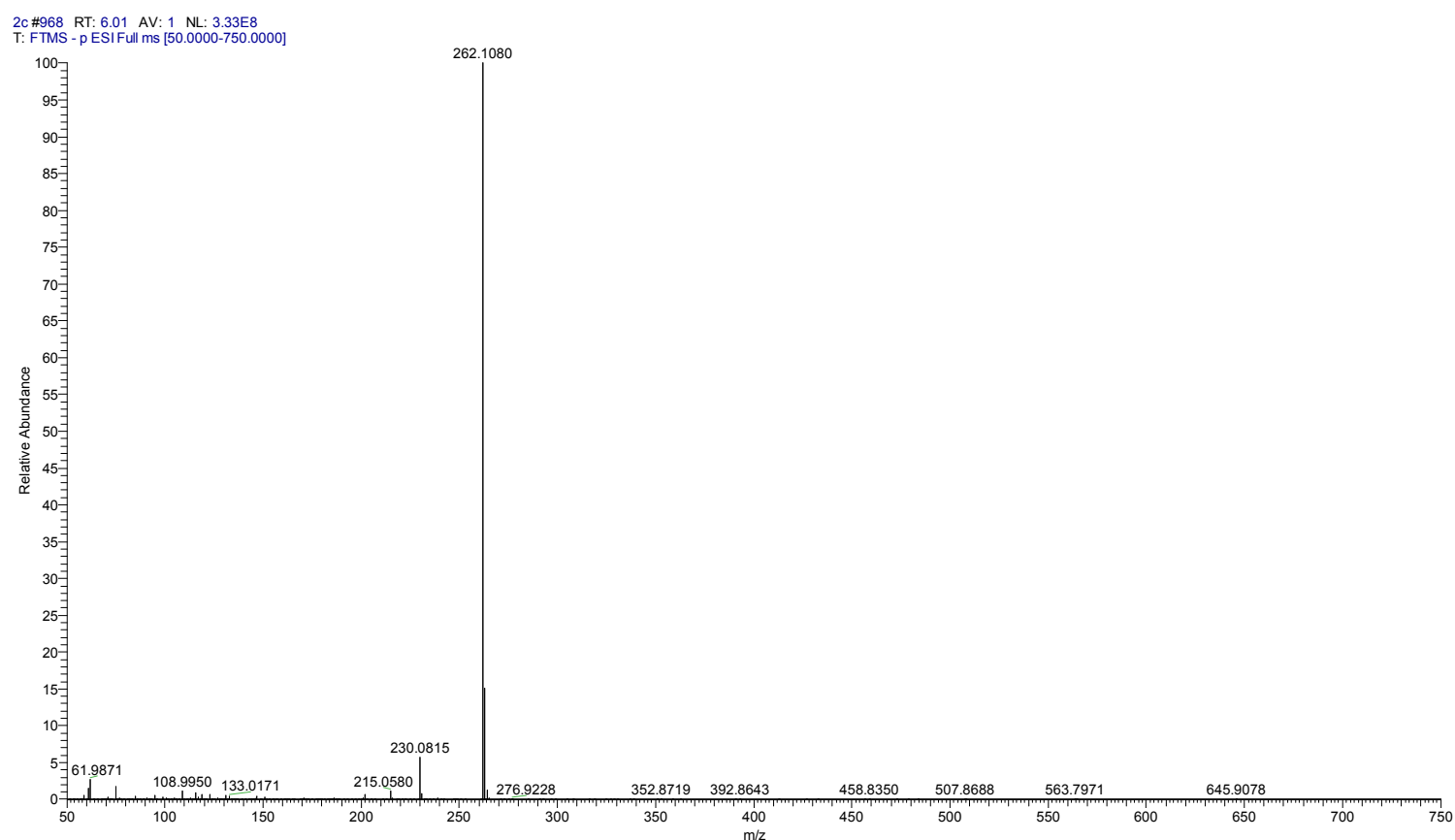

Figure S51 HRMS spectra of compound 2c 


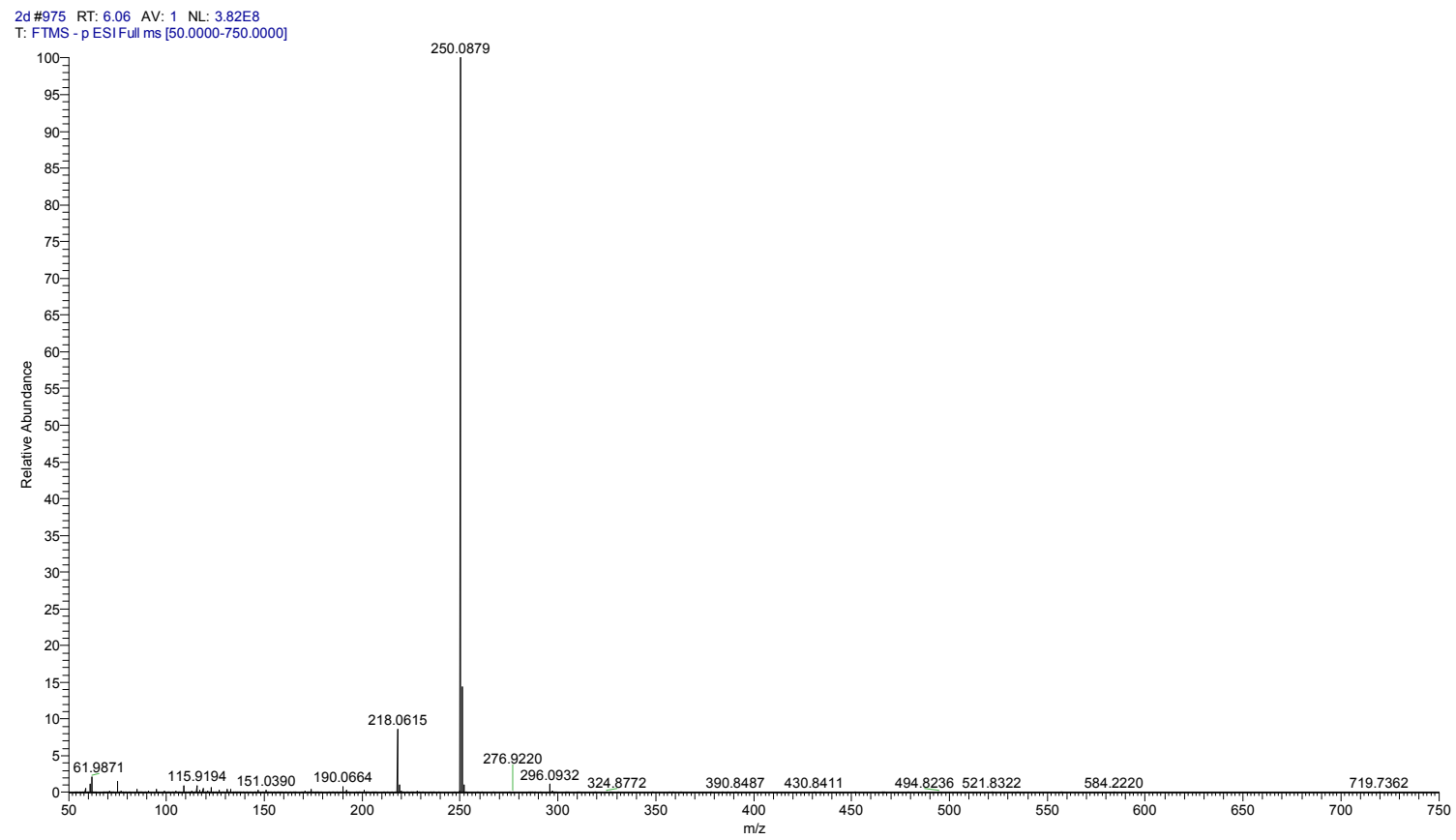

Figure S52 HRMS spectra of compound 2d

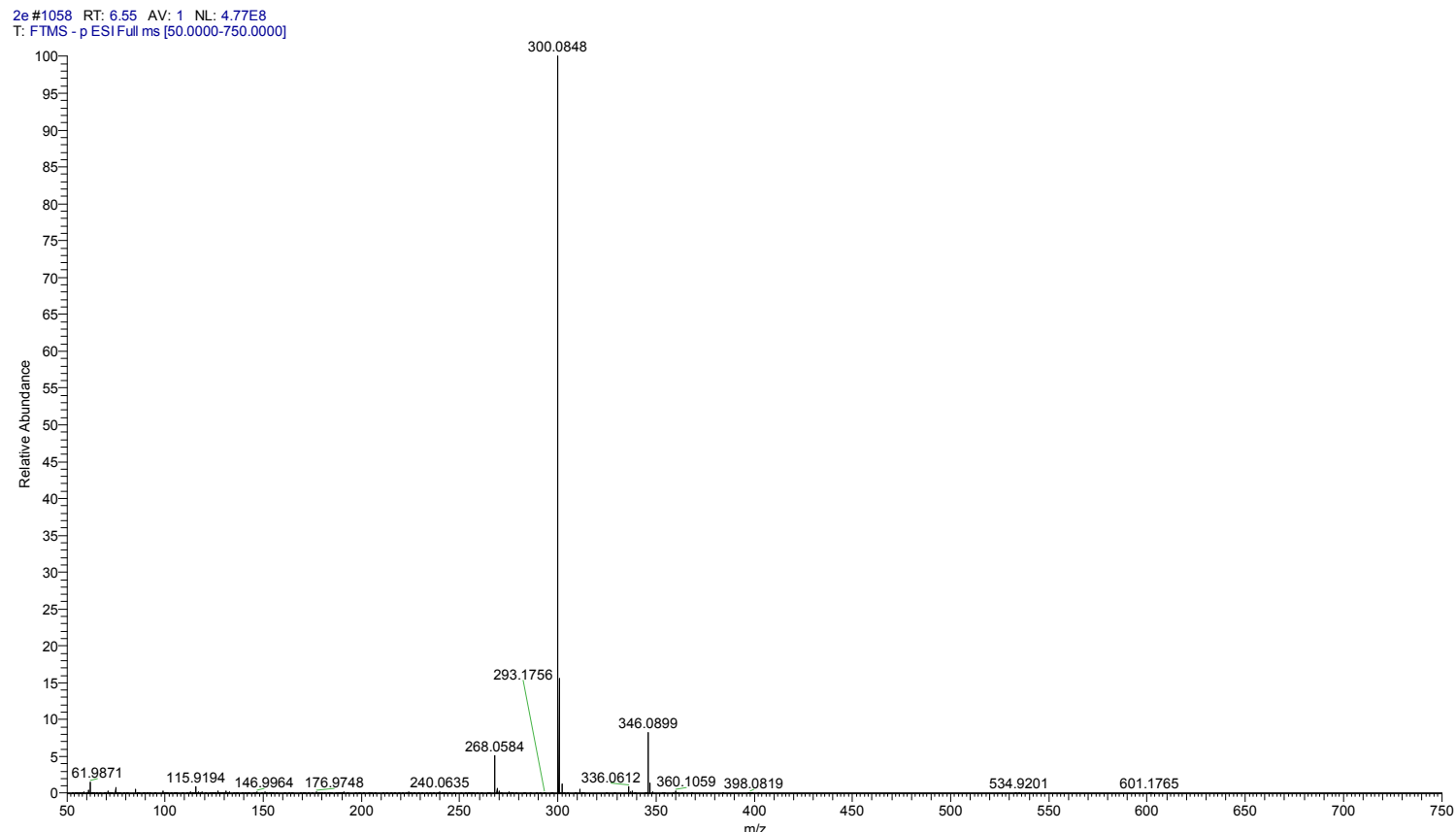

Figure S53 HRMS spectra of compound 2e 


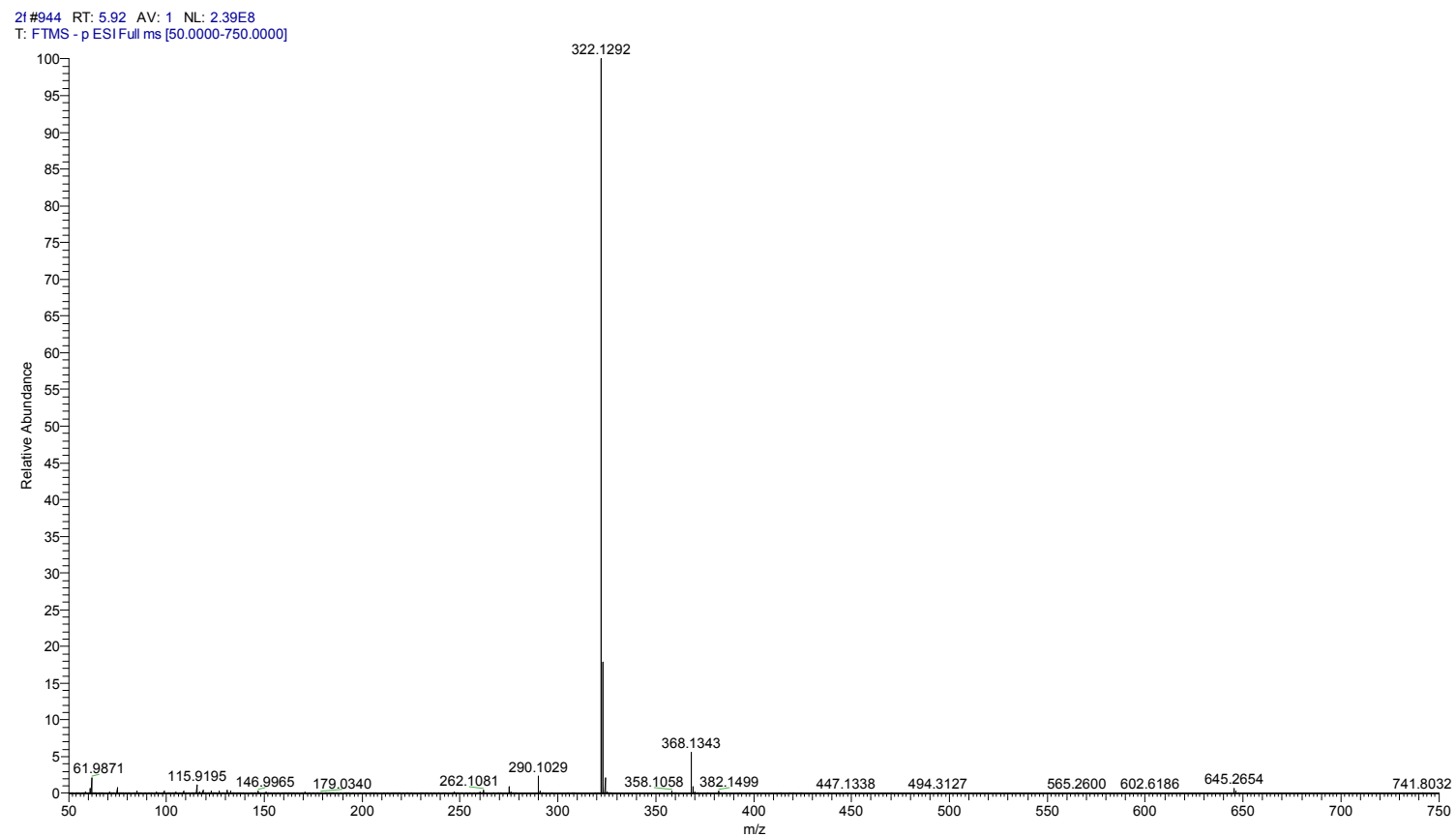

Figure S54 HRMS spectra of compound $2 \mathbf{f}$

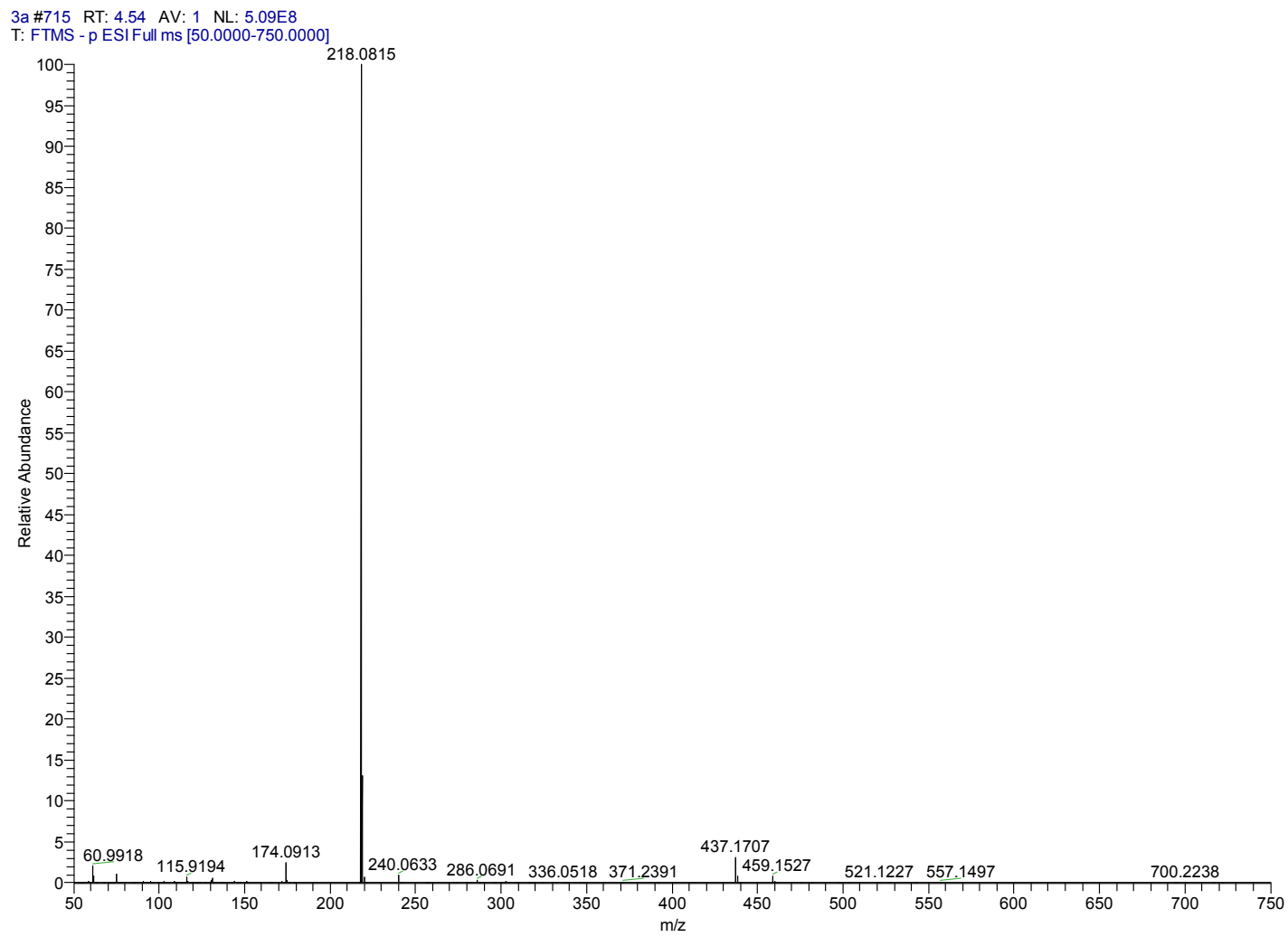

Figure S55 HRMS spectra of compound 3a 


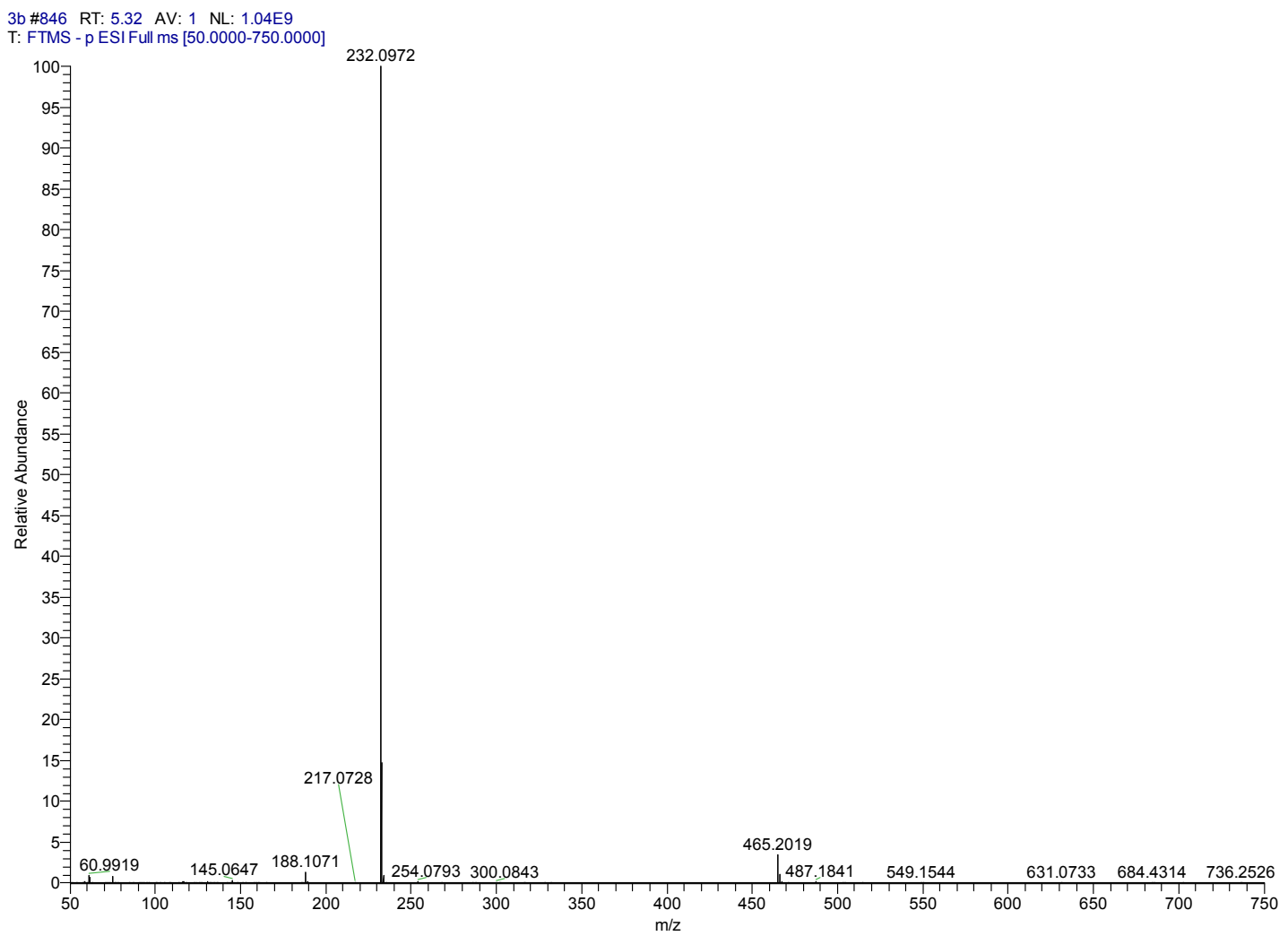

Figure S56 HRMS spectra of compound $\mathbf{3 b}$

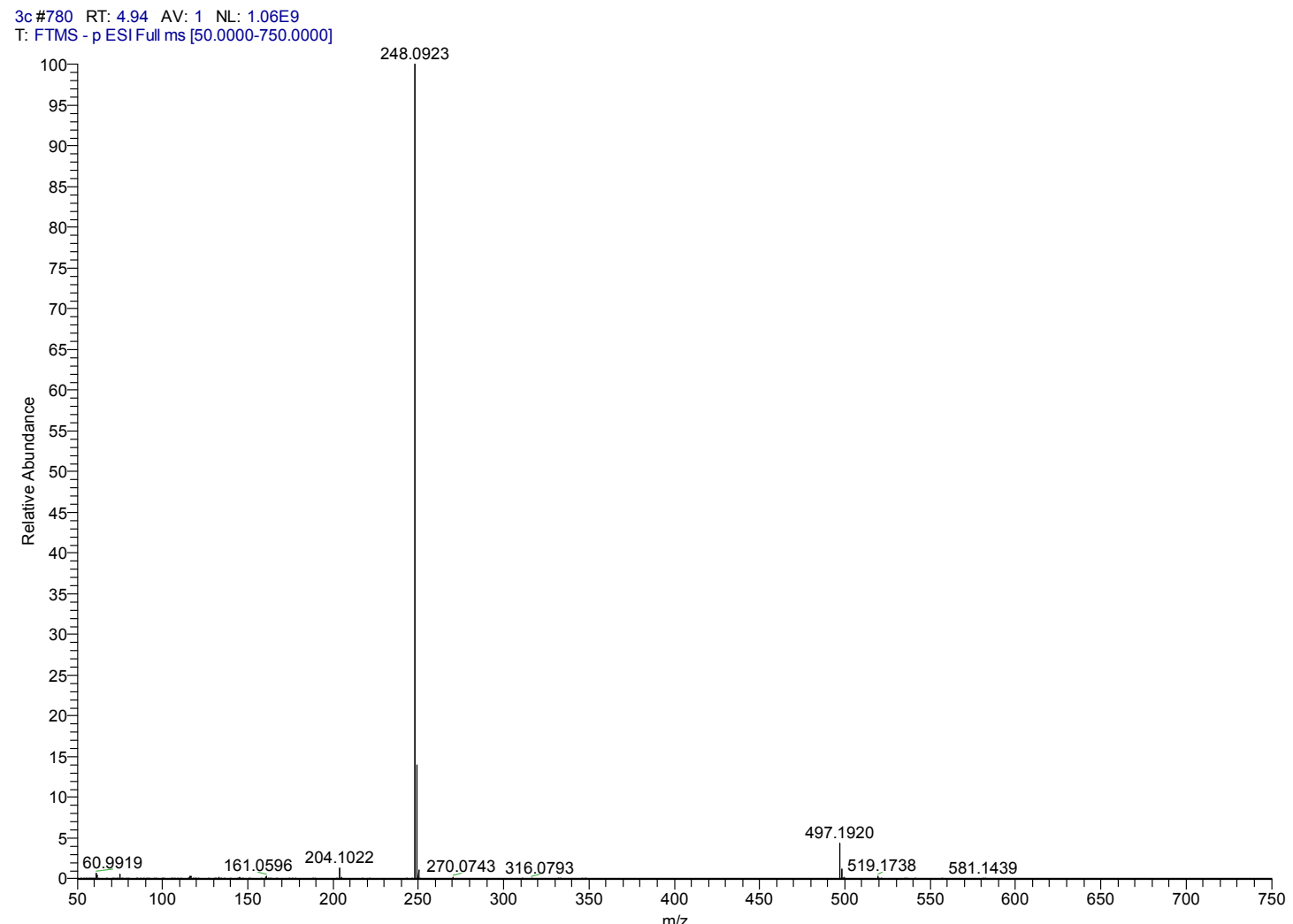

Figure S57 HRMS spectra of compound 3c 


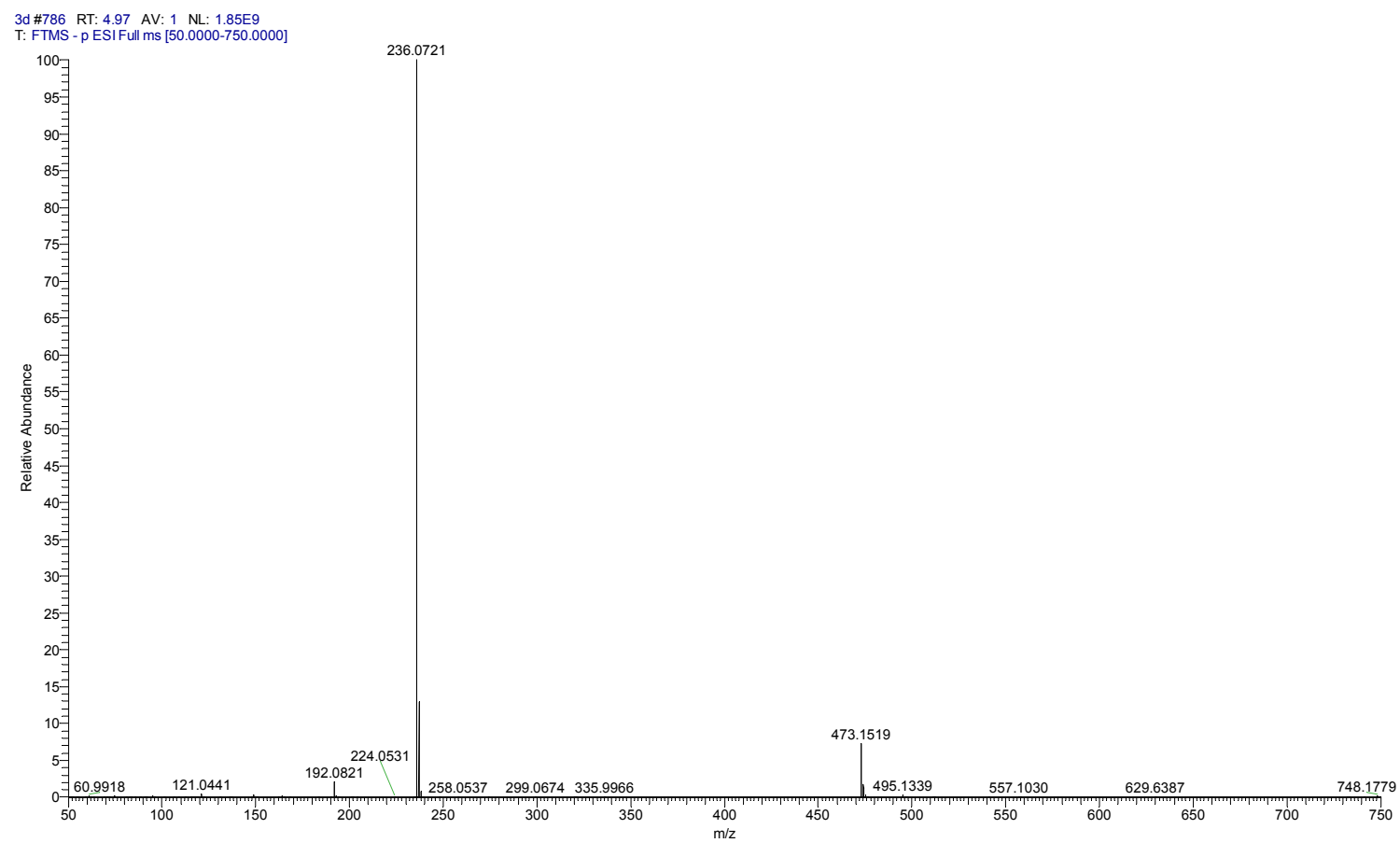

Figure S58 HRMS spectra of compound 3d

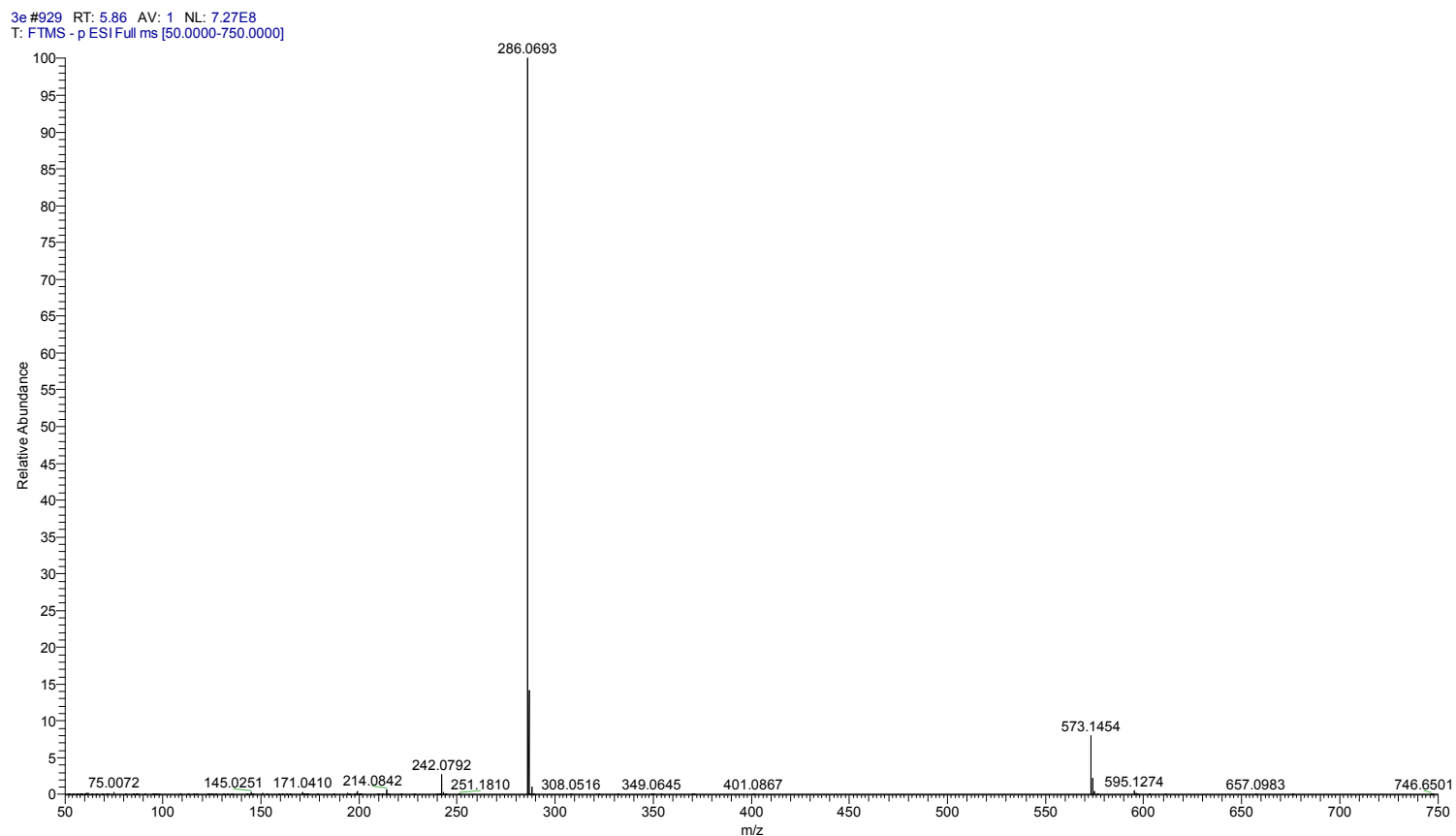

Figure S59 HRMS spectra of compound $\mathbf{3 e}$ 


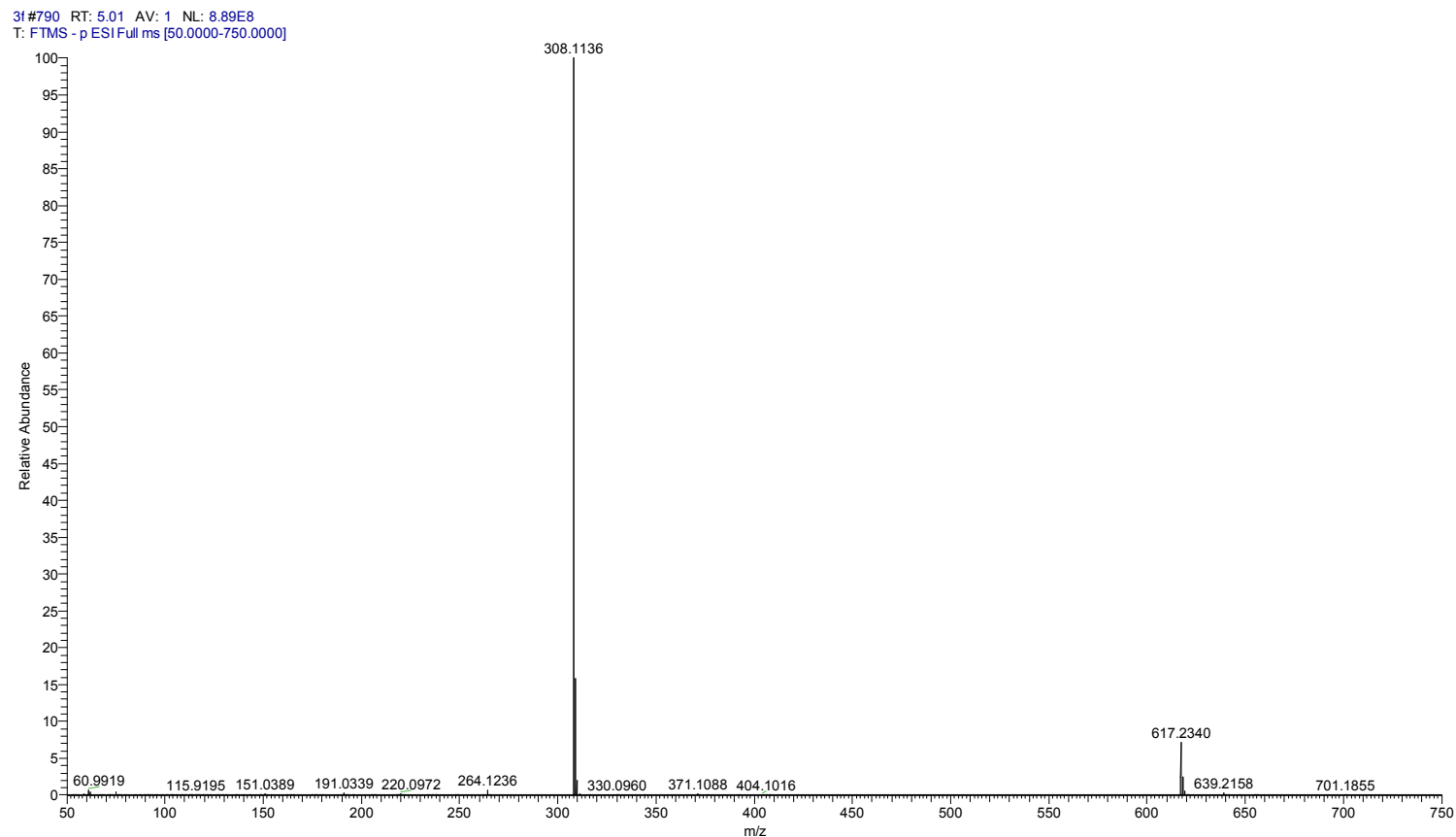

Figure S60 HRMS spectra of compound $\mathbf{3 f}$

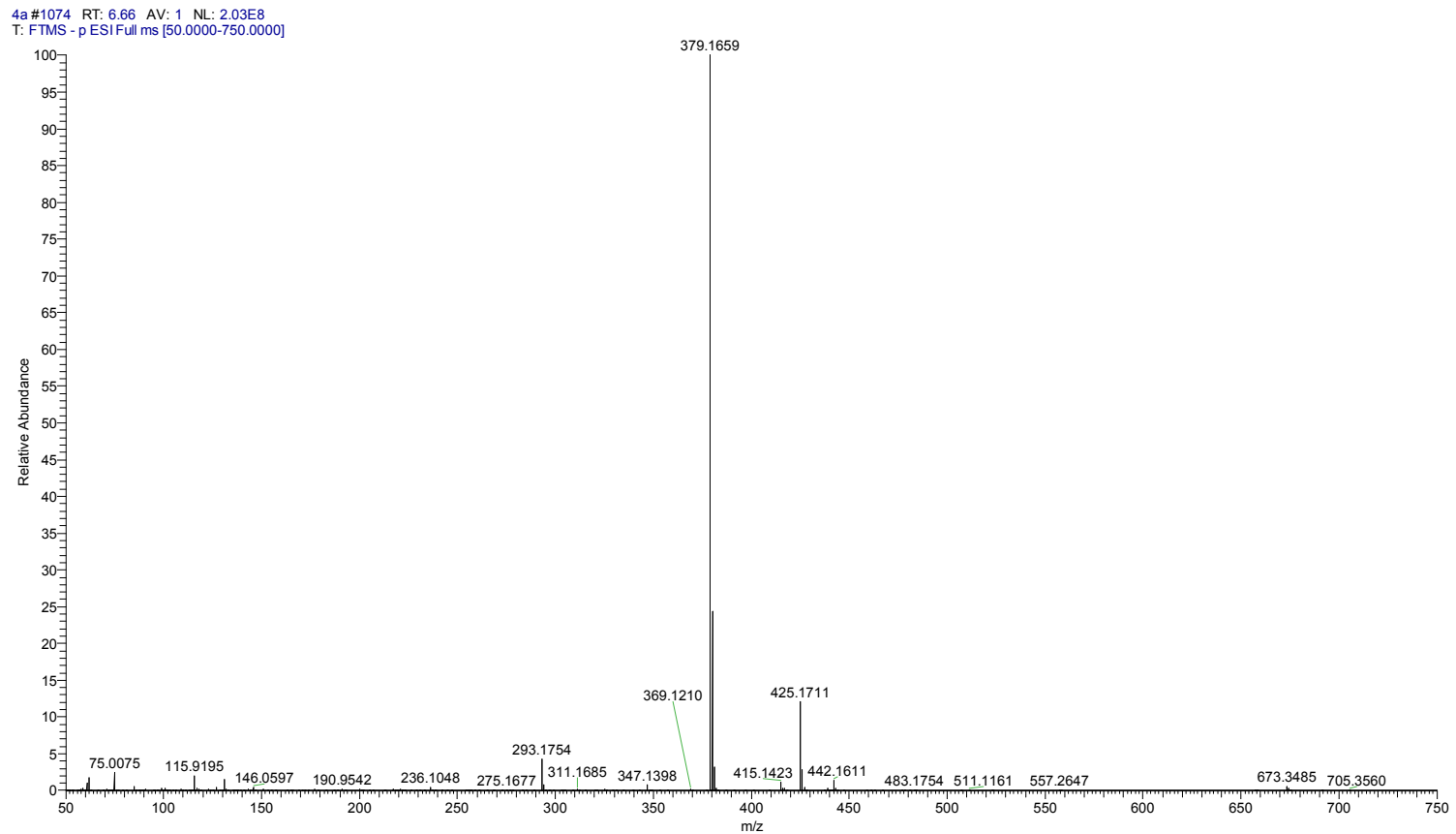

Figure S61 HRMS spectra of compound 4a 


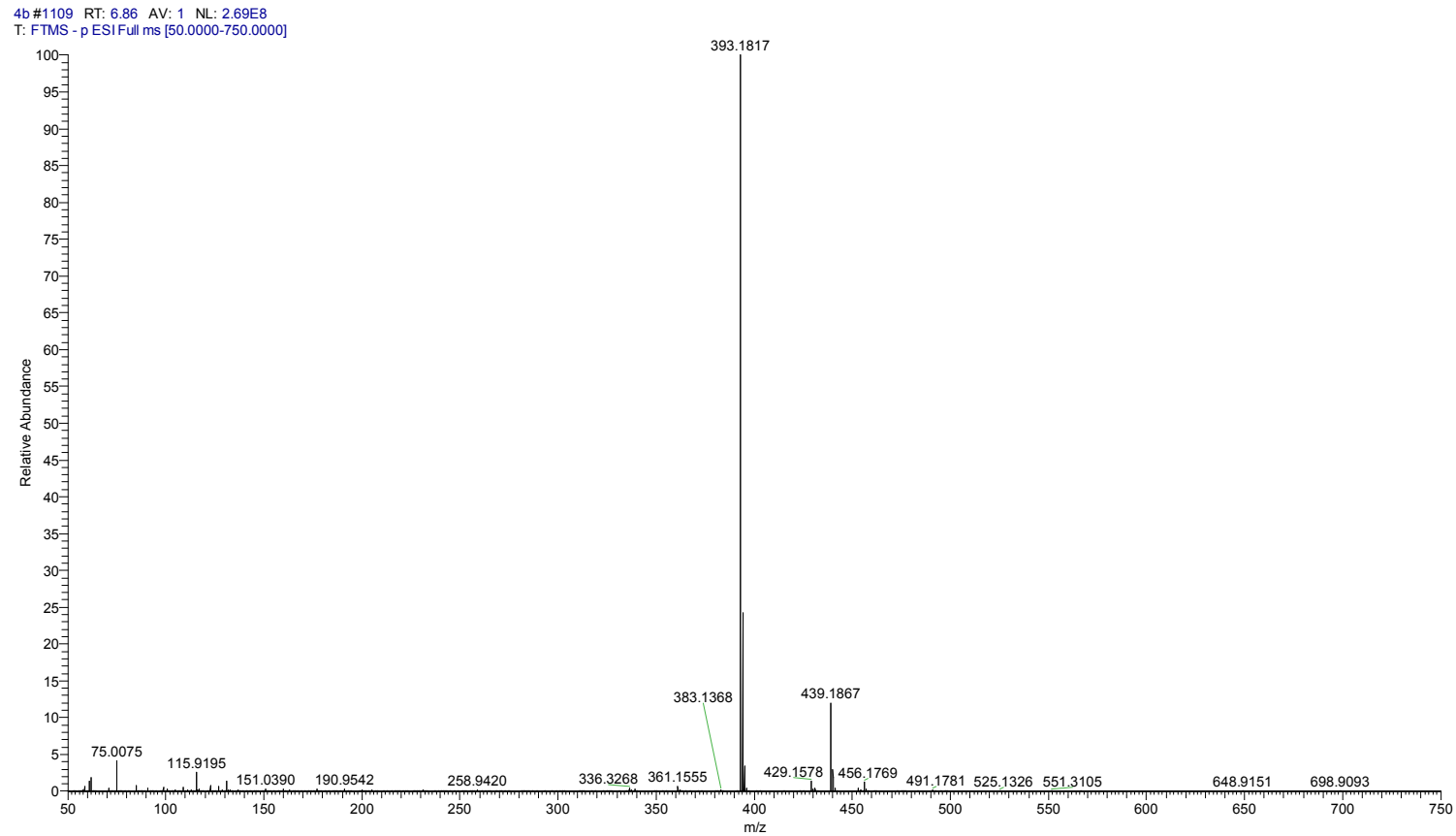

Figure S62 HRMS spectra of compound $\mathbf{4 b}$

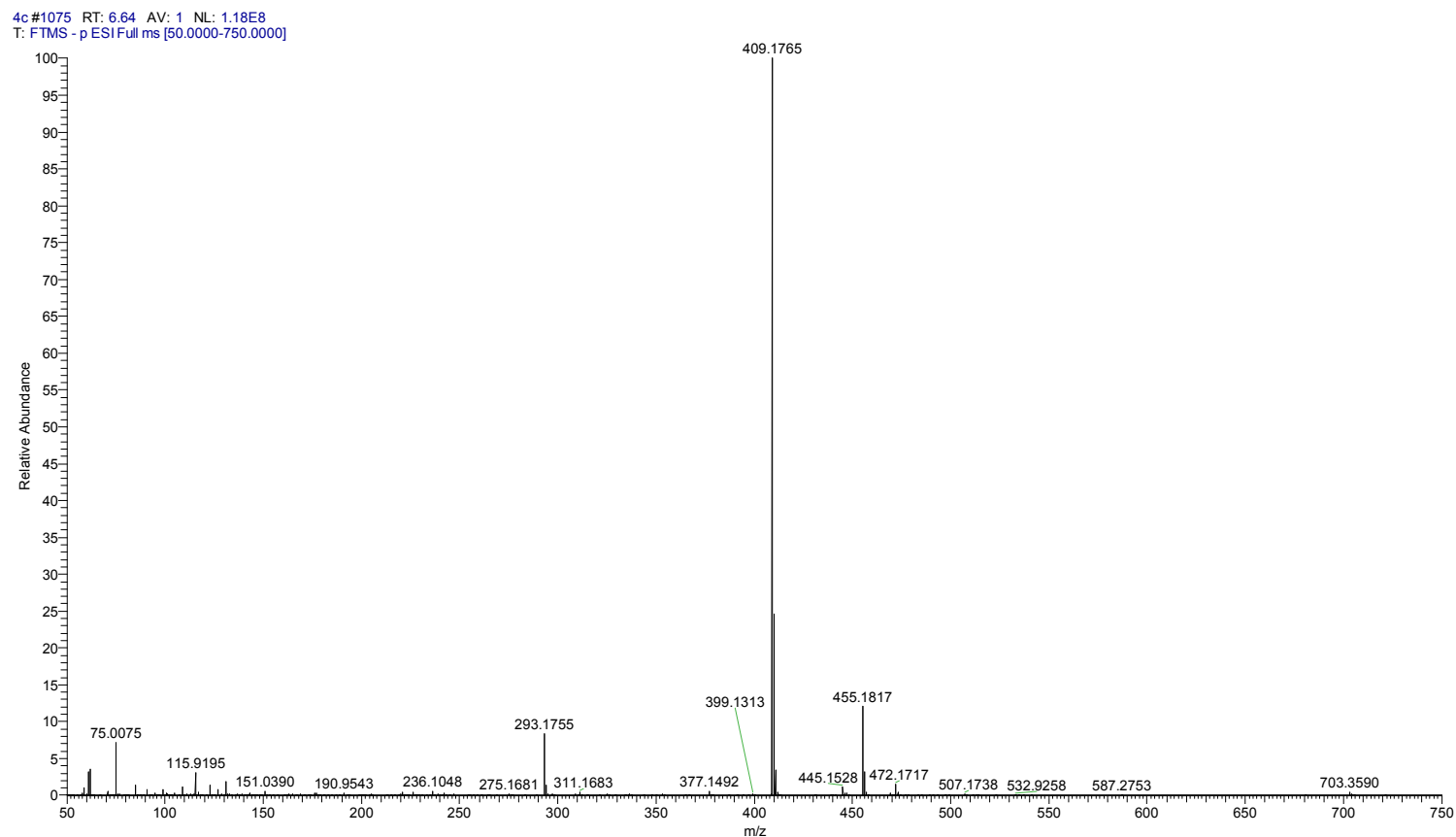

Figure S63 HRMS spectra of compound 4c 


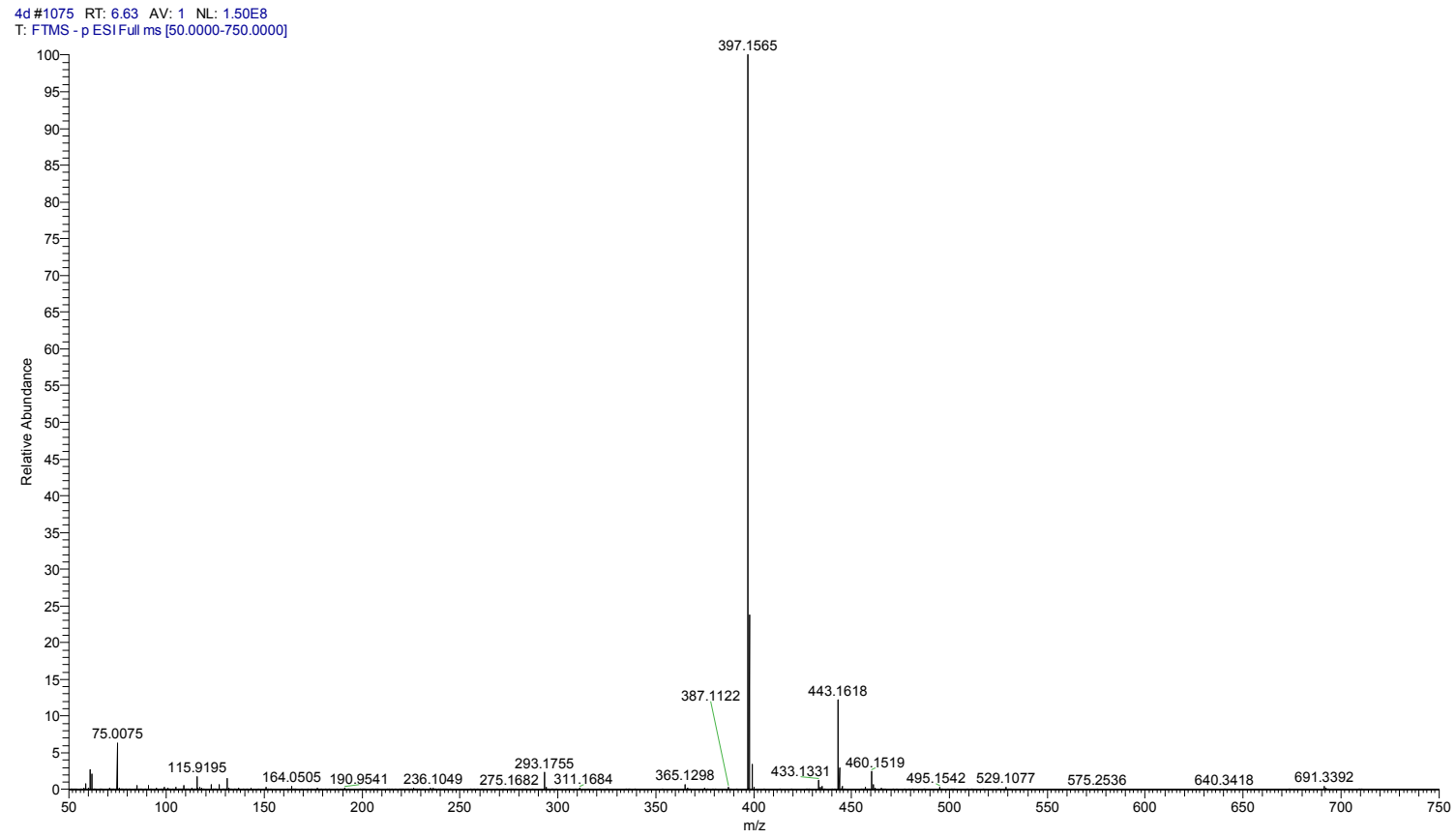

Figure S64 HRMS spectra of compound 4d

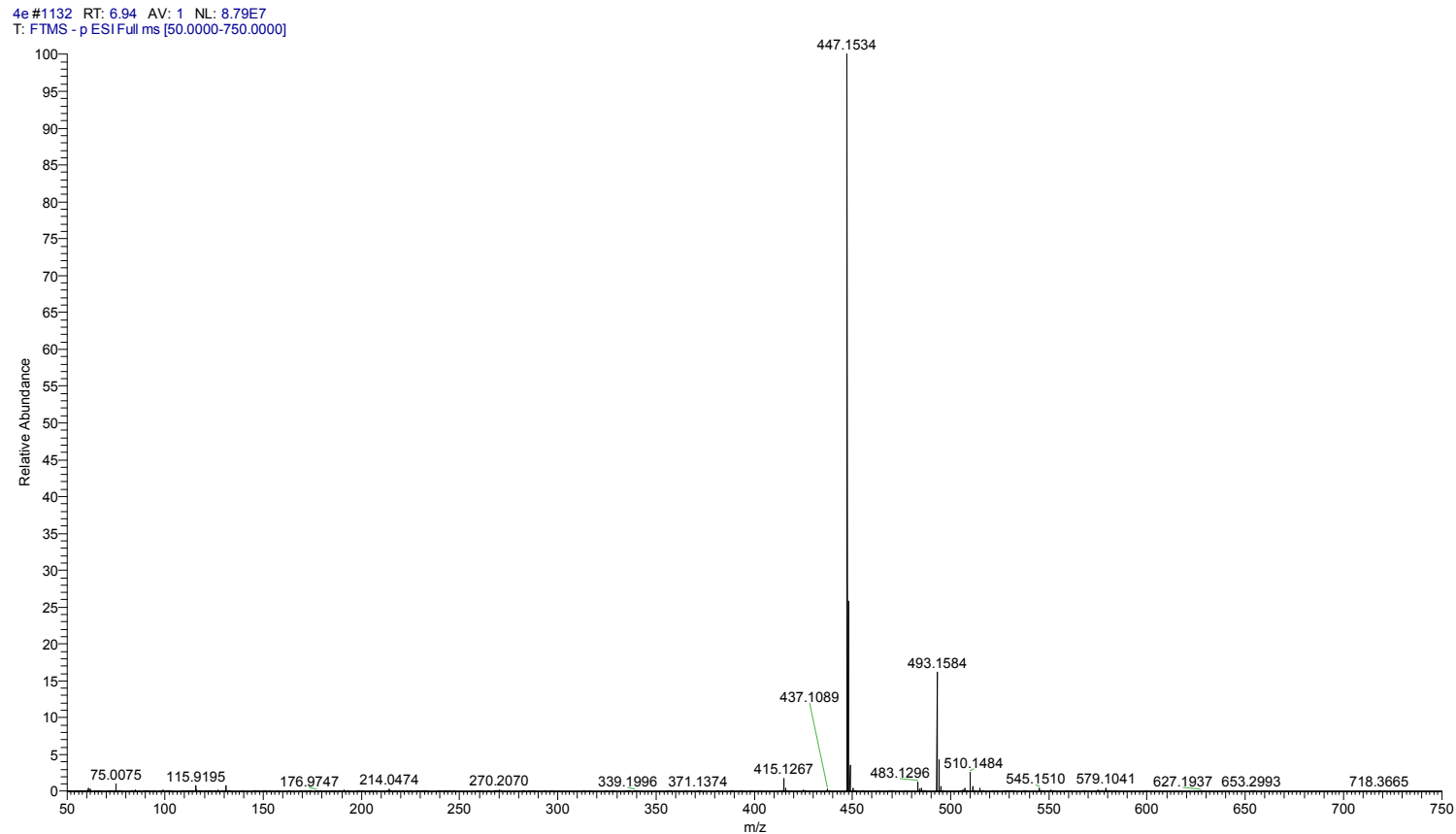

Figure S65 HRMS spectra of compound 4e 


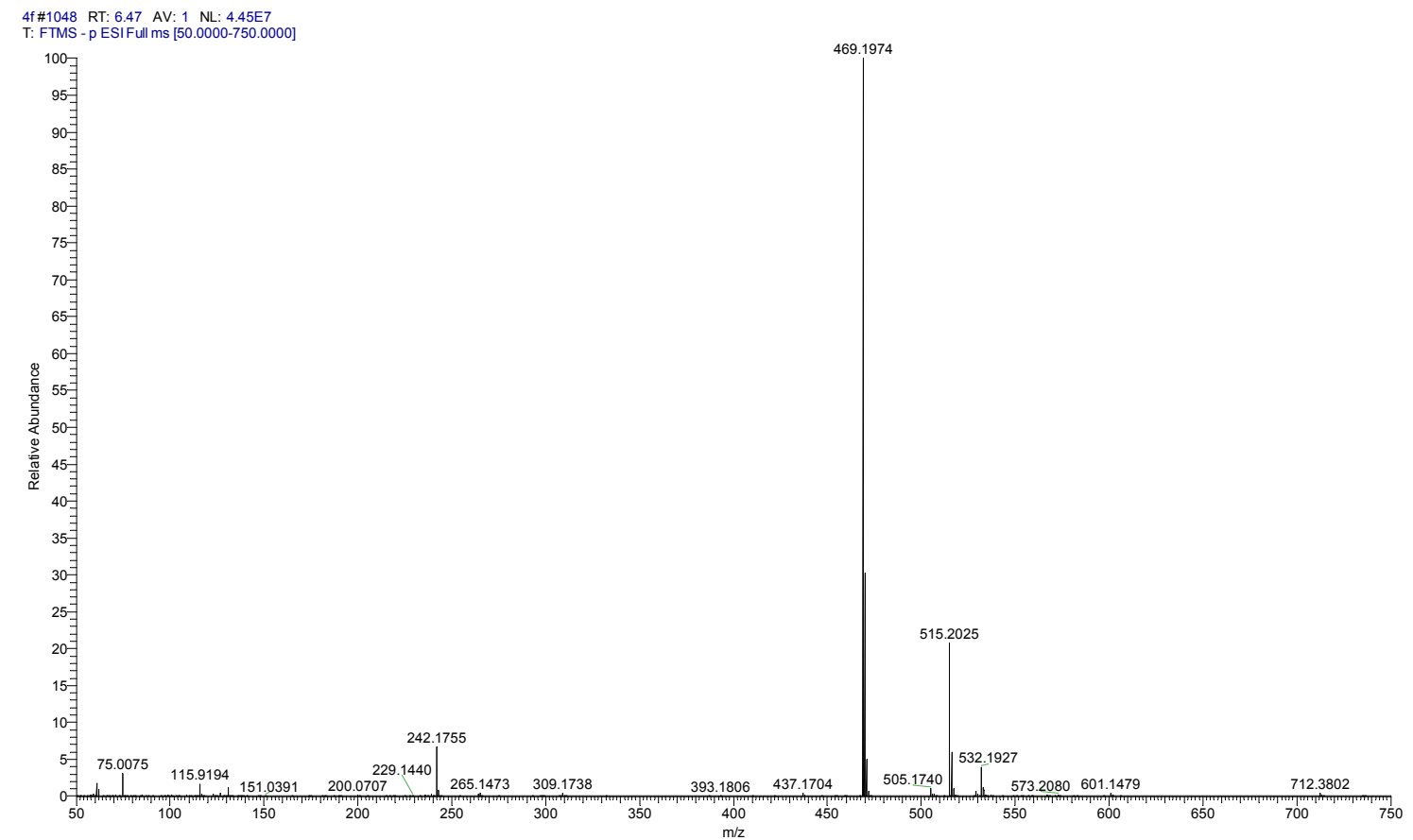

Figure S66 HRMS spectra of compound $\mathbf{4 f}$

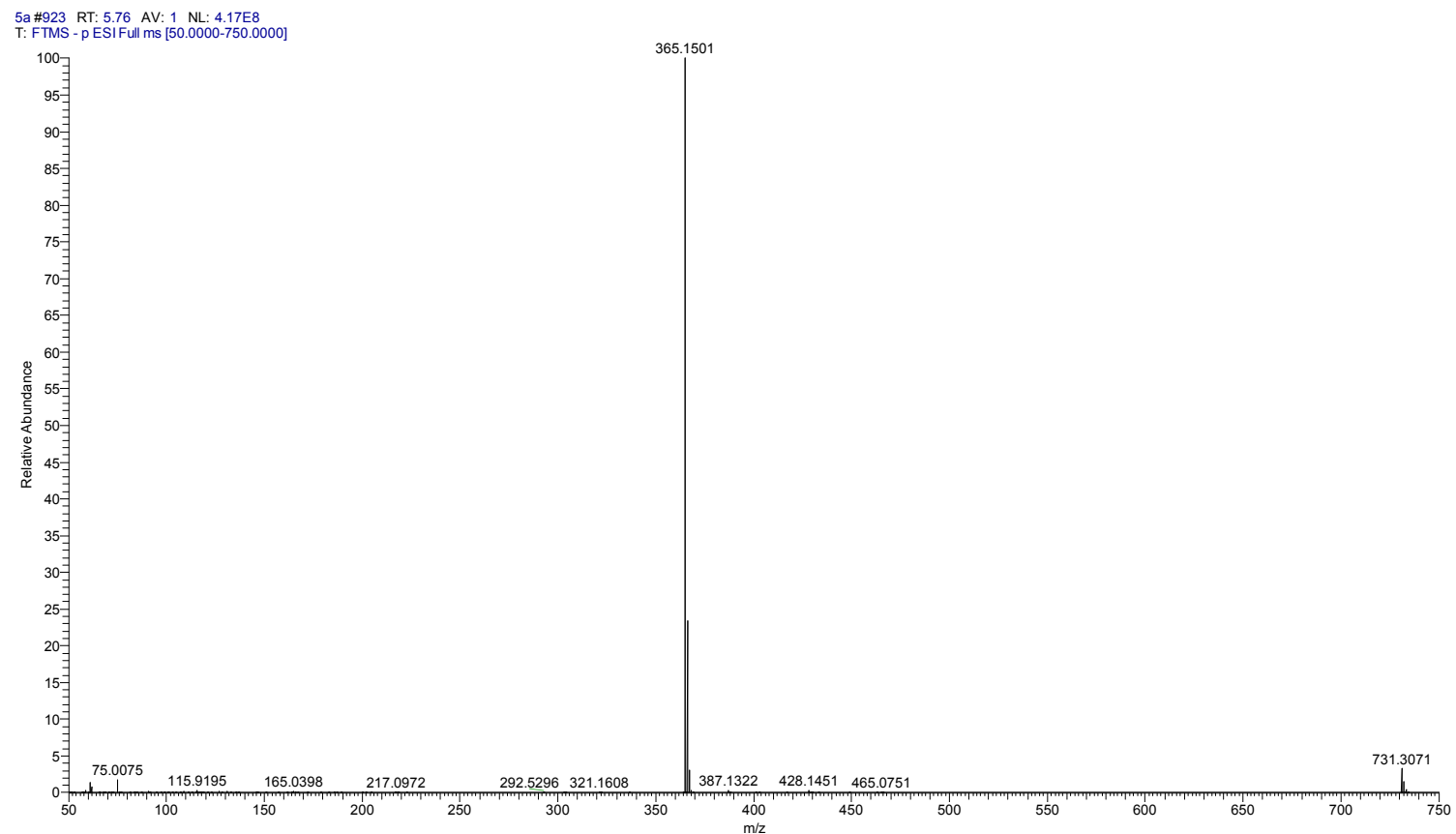

Figure S67 HRMS spectra of compound 5a 


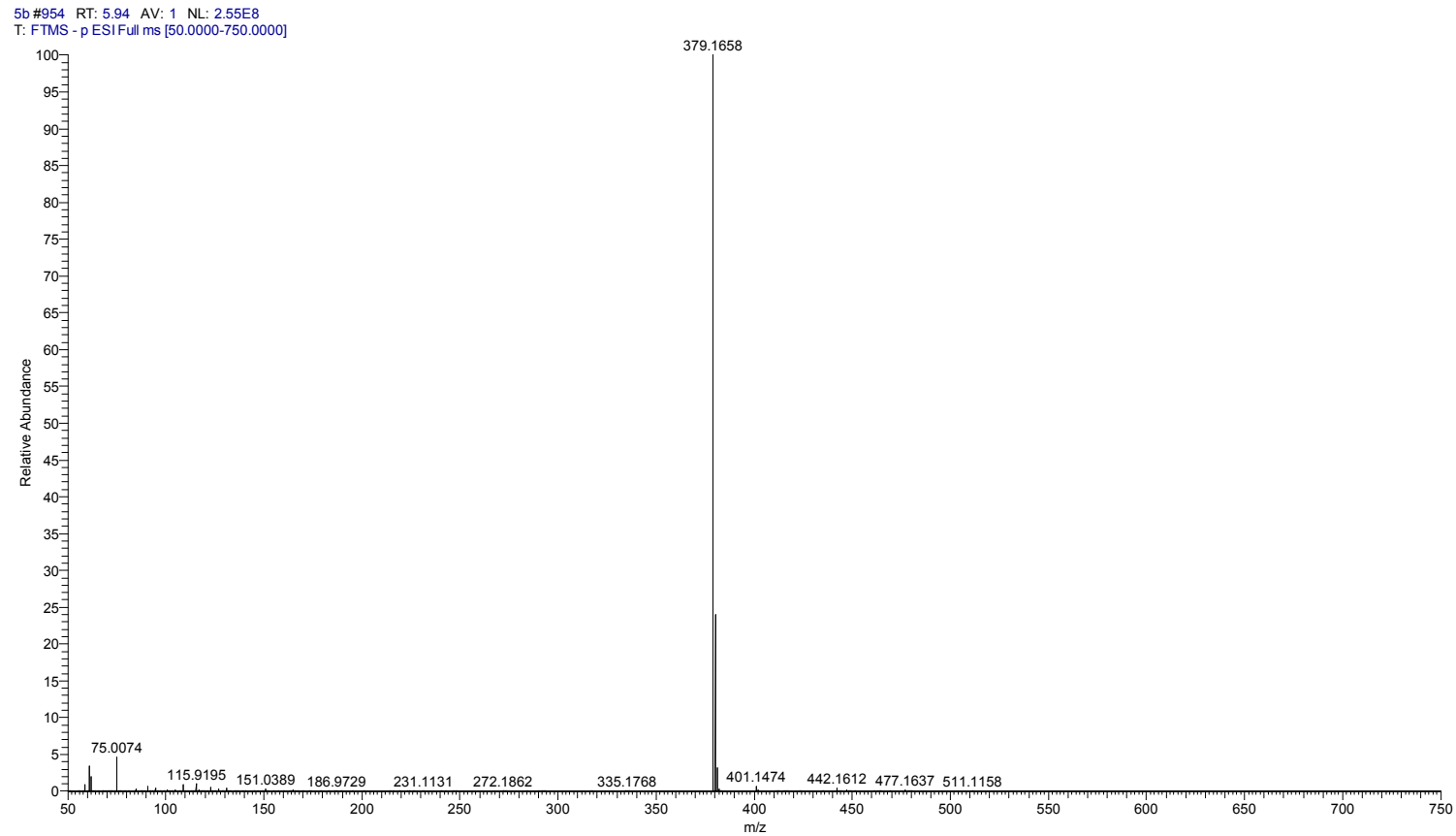

Figure S68 HRMS spectra of compound $\mathbf{5 b}$

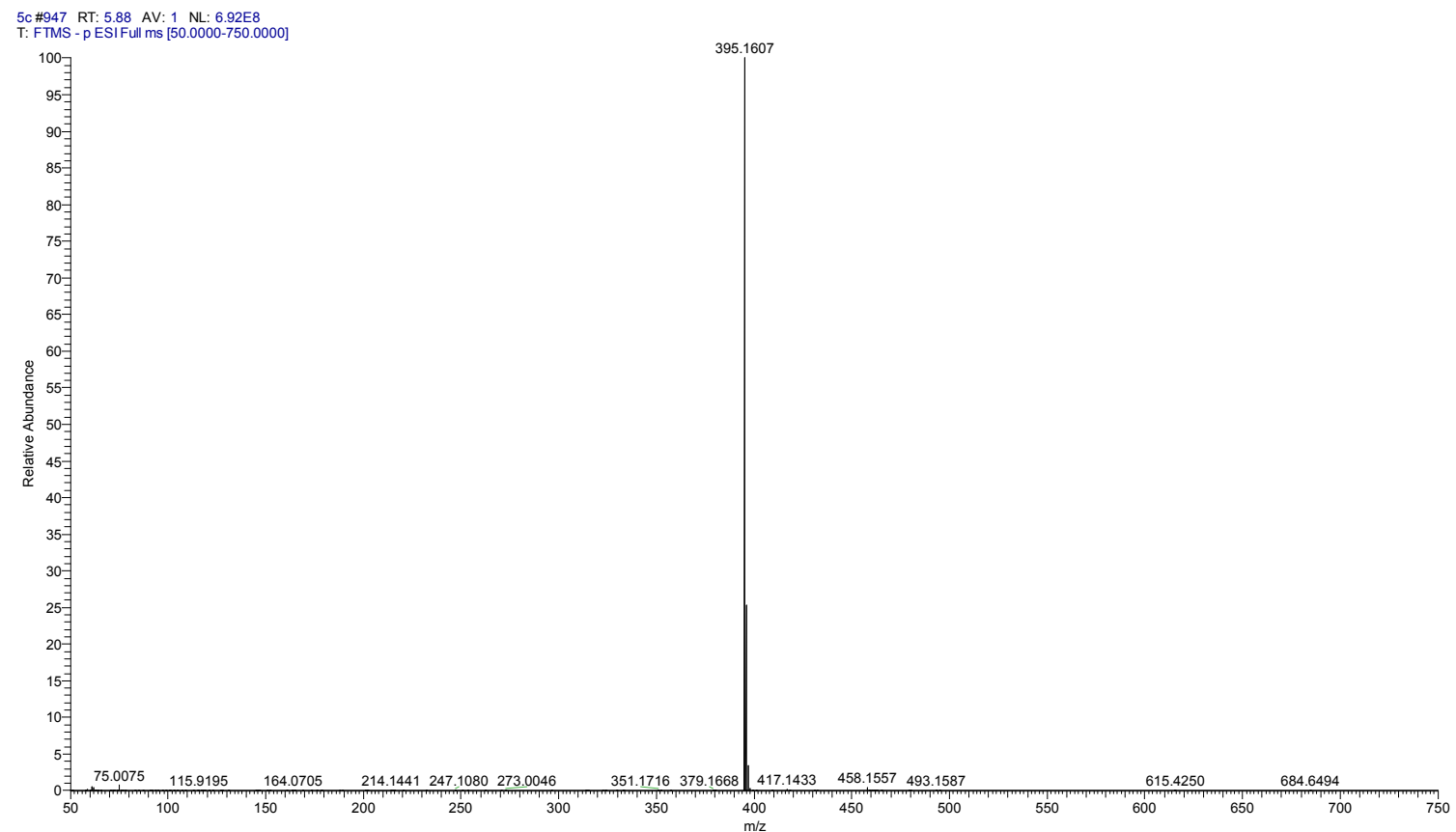

Figure S69 HRMS spectra of compound 5c 


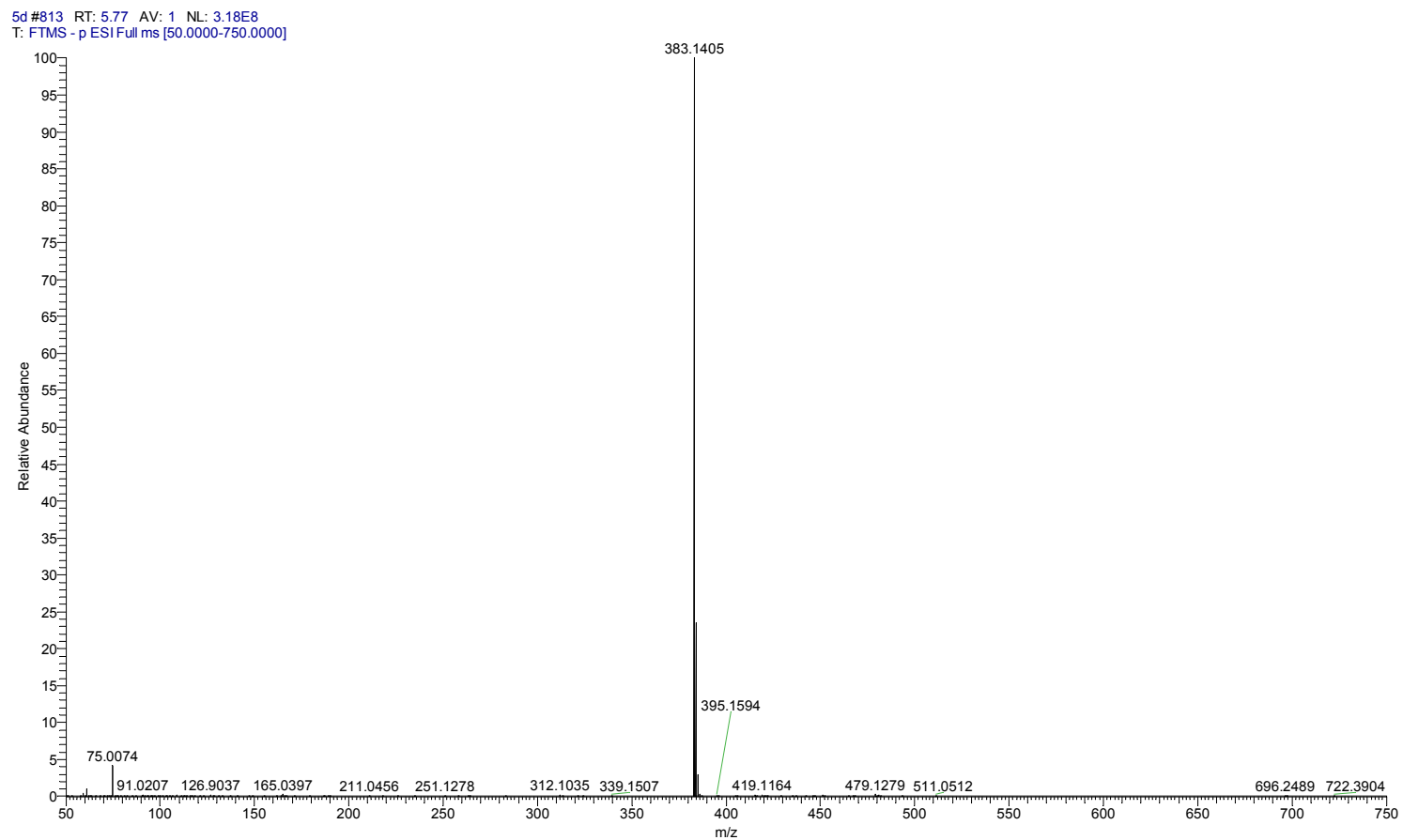

Figure S70 HRMS spectra of compound 5d

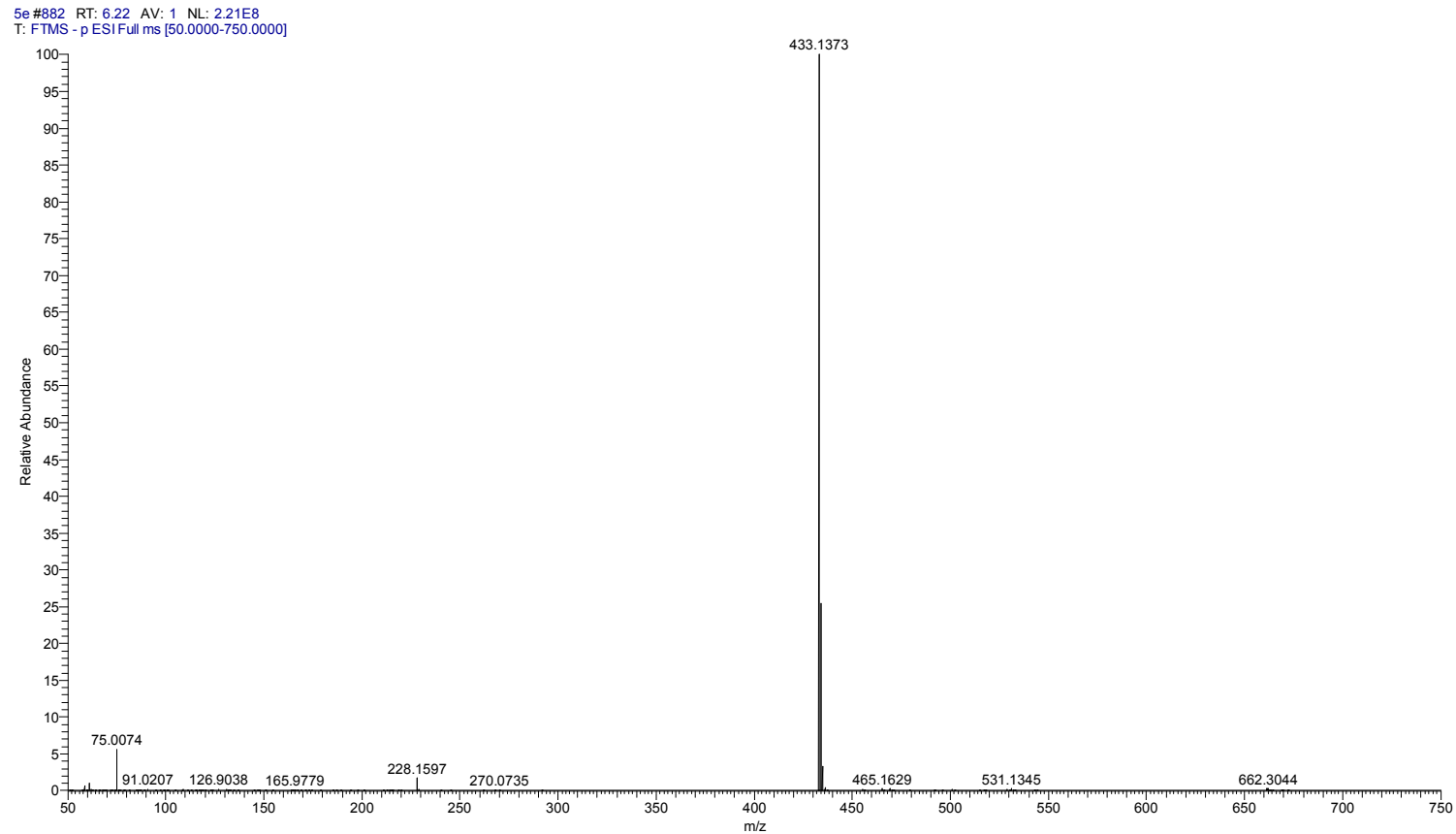

Figure S71 HRMS spectra of compound $\mathbf{5 e}$ 


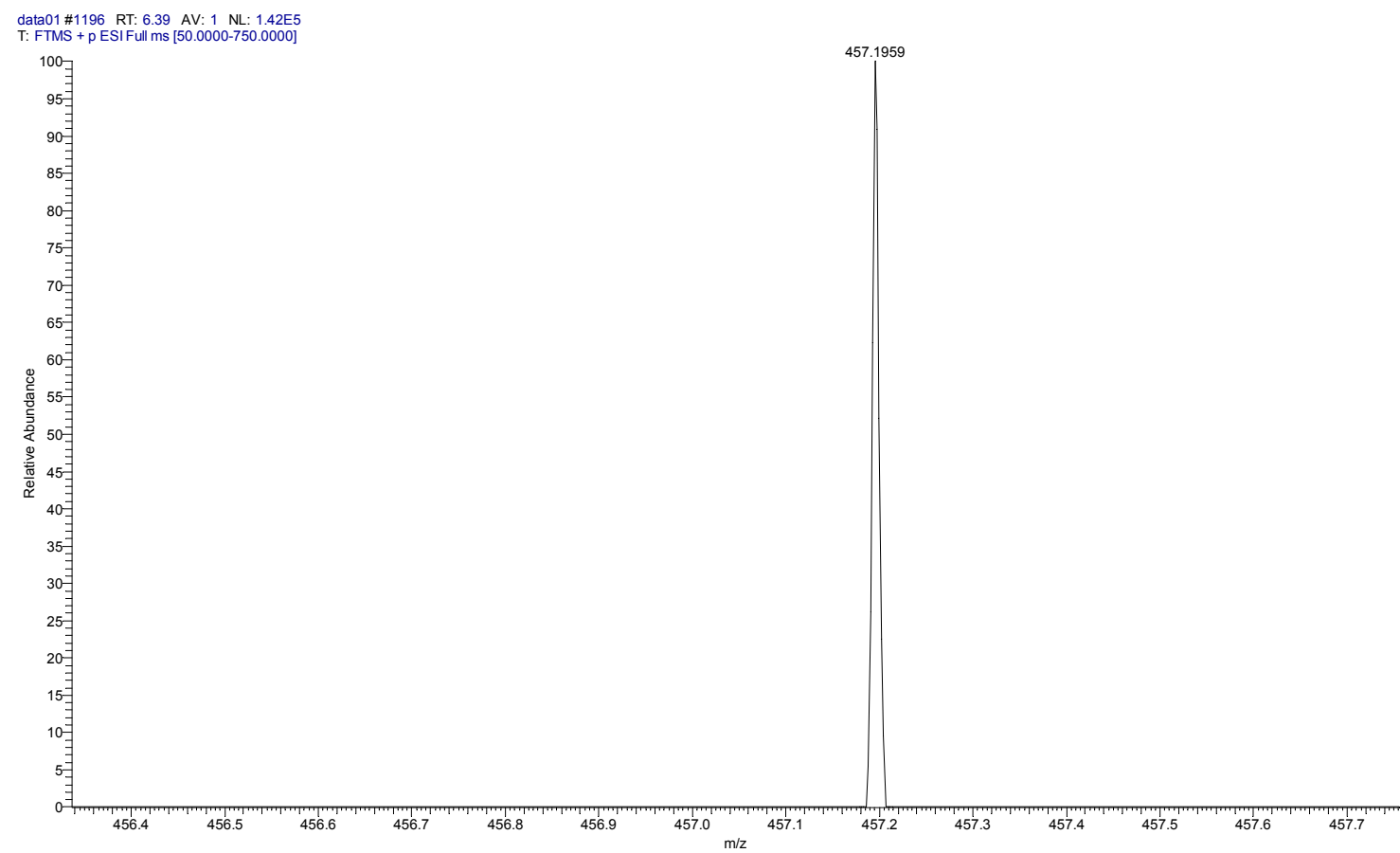

Figure S72 HRMS spectra of compound $\mathbf{5 f}$ 